SORAYA LAGE DE SÁ

\title{
ANÁLISE COMPORTAMENTAL E ELETROFISIOLÓGICA DO CONTROLE INIBITÓRIO VERBAL E MOTOR EM JOVENS UNIVERSITÁRIOS
}

Brasília 


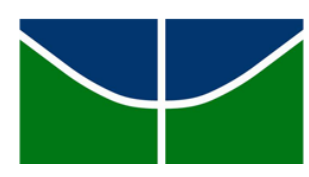

\section{Universidade de Brasília \\ Instituto de Ciências Biológicas}

Programa de Pós Graduação em Biologia Animal

Laboratório de Neurociência e Comportamento

SORAYA LAGE DE SÁ

\section{ANÁLISE COMPORTAMENTAL E \\ ELETROFISIOLÓGICA DO CONTROLE \\ INIBITÓRIO VERBAL E MOTOR EM JOVENS \\ UNIVERSITÁRIOS}

Dissertação apresentada como requisito parcial para a obtenção do Grau de Mestre em Biologia Animal junto ao Programa de Pós Graduação em Biologia Animal da Universidade de Brasília.

Orientadora: Prof ${ }^{a}$. Dr ${ }^{a}$. Maria Clotilde H. Tavares

Brasília

Março de 2015 
Dedico este estudo:

A Izabella Crosara Leite (em memória).

Você deixou uma saudade constante, imutável

e um sentimento de admiração que se

multiplica a cada dia. 


\section{Agradecimentos}

Agradeço a Profa. Dra. Maria Clotilde Henriques Tavares, pela orientação e boa vontade ao me receber e confiar no meu trabalho. Pelo carinho com que me orientou ao longo de todo esse processo;

Aos participantes do estudo, pela disponibilidade e pela confiança depositada;

À Dra. Ana Garcia, por tão generosamente me conceder os dados por ela coletados e pelo apoio constante e amizade ao longo do desenvolvimento dessa pesquisa. Sem ela, esse estudo não teria se concretizado;

À Coordenação de Aperfeiçoamento de Pessoal de Nível Superior (CAPES) do Ministério da Educação (MEC) pela concessão da bolsa de estudos no nível de mestrado por meio do Programa de Demanda Social (DS);

À Universidade de Brasília, ao Instituto de Ciências Biológicas, ao Departamento de Ciências Fisiológicas, ao Programa de Pós Graduação em Biologia Animal e ao Laboratório de Neurociência e Comportamento pelo apoio institucional indispensável à realização deste estudo;

À Coordenação e à Secretaria do Programa de Pós Graduação em Biologia Animal, em especial, à Daniele, Ana Paula, Kelly e Kézia, pelo esforço em manter a qualidade do programa e pelo cuidado com que sempre me auxiliaram;

Aos professores Dr. Carlos Alberto Bezerra Tomaz, Dr. Rafael Souto Maior, Dr. Sérgio Leme, Dr. Gerson Américo Janczura e Dr. Joaquim Pereira Brasil-Neto pelos valiosos ensinamentos; 
Um agradecimento especial à Profa. Dra. Corina Elizabeth Satler, pelas inúmeras parcerias já realizadas e as que virão. Pelo exemplo, inspiração e amizade.

Aos meus colegas de laboratório, Natália, Mariana, Rosângela, Renata, Patrícia, Aline e Danilo por me receberem calorosamente e por me fazerem acreditar que era possível. À Lía e Edward pela companhia, pela amizade, pelas trocas de conhecimento e ajuda mútua constante.

Aos meus pais, Alceu e Angélica e ao meu irmão Vinícius pelo estímulo e confiança ininterruptos e por serem sempre meu porto seguro;

A minha querida e grande família, especialmente aos meus primos;

Ao meu namorado, Paulo, pelo amor e carinho com que me estimula a superar meus obstáculos e por não me deixar esquecer de que o lazer também é muito importante.

A todos, o meu insuficiente e humilde, Muito obrigada. 
"O que sabemos é uma gota, o que ignoramos é um oceano."

Isaac Newton 


\section{Resumo}

As funções executivas abrangem uma grande variedade de processos cognitivos complexos que coordenam a atividade neural de forma a produzir comportamentos orientados ao cumprimento de objetivos. O controle inibitório consiste no componente das funções executivas responsável por inibir tendências inapropriadas de respostas a estímulos irrelevantes. O presente estudo teve por objetivo comparar o desempenho comportamental, o padrão de ativação cortical e a variação da frequência cardíaca (VFC) durante a realização de dois testes de controle inibitório, verbal (teste de Stroop) e motor (teste de Tempo de Reação - TR), além de investigar possíveis diferenças entre os gêneros na realização de tais testes. Participaram do estudo 53 jovens universitários hígidos (27 mulheres, 26 homens), na faixa etária de 17 a 28 anos (média de idade: $21,5 \pm 2,9$ ). Em relação ao desempenho comportamental, houve efeito de interferência no teste de Stroop e um possível efeito teto no TR. Em ambos, foi observada uma lateralização esquerda no padrão de ativação cortical em um gradiente fronto-parietal com participação evidente de diferentes regiões do córtex pré-frontal e ainda, ativação dos córtices temporal e occipital. Os mapas topográficos de ativação cortical para o teste de Stroop evidenciaram a representação mental das palavras, a preparação da resposta verbal e o processamento visual dos estímulos. Para o TR, além do processamento visual, foram evidenciados nos mapas topográficos os mecanismos preparatórios do movimento e a execução da resposta motora. Os resultados da comparação da VFC entre os testes indicaram que houve maior atividade autonômica simpática e consequentemente, maior esforço mental para os participantes no teste de Stroop quando comparado ao TR. Resultados da comparação entre os gêneros sugeriram que esse fator não influenciou de forma consistente o desempenho comportamental nos dois testes, mas influenciou as medidas eletrofisiológicas de ativação cortical e a VFC. A potência da atividade cerebral foi maior entre as mulheres e os índices de VFC no domínio do tempo, geralmente foram maiores entre os homens. O presente estudo contribuiu para elucidar as semelhanças e diferenças existentes nos mecanismos subjacentes a esses tipos de controle inibitório, verbal e motor, do ponto de vista comportamental e eletrofisiológico. Os resultados estiveram em consonância com a literatura, com algumas ressalvas. Em primeiro lugar, para a elevação nos valores dos parâmetros comportamentais do TR, que possivelmente refletiram a complexidade do protocolo utilizado no presente estudo. Em segundo lugar, para o aumento da potência da ativação cortical entre as mulheres. Contudo, em conjunto com os resultados de VFC, esse aumento indicou que diferentes estratégias foram utilizadas pelos sujeitos em função de seu gênero para o sucesso na realização dos testes.

Palavras-chave: Córtex Pré-Frontal; Eletrocardiograma (ECG); Eletroencefalograma (EEG); Inibição de respostas; Mapeamento topográfico cerebral; Teste de Stroop; Teste de Tempo de Reação; Variação da frequência cardíaca. 


\begin{abstract}
Executive functions involve a wide range of complex cognitive processes that coordinate neural activity in order to produce goal oriented behaviors. The inhibitory control is the component of executive functions responsible for inhibiting inappropriate responses to irrelevant stimuli. The present study aimed to compare the behavioral performance, the pattern of cortical activation, and the heart rate variability (HRV) during the performance of two types of inhibitory control tests, verbal (Stroop test) and motor (Reaction Time task - RTT), and to investigate possible gender differences in performing such tests. The study included 53 healthy undergraduate students (27 women, 26 men), aged 17-28 years (mean age, $21.5 \pm 2.9$ ). Considering the behavior, there was an interference effect in Stroop test, and a possible ceiling effect in the RTT. In both tests, left asymmetry was observed for the cortical activation pattern in a frontoparietal gradient with marked participation of different regions of the prefrontal cortex and also activation of the temporal and occipital cortices. Topographic maps of brain activity for the Stroop test revealed the mental representation of words, the preparation for the verbal response, and the visual processing of the stimuli. For RTT, besides visual processing, preparatory movement mechanisms, and the execution of the motor response were also found in topographic maps. HRV comparison between the tests suggested a higher sympathetic activity and consequently greater mental effort for Stroop test compared to RTT. The results of the comparison between genders suggested that this factor did not influence consistently the performance on the two tests, but influenced the electrophysiological measures of cortical activation and HRV. The power of brain activity was higher among women and time domain HRV indexes generally were higher among men. This study contributed to elucidate the similarities and differences on the mechanisms underlying these types of inhibitory control, verbal and motor, on the behavioral and electrophysiological aspects. The results were in agreement with the literature, with exceptions. First, for the increased RTT behavioral parameters values and this possibly reflected the complexity of the protocol used in the present study. Secondly, for the higher power of cortical activation among women. However, in conjunction with the HRV results, this increase indicated that different strategies were used by the subjects according to their gender leading to the success on the execution of the tasks.
\end{abstract}

Keywords: Electrocardiogram (ECG); Electroencephalogram (EEG); Heart rate variability; Prefrontal Cortex; Reaction Time task; Response Inhibition; Stroop task; Topographic brain mapping. 


\section{Lista de Abreviaturas}

ANOVA - Análise de variância

CCA - Córtex cingulado anterior

CPF - Córtex pré-frontal

CPFDL - Córtex pré-frontal dorsolateral

CPFOF - Córtex pré-frontal orbitofrontal

CPFVL - Córtex pré-frontal ventrolateral

CPFVM - Córtex pré-frontal ventromedial

$E C G$ - Eletrocardiograma ou eletrocardiografia

EEG - Eletroencefalograma ou eletroencefalografia

EEGQT - Eletroencefalograma quantitativo e topográfico

EMG - Eletromiograma ou eletromiografia

ERP - Potenciais relacionados a eventos

FC - Frequência cardíaca

FDR - False Discovery Rate Method, em português, Controle das taxas de falsos positivos

FE - Funções executivas

FFT - Fourier Fast Transformation, em português, Transformada Rápida de Fourier

ICA - Análise de componentes independentes

LF/HF - Razão entre baixas e altas frequências da frequência cardíaca

LQ - Quociente de Lateralidade (Inventário de Endinburgh)

pNN50 - Percentual de intervalos RR adjacentes com diferença de duração superior a 50 milissegundos 
RGP - Resposta Galvânica da Pele

RMSSD - Raiz quadrada da soma do quadrado das diferenças entre intervalos RR adjacentes

SC - Etapa Congruente do teste de Stroop

SDNN - Desvio padrão da média dos intervalos RR

SI - Etapa Incongruente do teste de Stroop

SNA - Sistema Nervoso Autonômico

SSF - Etapa de Semelhança Fonética do teste de Stroop

TCLE - Termo de consentimento livre e esclarecido

tDCS - Transcranial Direct Current Stimulation, Estimulação Transcraniana por

Corrente Contínua

TR - Tempo de reação

TRD - Tempo de reação aos estímulos apresentados do lado direito da tela

TRE - Tempo de reação aos estímulos apresentados do lado esquerdo da tela VFC - Variação da frequência cardíaca 


\section{Lista de Figuras}

Figura 1. As cinco grandes regiões funcionais do córtex pré-frontal $(A)$ e a representação original das áreas de Brodmann (B) para comparação (retirado de Lent, 2010).

Figura 2. O crânio de Phineas Gage $(A)$ e a reconstrução computadorizada da anatomia da lesão que causou a sua mudança de personalidade (B) (retirado de Lent, 2010).

Figura 3. Aparelho Neuron-Spectrum-4/EPM (NeuroSoft@, Ivanovo, Rússia) utilizado para a coleta dos dados de EEG, ECG, RGP e EMG.

Figura 4. Esquema da sequência do teste de Stroop com imagens que exemplificam cada etapa do teste. O intervalo entre as etapas não foi controlado e consistia no tempo levado para abrir a próxima etapa no programa STROOP e repetir as instruções para os sujeitos. Estes ficavam de olhos fechados durante todo o intervalo. 57

Figura 5. Esquema da sequência do teste de Tempo de Reação com imagens exemplificativas.

Figura 6. Fluxo do procedimento do estudo mostrando a ordem dos testes, o registro contínuo de medidas eletrofisiológicas e a preparação que antecede o registro. Durante o primeiro intervalo, o programa STROOP foi aberto e as instruções do teste de Stroop foram informadas ao sujeito. No segundo intervalo, o programa REFLEX foi aberto e foram fornecidas as instruções do teste de Tempo de Reação. Nesses dois intervalos, os participantes permaneceram de olhos fechados. No último intervalo, os eletrodos foram retirados dos sujeitos e foi feita a limpeza das regiões em que estes haviam sido colocados.

Figura 7. Sistema internacional $10 / 20$ para posicionamento de eletrodos de registro de eletroencefalograma, a partir de vista lateral (A) e vista superior (B). Os eletrodos com números pares estão localizados no hemisfério direito e os ímpares, no esquerdo. Os eletrodos posicionados na linha média recebem a letra z (zero). A: Ponto pré-auricular; C: central; P: parietal; F: frontal; Fp: frontopolar; O: occipital (retirado de http://www.bem.fi/book/13/13.htm, acesso em 10 de dezembro de 2013, tradução própria).

Figura 8. Média da taxa de acertos ( \pm DP; em porcentagem) de jovens universitários $(n=22)$ para cada etapa do teste de Stroop. * SC $>S S F, p<0,01 ; * *$ SC $>S I, p<0,001 ; * * *$ Sl $<S S F$, $\mathrm{p}<0,05$; ANOVA de medidas repetidas. SC: Etapa Congruente; SI: Etapa Incongruente; SSF: Etapa de Semelhança fonética. 70

Figura 9. Média da taxa de erros de omissão ( $\pm \mathrm{DP}$; em porcentagem) de jovens universitários $(n=22)$ para cada etapa do teste de Stroop. $* S C<S I, p<0,001 ; * * S I>S S F, p<0,01$; ANOVA de medidas repetidas. SC: Etapa Congruente; SI: Etapa Incongruente; SSF: Etapa de Semelhança fonética.

Figura 10. Média da taxa de acertos (A) e da taxa de erros de omissão (B) ( \pm DP; em porcentagem), para cada gênero no teste de Stroop, realizado por jovens universitários ( $n=22$; o : $n=10 ; 0$ : $n=12$ ). Teste t para medidas independentes. Fem: Gênero Feminino; Masc: Gênero Masculino.

Figura 11. Média da taxa de acertos ( $\pm \mathrm{DP}$; em porcentagem) para cada gênero nas etapas do teste de Stroop, realizadas por jovens universitários ( $n=22 ; O$ : $n=10 ; \quad$ : $n=12)$ * Entre as mulheres, $\mathrm{SC}>\mathrm{SI}, \mathrm{p}<0,001 ; * \star$ Entre os homens, $\mathrm{SC}>\mathrm{SI}, \mathrm{p}<0,001$; ANOVA bifatorial (como as variâncias não são iguais, valor de $p=0,001)$. SC: Etapa Congruente; SI: Etapa Incongruente; SSF: Etapa de Semelhança fonética; Fem: Gênero Feminino; Masc: Gênero Masculino.

Figura 12. Média da taxa de erros de omissão ( \pm DP; em porcentagem) para cada gênero nas etapas do teste de Stroop, realizadas por jovens universitários $(n=22 ;$ o $: n=10 ; \delta: n=12)$ * Entre os homens, $S C<S I, p<0,001$; ANOVA bifatorial (como as variâncias não são iguais, valor de $p=0,001)$. SC: Etapa Congruente; SI: Etapa Incongruente; SSF: Etapa de Semelhança fonética; Fem: Gênero Feminino; Masc: Gênero Masculino. .73 
Figura 13. Mapas topográficos de comparação da atividade Teta entre SC, SI e SSF no teste de Stroop, realizado por jovens universitários $(n=49)$. Os pontos vermelhos na representação à direita indicam os eletrodos para os quais foram encontradas diferenças significativas de acordo com o teste t pareado com correção pelo método FDR. SC: Etapa Congruente; SI: Etapa Incongruente; SSF: Etapa de Semelhança Fonética.

74

Figura 14. Mapas topográficos de comparação da atividade Alfa entre SC, SI e SSF no teste de Stroop, realizado por jovens universitários $(n=49)$. Os pontos vermelhos na representação à direita indicam os eletrodos para os quais foram encontradas diferenças significativas de acordo com o teste t pareado com correção pelo método FDR. SC: Etapa Congruente; SI: Etapa Incongruente; SSF: Etapa de Semelhança Fonética.

75

Figura 15. Mapas topográficos de comparação da atividade Beta entre SC, SI e SSF no teste de Stroop, realizado por jovens universitários $(n=49)$. Os pontos vermelhos na representação à direita indicam os eletrodos para os quais foram encontradas diferenças significativas de acordo com o teste t pareado com correção pelo método FDR. SC: Etapa Congruente; SI: Etapa Incongruente; SSF: Etapa de Semelhança Fonética. 76

Figura 16. Mapas topográficos de comparação da atividade Gama entre SC, SI e SSF no teste de Stroop, realizado por jovens universitários $(n=49)$. Os pontos vermelhos na representação à direita indicam os eletrodos para os quais foram encontradas diferenças significativas de acordo com o teste t pareado com correção pelo método FDR. SC: Etapa Congruente; SI: Etapa Incongruente; SSF: Etapa de Semelhança Fonética.

77

Figura 17. Mapas topográficos de comparação da atividade Teta entre os gêneros para cada etapa do teste de Stroop, realizado por jovens universitários $(n=49 ;$; $: n=24 ; \hat{\delta}: n=25)$. Os pontos vermelhos na representação à direita indicam os eletrodos para os quais foram encontradas diferenças significativas de acordo com o teste t para medidas independentes com correção pelo método FDR. Fem: Gênero Feminino; Masc: Gênero Masculino; SC: Etapa Congruente; SI: Etapa Incongruente; SSF: Etapa de Semelhança Fonética. ........................... 79

Figura 18. Mapas topográficos de comparação da atividade Alfa entre os gêneros para cada etapa do teste de Stroop, realizado por jovens universitários $(n=49 ;$; : $n=24 ; 0: n=25)$. Os pontos vermelhos na representação à direita indicam os eletrodos para os quais foram encontradas diferenças significativas de acordo com o teste t para medidas independentes com correção pelo método FDR. Fem: Gênero Feminino; Masc: Gênero Masculino; SC: Etapa Congruente; SI: Etapa Incongruente; SSF: Etapa de Semelhança Fonética.

Figura 19. Mapas topográficos de comparação da atividade Beta entre os gêneros para cada etapa do teste de Stroop, realizado por jovens universitários $(n=49 ;$; $: n=24 ; \lambda: n=25)$. Os pontos vermelhos na representação à direita indicam os eletrodos para os quais foram encontradas diferenças significativas de acordo com o teste t para medidas independentes com correção pelo método FDR. Fem: Gênero Feminino; Masc: Gênero Masculino; SC: Etapa Congruente; SI: Etapa Incongruente; SSF: Etapa de Semelhança Fonética. .......................... 81

Figura 20. Mapas topográficos de comparação da atividade Gama entre os gêneros para cada etapa do teste de Stroop, realizado por jovens universitários $\left(n=49 ;\right.$; : $\left.n=24 ; \delta^{\lambda}: n=25\right)$. Os pontos vermelhos na representação à direita indicam os eletrodos para os quais foram encontradas diferenças significativas de acordo com o teste t para medidas independentes com correção pelo método FDR. Fem: Gênero Feminino; Masc: Gênero Masculino; SC: Etapa Congruente; SI: Etapa Incongruente; SSF: Etapa de Semelhança Fonética. ........................... 82

Figura 21. Médias ( $\pm \mathrm{DP}$ ) dos índices de variação da frequência cardíaca de jovens universitários $(n=49)$ em função das etapas do teste de Stroop, no domínio do tempo - pNN50 (A; em porcentagem), SDNN (B; ms), RMSSD (C; ms) - e da frequência - razão LF/HF (D). A: * SC>SSF, $p<0,01 ; * *$ SI $>S S F, p<0,05$. B: * SC>SSF, $p<0,01 ; * *$ SC $>S I, p<0,05$. C: * $S C>S S F, p<0,01 ; * *$ SI $>S S F, p<0,001$. ANOVA de medidas repetidas. SC: Etapa Congruente; SI: Etapa Incongruente; SSF: Etapa de Semelhança fonética. 84

Figura 22. Médias ( \pm DP) dos índices de variação da frequência cardíaca de jovens universitários $(n=49 ;$ tempo - pNN50 (A; em porcentagem), SDNN (B; ms), RMSSD (C; ms) - e da frequência Razão LF/HF (D). A: * Fem<Masc, $p<0,01$. B: * Fem<Masc, $p<0,01$. C: * Fem<Masc, $p<0,001$. Teste $t$ para medidas independentes. Fem: Gênero Feminino; Masc: Gênero Masculino. 85 
Figura 23. Média da taxa de acertos ( $A$; em porcentagem) e do tempo de reação (B; ms) $( \pm D P)$ para cada gênero no teste de Tempo de Reação, realizado por jovens universitários $(n=48$; $\odot$ : $n=24 ; \quad \delta$ : $n=24$ ). Teste $t$ para medidas independentes. Fem: Gênero Feminino; Masc: Gênero Masculino.

Figura 24. Média da taxa de acertos ( $A$; em porcentagem) e do tempo de reação (B; ms) $( \pm D P)$ de jovens universitários $(n=48)$ em função do lado em que o estímulo foi apresentado no teste de Tempo de Reação. ANOVA de medidas repetidas. Fem: Gênero Feminino; Masc: Gênero Masculino; TRD: Tempo de reação aos estímulos apresentados do lado direito e TRE: do lado esquerdo da tela. 88

Figura 25. Mapas topográficos da atividade cortical de jovens universitários $(n=48 ; \circ$ : $n=24 ; \hat{\jmath}$ : $\mathrm{n}=24$ ) nas bandas Teta, Alfa, Beta e Gama para a comparação entre gêneros no teste de Tempo de Reação. Os pontos vermelhos na representação à direita indicam os eletrodos para os quais foram encontradas diferenças significativas de acordo com o teste t para medidas independentes com correção pelo método FDR. Fem: Gênero Feminino; Masc: Gênero Masculino. 90

Figura 26. Médias ( \pm DP) dos índices de variação da frequência cardíaca de jovens universitários $(n=49 ;$; $: n=24 ; \hat{O}: n=25)$, em função do gênero no teste de Tempo de Reação, no domínio do tempo - pNN50 (A; em porcentagem), SDNN (B; ms), RMSSD (C; ms) - e da frequência - Razão LF/HF (D). C: * Fem<Masc, $p<0,01$. Teste t para medidas independentes. Fem: Gênero Feminino; Masc: Gênero Masculino.

Figura 27. Mapas topográficos da atividade cortical de jovens universitários $(n=48)$ nas bandas Teta, Alfa, Beta e Gama para a comparação entre a etapa Incongruente do Teste de Stroop e o teste de Tempo de Reação. Os pontos vermelhos na representação à direita indicam os eletrodos para os quais foram encontradas diferenças significativas de acordo com o teste $t$ pareado com correção pelo método FDR. SI: Etapa Incongruente; TR: teste de Tempo de Reação. .94

Figura 28. Médias $( \pm \mathrm{DP})$ dos índices de variação da frequência cardíaca de jovens universitários $(n=49)$ nos testes de Stroop e de Tempo de Reação, no domínio do tempo pNN50 (A; em porcentagem), SDNN (B; ms), RMSSD (C; ms) - e da frequência - Razão LF/HF (D). A: * SI<TR, $p<0,001$. C: * Sl<TR, $p<0,001$. D: * SI>TR, $p<0,001$. ANOVA de medidas repetidas. SI: Teste de Stroop (Etapa Incongruente); TR: Teste de Tempo de Reação. .95 


\section{Lista de Tabelas}

Tabela 1. Discriminação do número de sujeitos (total, mulheres e homens), da faixa etária e da idade (média e desvio padrão) para cada análise.

Tabela 2. Médias das taxas de acertos ( \pm DP; em porcentagem) de jovens universitários $(n=48$; o : $n=24 ; \hat{\delta}: n=24$ ) no teste de Tempo de Reação em função do gênero e do lado em que o estímulo foi apresentado.

Tabela 3. Médias do Tempo de Reação ( \pm DP, em ms) de jovens universitários ( $n=48$; $:$ : $n=24$; ô: $n=24$ ) no teste de Tempo de Reação em função do gênero e do lado em que o estímulo foi apresentado. 
SUMÁRIO

DEDICATÓRIA

iii

AGRADECIMENTOS

iv

EPÍGRAFE

vi

RESUMO

vii

ABSTRACT

viii

LISTA DE ABREVIATURAS

ix

LISTA DE FIGURAS

$\mathbf{x i}$

LISTA DE TABELAS

xiv

1. INTRODUÇÃO

1.1. FUNÇÕES EXECUTIVAS 19

1.1.1. Bases Neurobiológicas 21

1.1.2. Breve Histórico do Estudo das Funções Executivas 23

1.1.3. Controle Inibitório 26

1.1.4. Flexibilidade cognitiva 29

1.1.5. Memória operacional 32

1.1.6. Atenção 34

1.2. TÉCNICAS DE ESTUDO 37

1.2.1. Eletroencefalografia 37

1.2.2. Eletrocardiografia 41

1.3. AVALIAÇÃO COGNITIVA 43

1.3.1. Teste de Stroop 43

1.3.2. Teste de Tempo de Reação 45

2. JUSTIFICATIVA 47

3. OBJETIVOS 49 
4.1. CONSIDERAÇÕES ÉTICAS 52

4.2. PARTICIPANTES 53

4.2.1. Critérios de inclusão 53

4.2.2. Critérios de exclusão 53

4.3. EQUIPAMENTOS 54

4.4. INSTRUMENTOS 55

4.4.1. Teste de Stroop 56

4.4.2. Teste de Tempo de Reação 58

4.5. PROCEDIMENTO 60

4.6. PROCESSAMENTO DOS DADOS ELETROFISIOLÓGICOS 63

4.7. ANÁLISE DE DADOS 65

5. RESULTADOS 69

5.1. TESTE DE STROOP 70

5.1.1. Comportamento 70

5.1.2. Eletroencefalograma 73

5.1.3. Eletrocardiograma 83

5.2. TESTE DE TEMPO DE REAÇÃO 85

5.2.1. Comportamento 85

5.2.2. Eletroencefalograma 88

5.2.3. Eletrocardiograma 91

5.3. TESTE DE STROOP vs. TESTE DE TEMPO DE REAÇÃO 92

5.3.1. Eletroencefalograma 92

5.3.2. Eletrocardiograma 95

6. DISCUSSÃO 96

6.1. Comportamento 97 
8. CONSIDERAÇÕES FINAIS

8.1. LIMITAÇÕES DO ESTUDO 128

8.2. PERSPECTIVAS FUTURAS 129 REFERÊNCIAS BIBLIOGRÁFICAS 130 APÊNDICE A - TERMO DE CONSENTIMENTO LIVRE E ESCLARECIDO 138 APÊNDICE B - FICHA EXPERIMENTAL 139 APÊNDICE C - INVENTÁRIO DE EDINBURGH 140 ANEXO A - APROVAÇÃO DO PROJETO 160/08 PELO COMITÊ DE ÉTICA EM PESQUISA (CEP/FS-UNB) 141 ANEXO B - APROVAÇÃo do PRESENTE PROJETO PELO COMITÊ dE ÉTICA EM PESQUISA (CEP/FS-UNB) 142 
1. INTRODUÇÃO 


\subsection{FUNÇÕES EXECUTIVAS}

As funções executivas (FE) consistem em processos cognitivos intimamente associados ao controle cognitivo, responsáveis pela coordenação da atividade neural de forma a produzir comportamentos orientados ao cumprimento de objetivos e consistentes ao longo do tempo (Squire et al., 2008).

A grande variedade de processos cognitivos complexos abrangidos pelas FE dificulta a elaboração de uma definição precisa capaz de descrevê-las, o que resultou na acepção de que "funções executivas" seja um termo guardachuva para diversos componentes separados (Chan et al., 2008). Dentre estes, podem ser destacados o controle inibitório, a flexibilidade cognitiva, a memória operacional, a atenção, o raciocínio, a resolução de problemas e a tomada de decisões (Diamond, 2013; Elliot, 2003).

De forma integrada, esses componentes permitem que um indivíduo seja capaz de elaborar e executar planos de forma a atingir seus objetivos, monitorar suas ações e avaliar as consequências destas, tomar decisões, resolver problemas, resistir a interferências, sustentar a atenção ao longo de uma tarefa, lidar com novidades, antecipar as consequências das ações de outros e regular seu comportamento de acordo com o que é socialmente aceito (Ardila, 2008; Chan et al., 2008; Diamond, 2013; Elliot, 2003).

A associação entre as FE e o conceito de controle cognitivo está relacionada com a dicotomia existente entre processamentos automáticos e processamentos controlados. Os processamentos automáticos são aqueles de reação direta ao ambiente, que partem de um processamento bottom-up e dependem de vias neurais bem estabelecidas, seja de forma inata ou 
aprendida (Squire et al., 2008). Os processamentos controlados, por sua vez, estão alocados em um nível mais complexo de processamento top-down, no qual as experiências anteriores dos sujeitos e seus objetivos possuem grande influência nos comportamentos a serem produzidos. Os comportamentos controlados, portanto, são flexíveis, direcionados a objetivos, quase em sua totalidade aprendidos por meio da experiência e possuem uma capacidade limitada que resulta em uma seleção de um ou poucos processamentos simultâneos (Squire et al., 2008).

Atividades aparentemente simples e cotidianas dependem da capacidade dos indivíduos de definirem um objetivo e organizarem seu comportamento de forma a atingi-lo. Já foi demonstrada a importância das FE para o sucesso de vários aspectos da vida dos indivíduos, dentre eles a qualidade de vida, aspectos da saúde mental e física, o sucesso no trabalho e o sucesso e prontidão escolar (Diamond, 2013).

Mesmo uma atividade rotineira, como por exemplo, cozinhar requer habilidades executivas, pois tal atividade envolve a definição de um objetivo, a elaboração e a execução de um plano e por fim, uma avaliação das consequências. Os diversos componentes das funções executivas, como o controle inibitório, a atenção e a memória operacional (a serem explicados em detalhes nas próximas seções), são muito importantes para que se obtenha sucesso em cada uma dessas etapas.

Primeiramente, o sujeito deve definir seu objetivo, escolhendo uma receita, por exemplo. Então, deve separar os ingredientes necessários e definir os passos a serem seguidos, ou seja, é necessário que se elabore um plano. Durante a execução da ação, ele precisa prestar atenção a cada um dos 
passos da receita ao longo do tempo, ignorando estímulos irrelevantes que possam atrapalhar o que foi planejado, o que requer motivação, controle inibitório e um bom funcionamento dos sistemas atencionais. Além disso, o indivíduo deve ser capaz de manter seu objetivo e as variáveis relevantes em mente ao longo de todo o processo, o que requer um bom funcionamento da memória operacional. Ao final, o sujeito deve avaliar as consequências de sua ação, reconhecendo aquilo que foi importante para o seu sucesso ou fracasso. Assim, mesmo atividades cotidianas exigem uma alta capacidade de controle cognitivo.

\subsubsection{Bases Neurobiológicas}

As funções executivas estão intimamente relacionadas com a atividade do lobo frontal. O lobo frontal associa regiões motoras, perceptuais e límbicas, sendo subdivido em três componentes: o córtex motor, as zonas motoras secundárias e o córtex pré-frontal (Gazzaniga, Ivry \& Mangun, 1998), que ocupa cerca de 30\% do córtex total em humanos (Goldberg, 2009).

Há concordância entre diversos autores de que a função principal do córtex pré-frontal (CPF) é o controle cognitivo, entretanto há controvérsias sobre a possibilidade de haver diferenciação funcional entre os seus diversos componentes (Aron, Robbins \& Poldrack, 2004). Uma visão complementar afirma que a função do CPF é integrar eventos ao longo do tempo (Aron et al., 2004), o que resulta em um padrão funcional de organização temporal do comportamento (Bjorklund \& Kipp, 1996).

Quase todas as regiões corticais e subcorticais influenciam o córtex préfrontal através de projeções diretas ou com poucas sinapses (Gazzaniga et al., 
1998). A extensa rede de conexões mantida pelo CPF permite acesso e influência sobre informações sensoriais de todas as modalidades, aos sistemas motores, aos sistemas de memória e ao sistema límbico, fazendo a ligação e a coordenação entre os inputs externos e internos com os possíveis outputs motores a serem gerados (Squire et al., 2008).

Entre as regiões subcorticais com as quais o CPF mantém conexões, destacam-se os núcleos da base. O corpo estriado recebe projeções do CPF, que se propagam em alças pelos núcleos subcorticais e são enviados de volta para o lobo frontal via tálamo, o que sugere uma alta interdependência entre o CPF e essas estruturas (Squire et al., 2008). Assim, as funções executivas, apesar de intimamente associadas com o CPF, não dependem apenas dele em isolamento, mas do funcionamento intacto do circuito cortico-estriatal dopaminérgico (Elliot, 2003). São mantidas, ainda, conexões com o sistema límbico e projeções diretas e indiretas, via tálamo, com o hipocampo, a amígdala e o hipotálamo (Squire et al., 2008).

Além disso, existem projeções intrínsecas entre as diferentes regiões do CPF, ipsilaterais e contralaterais (Gazzaniga et al., 1998), que são substratos para a distribuição de informações por toda a extensão dessa região do córtex. Desta forma, é possível sintetizar as informações relevantes para produzir comportamentos complexos orientados a objetivos.

São reconhecidas cinco grandes regiões funcionais para o córtex préfrontal (Figura 1), o córtex pré-frontal dorsolateral (CPFDL), ventrolateral (CPFVL), orbitofrontal (CPFOF), ventromedial (CPFVM) e cingulado anterior (CCA) (Lent, 2010). Estas, entretanto, podem ser subdivididas em pelo menos 18 áreas citoarquitetônicas (Squire et al., 2008). 


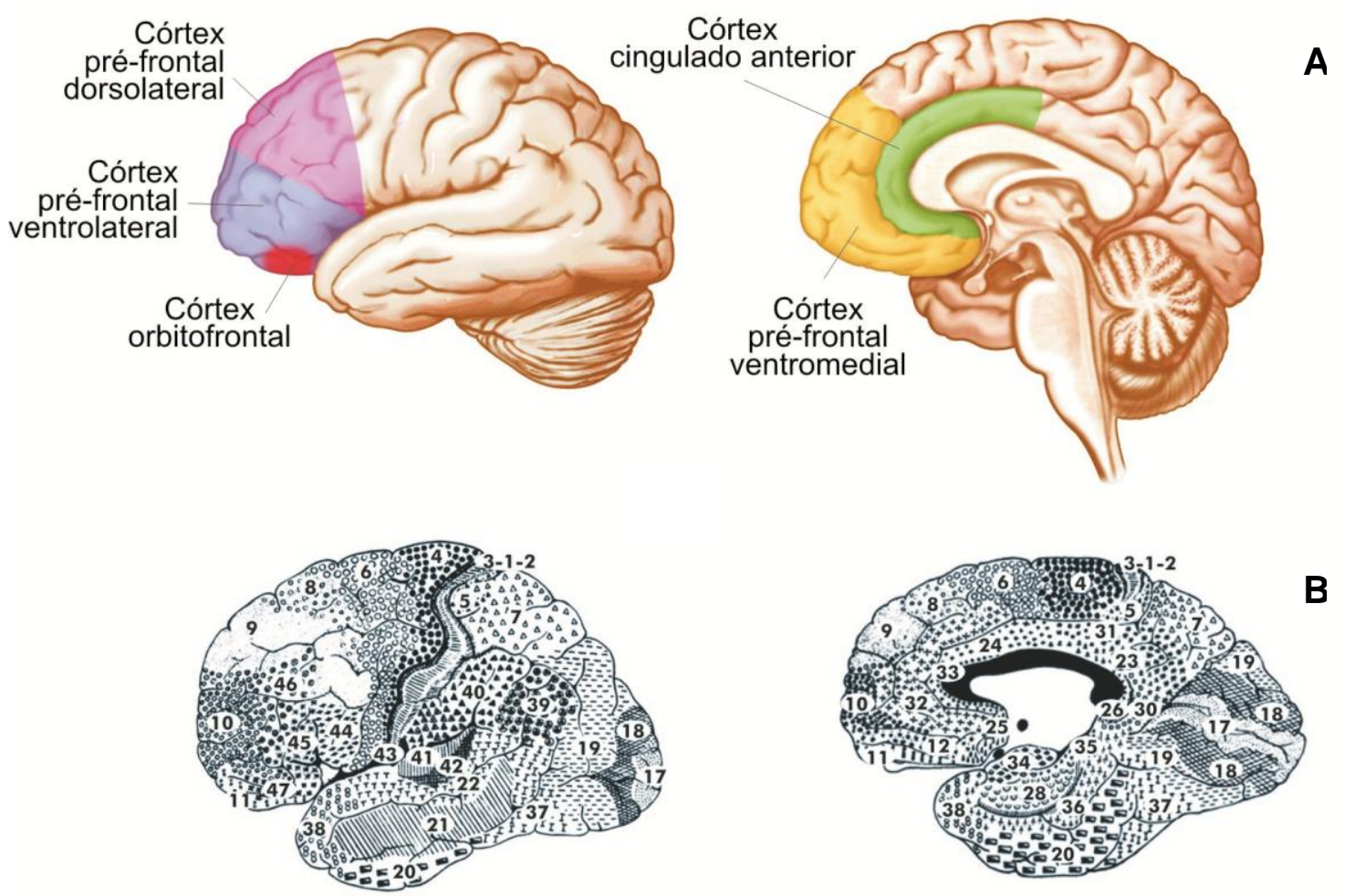

Figura 1. As cinco grandes regiões funcionais do córtex pré-frontal $(A)$ e a representação original das áreas de Brodmann (B) para comparação (retirado de Lent, 2010).

O planejamento de ações, o raciocínio, o ajuste social do comportamento e as interações com aspectos emocionais são moduladas pelas regiões ventromedial e orbitofrontal. A modulação das emoções também conta com a participação do cingulado anterior, região envolvida, ainda, com processos atencionais. Já a região ventrolateral, está envolvida com a memória operacional, cujos dados são manipulados com o apoio da região dorsolateral (Lent, 2010).

\subsubsection{Breve Histórico do Estudo das Funções Executivas}

O interesse no córtex pré-frontal apresentou-se tardiamente na história da neurociência (Goldberg, 2009) e tem aumentado nas últimas décadas 
(Anderson, Jacobs \& Anderson, 2008). Antes disso, contudo, já existiam inúmeros relatos sobre déficits nos processos cognitivos que hoje são conhecidos como funções executivas.

Um dos primeiros casos (e mais famosos) foi o de Phineas Gage, um operário na construção de uma linha férrea que sofreu uma lesão em ambos os hemisférios do CPF (Figura 2), especialmente na região ventromedial, após uma explosão acidental (Lent, 2010). Apesar de manter a linguagem e a capacidade de locomoção intactas, sua personalidade mudou drasticamente de um operário exemplar para uma pessoa impulsiva, desinibida, perseverante em respostas não recompensadas, negligente a objetivos e às consequências de suas ações, indiferente às próprias emoções e emoções de outros; em um padrão de dificuldades no planejamento e organização do comportamento (Gazzaniga et al., 1998).
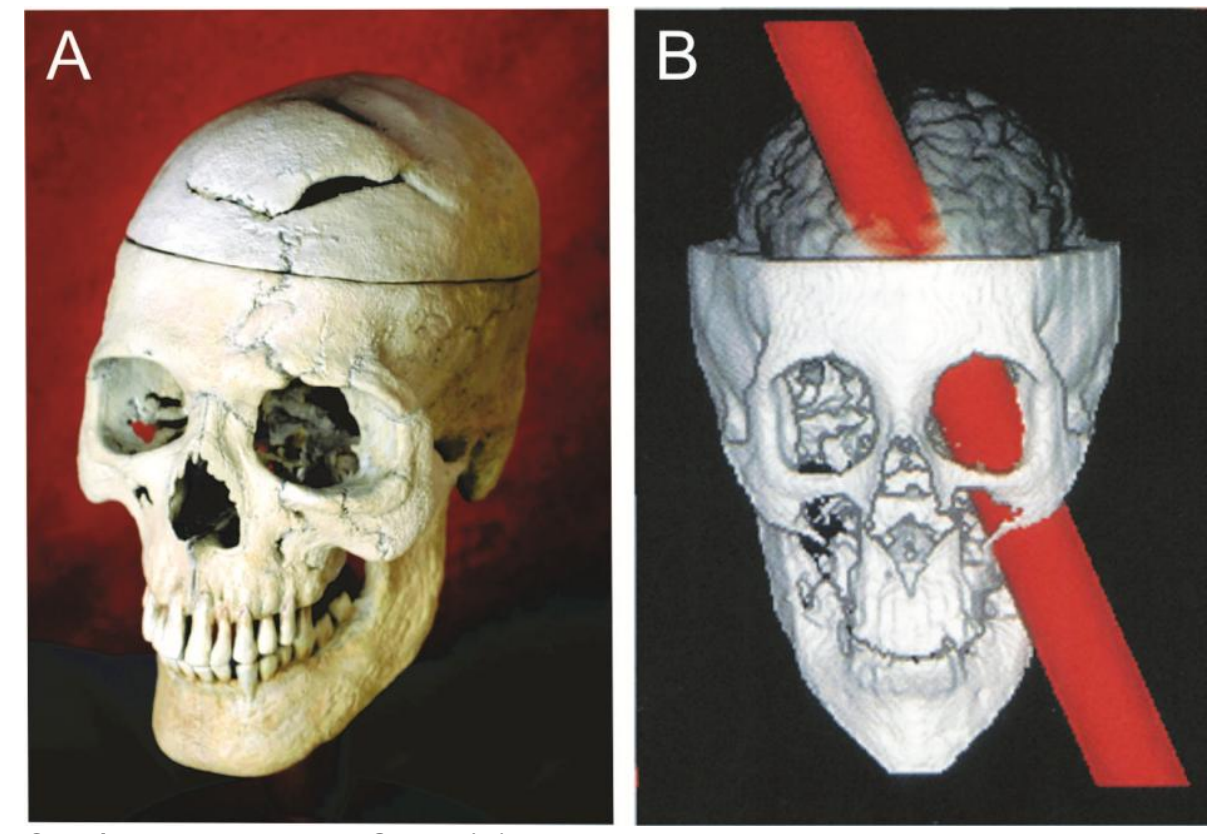

Figura 2. O crânio de Phineas Gage $(A)$ e a reconstrução computadorizada da anatomia da lesão que causou a sua mudança de personalidade (B) (retirado de Lent, 2010).

A partir desse caso, as lesões no CPF foram extensivamente estudadas em primatas humanos e não-humanos. Em humanos, o conjunto de alterações 
comportamentais, semelhantes às de Gage, em pacientes com lesões no córtex pré-frontal ficou conhecido como "Síndrome Desexecutiva". Os estudos de lesões focais em primatas não-humanos, por sua vez, foram importantes para investigar as funções específicas de cada área do CPF (Gazzaniga et al., 1998; Squire et al., 2008).

Ao longo dos anos, foram desenvolvidas inúmeras teorias a respeito do funcionamento executivo, considerado inicialmente como um constructo unitário (Anderson et al., 2008). Atualmente, sabe-se que as FE englobam uma grande variedade de habilidades cognitivas de controle do comportamento, das quais três recentemente foram consideradas como primordiais - a memória operacional, a flexibilidade cognitiva e o controle inibitório (Diamond, 2013). Destas, o controle inibitório consistiu no foco do presente estudo, contudo os demais componentes das FE foram levados em consideração, para que se pudesse alcançar uma compreensão mais abrangente das avaliações realizadas.

Os estudos recentes sobre a relação entre o funcionamento executivo e o processamento emocional permitiram, ainda, a distinção entre FE metacognitivas ou "frias" e FE emocionais/motivacionais ou "quentes" (Ardila, 2008). Estas últimas são importantes na coordenação entre cognição e emoção por meio da atividade do CPFVM e CPFOF, levando em consideração os comportamentos socialmente aceitos. Já as FE metacognitivas são subsidiadas pelo CPFDL e principalmente utilizadas em contextos sem conteúdo emocional evidente. O controle inibitório é considerado como um componente das FE quentes. 


\subsubsection{Controle Inibitório}

O controle inibitório é uma função de controle cognitivo, responsável por inibir tendências inapropriadas de respostas a determinados estímulos (Bunge, Mackey \& Whitaker, 2009). As tarefas Go/No-Go e Stop-signal (Aron et al., 2004) e o teste de Stroop (Stroop, 1935) são frequentemente utilizados para avaliar a capacidade de inibir respostas inapropriadas.

A ativação do giro frontal inferior direito, que abrange porções das regiões dorsolateral, orbitofrontal e ventromedial do córtex pré-frontal (Ditye et al., 2012; Jacobson, Javitt \& Lavidor, 2011) possui papel fundamental na inibição de respostas. Estudos tem demonstrado que a Estimulação Transcraniana por Corrente Contínua (tDCS, do inglês Transcranial Direct Current Stimulation) do tipo anódica de diferentes regiões do lobo frontal resulta em melhores desempenhos em testes de controle inibitório, tais como o CPFDL esquerdo (Boggio et al., 2007; Jeon \& Han, 2012; Plewnia et al., 2013) e direito (Jeon \& Han, 2012); o cingulado anterior (Smith \& Kosslyn, 2006b); as áreas prémotoras (Hsu et al., 2011; Kwon \& Kwon, 2013); e o giro frontal inferior direito (Ditye et al., 2012; Jacobson et al., 2012; Jacobson et al., 2011), evidenciando que a inibição de respostas é subsidiada pelo CPF, mas não limitada a ele.

Estudos com lesões e técnicas de neuroimagem, entretanto, sugerem que os mecanismos inibitórios estão diretamente relacionados ao córtex pré-frontal ventromedial direito (CPFVM) (Aron et al., 2004). Interações entre o CPF direito, os núcleos da base, as regiões motoras primárias e o lobo temporal medial são fundamentais para a manifestação do controle inibitório, de forma que seja possível que o CPFVM direito suprima o output dos núcleos da base (Aron et al., 2004). 
O controle inibitório possui desenvolvimento tardio. $\mathrm{Na}$ verdade, os componentes das FE são aprimorados de forma não homogênea ao longo da infância e tendem a atingir a maturidade durante a adolescência, a exemplo das habilidades de controle da atenção, do aumento da velocidade do processamento e do próprio controle inibitório (Anderson et al., 2008). Por isso, as crianças geralmente possuem maior dificuldade em inibir respostas inapropriadas, o que é evidenciado pelas diferenças encontradas entre o seu desempenho e o de adultos (Aron et al., 2004).

Algumas habilidades compreendidas dentre as funções executivas como a memória operacional, o planejamento estratégico, a resolução de problemas, a fluência verbal e a tomada de decisões - entretanto, somente são aperfeiçoadas do final da adolescência ao início da vida adulta, pois nessa fase acredita-se que há uma melhora na aplicação efetiva e eficiente das habilidades de controle do comportamento já adquiridas na infância e na adolescência (Jurado \& Rosselli, 2007).

Esse padrão se deve a alterações na anatomia cortical e na crescente inclusão de áreas frontais em diversos circuitos cognitivos, indicando uma crescente influência das FE no comportamento ao longo do desenvolvimento (Anderson et al., 2008).

É esperado, portanto, que o recrutamento de regiões corticais e consequentemente, a habilidade de controlar o comportamento, sejam influenciados pela idade dos indivíduos. Contudo, outros aspectos também são fundamentais para o controle inibitório, tais como fatores socioculturais e o gênero (Barbarotto et al., 1998; Der \& Deary, 2006; Van Der Elst et al., 2006). Foi demonstrada, por exemplo, uma forte correlação entre a escolaridade dos 
pais (em anos) e o desempenho de seus filhos em testes executivos (Jurado \& Rosselli, 2007).

Em uma revisão sobre diferenças entre os gêneros para os mecanismos inibitórios, Bjorklund e Kipp (1996) concluíram que, no domínio cognitivo, em testes como o de Stroop, não há evidências da existência de diferenças de desempenho entre os gêneros. Nos domínios social e comportamental, entretanto, existe favorecimento do desempenho das mulheres, incluindo a inibição motora, na qual estas apresentaram desempenho ligeiramente superior aos homens.

Bjorklund e Kipp (1996) defendem a hipótese de que essas diferenças são originadas de uma maior pressão seletiva imposta às mulheres ao longo da evolução humana, de acordo com a Teoria do Investimento Parental. Os mecanismos inibitórios podem ter surgido em um contexto social, com o papel de diminuir comportamentos agressivos em grupos de hominídeos e posteriormente, passaram a desempenhar também um papel importante na escolha de parceiros e no cuidado parental, principalmente para as mulheres (Bjorklund \& Kipp, 1996). Isto provavelmente resultou em melhor desempenho feminino em tarefas que envolvem inibição de respostas em um domínio social e comportamental. A ausência de diferenças no domínio cognitivo pode ser explicada por este domínio não estar diretamente associado aos contextos em que há pressões seletivas maiores para o sexo feminino (Bjorklund \& Kipp, 1996). 


\subsubsection{Flexibilidade cognitiva}

A flexibilidade cognitiva começou a ser estudada a partir de 1990, com três abordagens principais (Déak, 2003). A primeira, dentro do contexto da psicologia da Gestalt, revelou que adultos possuem dificuldades em usar e combinar objetos de formas flexíveis e inovadoras para resolverem problemas, um fenômeno que ficou conhecido como fixação funcional. A segunda não obteve muito êxito, por tratar o pensamento flexível como componente da criatividade, um traço que variava entre os indivíduos. Por último, a terceira é atribuída à neurociência cognitiva e situou a flexibilidade cognitiva no contexto das funções executivas.

Essa última abordagem definiu a flexibilidade cognitiva como a habilidade de uma pessoa em adaptar as estratégias de processamento cognitivo em resposta a possíveis mudanças que ocorram durante a execução de uma tarefa (Déak, 2003), mudanças estas que resultem em condições novas e inesperadas do ambiente (Diamond, 2013). A flexibilidade é testada quando as modificações são até certo grau, imprevisíveis ou novas, de forma que os sujeitos não possam utilizar respostas automáticas e que o conflito entre as respostas alternativas não seja trivial (Déak, 2003). Essa importante habilidade executiva possui um valor de sobrevivência (Kehagia, Murray \& Robbins, 2010).

A flexibilidade cognitiva prevê ainda, a capacidade de um indivíduo em utilizar experiências anteriores para conduzir situações novas, realizar rearranjos que permitam a elaboração de novos comportamentos, alterar a perspectiva de visualização de um problema ou um estímulo, aproveitar novas oportunidades e alternar, quando necessário, a produção de comportamentos 
diferentes para o cumprimento de mais de um objetivo importante (Diamond, 2013; Squire et al., 2008).

A adaptação prevista pela flexibilidade cognitiva pode ocorrer por meio da alternação da atenção, da seleção de informações atualizadas para guiar respostas futuras, da elaboração de novos planos ou do delineamento de novos objetivos mais adequados às condições ambientais modificadas (Déak, 2003). Os sujeitos poderão ser considerados flexíveis cognitivamente se esses processos resultarem em representações e ações bem adaptadas para a tarefa e para o contexto alterados.

Quando o sujeito falha na adaptação de suas estratégias às novas condições de uma tarefa e isto resulta em um desempenho comprometido, falase em falta de flexibilidade cognitiva. Esta pode ocorrer devido a déficits de atenção, a dificuldades relacionadas à memória operacional ou a perturbações no controle inibitório, respectivamente, quando não se percebe que duas tarefas são diferentes ou que as condições de realização de uma tarefa foram alteradas, quando há falhas no monitoramento simultâneo de respostas alternativas ou quando há perseveração na repetição de respostas inapropriadas, mas que eram adequadas antes de uma mudança (Déak, 2003; Diamond, 2013).

As pesquisas envolvendo flexibilidade cognitiva têm focado no CPF, nos núcleos da base, particularmente no corpo estriado e nas interações múltiplas entre eles (Kehagia et al., 2010). Thayer e colaboradores (2009) propõem uma rede neural relacionada com a capacidade de flexibilidade do indivíduo, com unidades funcionais integradas que incluem a rede autonômica central, composta pelas divisões simpática e parassimpática do Sistema Nervoso 
Autonômico (SNA) e a porção rostral do sistema límbico. De acordo com esses autores, dificuldades na integração dessas unidades tornam o organismo inflexível e, portanto, menos adaptativo.

Kehagia e colaboradores (2010) defendem a existência de múltiplas formas de flexibilidade cognitiva organizadas em uma hierarquia de complexidades, dentro de uma mesma espécie e entre as espécies.

Níveis inferiores de flexibilidade cognitiva são observados em tarefas que envolvem aprendizagem reversa, isto é, situações em que os sujeitos precisam trocar os estímulos para os quais emitem respostas, daqueles reforçados para os não reforçados anteriormente. Nesses casos, a flexibilidade é mediada pelo corpo estriado e pelo CPF por meio de vias dopaminérgicas (Kehagia et al., 2010).

Tarefas de mudança de cenário (attentional set-shifting), nas quais é necessário responder entre modalidades de estímulos diferentes, também exigem flexibilidade cognitiva de níveis inferiores, com ativação do CPF ventromedial, responsável pela sinalização da necessidade de se modificar a estratégia; do núcleo talâmico mediodorsal, que elimina estratégias inapropriadas; e do núcleo accumbens, responsável pela integração entre o reforço e o comportamento (Kehagia et al., 2010).

Níveis mais complexos de flexibilidade cognitiva são recrutados em situações de alternância de tarefas. Essa forma de flexibilidade também envolve os núcleos da base, que atuam na seleção da resposta e nas oscilações de flexibilidade e áreas frontoparietais, como o cingulado anterior, responsável pela atualização do objetivo, o CPF dorsolateral, responsável pela 
inibição dos estímulos irrelevantes (da tarefa anterior) e a região parietal inferior, responsável por sinalizar a mudança da tarefa.

\subsubsection{Memória operacional}

O sucesso no cumprimento de objetivos depende da manutenção das informações relevantes disponíveis para acesso ao longo do tempo, que pode se estender bastante a depender do objetivo. Esses longos intervalos de tempo podem ser um problema para o controle cognitivo, pois inúmeras distrações podem surgir enquanto se espera pelo melhor momento de agir (Squire et al., 2008). Assim, o bom funcionamento da memória operacional é imprescindível para a execução de comportamentos complexos, tais como as funções executivas.

O modelo original de memória operacional foi elaborado por Baddeley e Hitch em 1974 (Baddeley \& Hitch, 1974). Desde então, diversas pesquisas têm sido realizadas, com o intuito de aprimorar a compreensão do conceito de memória operacional, resultando em sua revisão por um de seus autores (Baddeley, 1992;2000;2001).

O modelo original da memória operacional inovou os modelos de memória de curto-prazo existentes na época com relação a dois aspectos: primeiramente, tratava-se de um modelo com múltiplos componentes, ao contrário dos modelos anteriores, cujo funcionamento se baseava em um sistema de armazenamento único; e em segundo lugar, fundamentava-se em um modelo de cognição complexa, e não exclusivamente de memória (Baddeley, 2000). 
A memória operacional consiste em um sistema que permite a manipulação e o armazenamento temporário de informações necessárias para tarefas complexas. Esse sistema, entretanto, possui capacidade limitada. Os três componentes da memória operacional propostos originalmente são o executivo central, a alça fonológica e o esboço visuo-espacial. O primeiro compreende um sistema atencional de controle relacionado ao lobo frontal e às funções executivas, enquanto os dois últimos são sistemas de apoio, subsidiários (Baddeley, 1992).

A alça fonológica armazena temporariamente informações verbais e acústicas por meio de uma estratégia de ensaio subvocal, ou seja, repetição mental das informações. Já o esboço visuo-espacial armazena informações visuo-espaciais e pode ser fracionado em componentes visuais, espaciais e possivelmente cinestésicos (Baddeley, 2000).

Inúmeras pesquisas foram desenvolvidas após a proposição do modelo de memória operacional por Baddeley e Hitch, focando principalmente na compreensão de seus componentes, especialmente a alça fonológica. A insuficiência do modelo para explicar novos resultados, fez com que Baddeley sugerisse um novo componente, o retentor episódico. Este é responsável por combinar as informações armazenadas nos dois sistemas de apoio, deixandoas disponíveis para acesso e modificação pelo executivo central de forma consciente (Baddeley, 2000). Assim, apesar de também possuir capacidade limitada, o retentor episódico pode ser considerado como um sistema reserva de armazenamento temporário, que aumenta a capacidade da memória operacional, especialmente quando integra informações de diferentes origens. 
A memória operacional ativa redes neurais que incluem o CPFDL e áreas posteriores (Sohlberg \& Mateer, 2001). Portanto, é possível presumir que desempenhos eficientes em funções executivas dependam, entre outros aspectos, do funcionamento da memória operacional, pois a sobreposição das regiões cerebrais ativadas para essas duas funções, com destaque para 0 córtex pré-frontal, fornece indícios de sua relação próxima (Thayer et al., 2009).

\subsubsection{Atenção}

A atenção é o processo cognitivo que seleciona algumas informações para processamentos adicionais, ao mesmo tempo em que inibe outras (Smith \& Kosslyn, 2006a). Isto se faz necessário devido à severa limitação na capacidade que o sistema de processamento de informações de humanos possui em realizar mais de um comportamento simultaneamente, especialmente quando esse comportamento prevê controle cognitivo. A realização de duas ou mais tarefas é possível, desde que não haja conflito entre elas. Contudo, nos casos em que essas tarefas requeiram um alto nível de processamento controlado é comum que uma interfira na execução da outra (Squire et al., 2008). Tendo em vista esta limitação, espera-se que durante a execução de uma tarefa, o sujeito selecione apenas as informações relevantes para o processamento cognitivo e ignore aspectos que possam atrapalhar seu desempenho.

Um modelo de atenção, desenvolvido inicialmente para classificar os seus componentes de acordo com sintomas apresentados por pacientes com danos cerebrais em estudos clínicos (Sohlberg \& Mateer, 2001), atualmente adquiriu importância e aplicação em diversos outros contextos. Este modelo propõe a 
divisão da atenção em cinco componentes: atenção concentrada, sustentada, seletiva, alternada e dividida.

A habilidade de um indivíduo em responder a um estímulo específico, seja ele visual, auditivo ou tátil, demanda o tipo de atenção concentrada (Sohlberg \& Mateer, 2001).

A atenção sustentada, ou vigilância, refere-se à manutenção de respostas comportamentais de forma consistente durante uma atividade contínua e repetitiva. Como esse componente da atenção requer a manipulação de informações e a manutenção destas na memória, ele envolve também a memória operacional (Sohlberg \& Mateer, 2001). Ambos os testes utilizados no presente estudo exigem atenção sustentada, que permita aos sujeitos manter 0 foco em uma regra específica ao longo de todo o teste, de forma a obter sucesso no desempenho.

A manutenção de um conjunto de comportamentos ou de processamentos cognitivos na presença de estímulos distratores demanda atenção seletiva. Além da atenção sustentada, o teste de Stroop, utilizado neste estudo, também demanda atenção seletiva à característica evidenciada pela instrução recebida, nomeadamente a cor que a palavra está escrita (Ghimire et al., 2015).

A atenção alternada é requerida em situações nas quais os indivíduos são solicitados a alternar o foco de sua atenção entre duas tarefas com requisitos cognitivos diferentes. Nessas situações é necessário um controle sobre qual informação será seletivamente processada, o que envolve por sua vez, flexibilidade cognitiva e o emprego da memória operacional. 
Por fim, a atenção dividida refere-se à habilidade de responder simultaneamente a múltiplas tarefas ou múltiplas demandas de uma mesma tarefa. Nesses casos, dois tipos de respostas comportamentais devem ser manifestados ou dois tipos de estímulos devem ser monitorados, respectivamente. Para que seja recrutado o uso da atenção dividida é necessário que pelo menos uma das tarefas seja processada de forma automática ou que exista atenção alternada entre as tarefas ou estímulos de forma rápida e contínua.

Três circuitos cerebrais controlam a atenção em humanos e, apesar de serem separados, podem funcionar de forma integrada (Sohlberg \& Mateer, 2001).

O primeiro, o sistema de atenção anterior, está envolvido na seleção de informações para o processamento cognitivo e na capacidade de alternar a atenção. Esse sistema é mediado pelo cingulado anterior (West \& Bell, 1997) e pelas áreas motoras suplementares (Sohlberg \& Mateer, 2001).

O segundo, o sistema de atenção posterior, está relacionado com a orientação espacial e é responsável pela orientação para estímulos simples no espaço visual. Esse sistema abrange o córtex parietal posterior, o núcleo pulvinar lateral do tálamo e o colículo superior (Sohlberg \& Mateer, 2001; West \& Bell, 1997).

Finalmente, o último sistema está relacionado com a atenção sustentada, em situações de ausência de estímulos externos novos e ressaltantes. Esse sistema é mediado principalmente pelo córtex pré-frontal direito (Sohlberg \& Mateer, 2001). 
A seleção de informações relevantes dentro de um contexto por parte de um indivíduo é, portanto, central para o funcionamento de sistemas de controle cognitivo, ao favorecer certos processos em detrimento de outros. No domínio sensorial, tal seleção é conhecida como atenção, que por vezes é tratada como sinônimo de controle cognitivo (Squire et al., 2008).

\subsection{TÉCNICAS DE ESTUDO}

Estudos eletrofisiológicos abrangem uma grande variedade de técnicas, capazes de registrar a atividade elétrica de diversas origens, tais como a atividade cerebral, a cardíaca, a muscular e a eletrodérmica. As técnicas utilizadas no presente estudo consistem em: a) registro eletroencefalográfico, que permite avaliar a localização das regiões corticais ativas durante a realização de testes cognitivos e b) registro da frequência cardíaca (FC), medida por meio da eletrocardiografia.

\subsubsection{Eletroencefalografia}

Existe uma estreita relação entre as funções executivas e a atividade do córtex pré-frontal, que por sua vez, mantém uma extensa rede de conexões recíprocas com outras regiões do cérebro, sejam elas corticais ou subcorticais, e ainda, no mesmo ou em outro hemisfério cerebral. O eletroencefalograma (EEG), uma das técnicas utilizadas no presente estudo, é uma técnica de registro eletrofisiológico que avalia a atividade pós-sináptica de neurônios corticais e permite investigar as regiões do cérebro nas quais as atividades 
corticais são mais evidentes, assim como a manifestação da atividade de outras estruturas subcorticais em razão destas.

O EEG permite estabelecer correlações potenciais entre padrões de ativação cortical e o comportamento efetivamente apresentado pelo indivíduo, embora se deva fazer a importante ressalva que os padrões de ativação cerebral observados não podem ser atribuídos, necessariamente, como a causa dos comportamentos observados. Os estudos de lesões cerebrais, em contrapartida, podem ser utilizados para avaliar se a ativação de determinada região é suficiente e necessária para promover um comportamento (Smith \& Kosslyn, 2006c).

O EEG registra atividades elétricas de neurônios corticais resultantes, principalmente, de aferências neuronais de estruturas subcortais por meio do posicionamento de eletrodos de superfície no couro cabeludo dos sujeitos. As ondas cerebrais resultantes do registro podem ser classificadas de acordo com sua banda de frequência, sendo as mais comuns, Delta (abaixo de 3,5 Hz), Teta (4-8 Hz), Alfa (8-13 Hz), Beta $(13-30 \mathrm{~Hz})$ e Gama $(30-70 \mathrm{~Hz})$.

Contudo, essas bandas devem ser interpretadas com cautela, pois no registro de EEG, a soma de diferentes ondas, em diferentes faixas de frequência, pode resultar na formação de uma única onda. Por isso, é importante a aplicação da Transformada Rápida de Fourier (FFT, do inglês Fourier Fast Transformation) nesta onda aparentemente única, que pode ser então decomposta, tornando evidentes, separadamente, todas as outras ondas nela contidas (Anghinah et al., 1998). Depois do uso desse procedimento matemático, a dominância de cada classe nas ondas cerebrais pode ser 
interpretada de acordo com determinados estados fisiológicos e psicológicos a que estão relacionadas.

Knyazev (2007) sugere a existência de duas subdivisões das frequências do EEG humano, as modalidades globais e locais de processamento. Supõe-se que as bandas Delta, Teta e Alfa sejam de processamento global e percorram áreas corticais relativamente grandes, efetuando a integração entre as regiões cerebrais. Já as bandas Beta e Gama, por serem distribuídas em áreas topográficas mais limitadas, seriam modalidades processadas localmente. As duas modalidades agiriam em conjunto, realizando interações dinâmicas (Knyazev, 2007).

O registro simultâneo do EEG e de tarefas específicas é importante para o estudo de processos cognitivos e por isso é realizado com frequência. $O$ desenvolvimento de novas técnicas, como o EEG quantitativo e topográfico (EEGQT), permitiu visualizar de forma clara os potenciais captados no escalpo durante a execução de testes cognitivos, com a opção da realização de análises estatísticas que comparam a ativação cortical em diferentes testes (Anghinah et al., 1998).

Uma técnica resultante do registro eletroencefalográfico possibilita 0 estudo dos padrões de ativação provocados pelos estímulos presentes nas tarefas, por meio da utilização de recursos chamados de potenciais evocados ou potenciais relacionados a eventos (ERP). Esse tipo de recurso analisa 0 decurso temporal de ondas cerebrais após a apresentação de estímulos. Para tal, obtém-se uma mediação das ativações ocorridas ao longo do tempo em resposta a um mesmo estímulo que é apresentado várias vezes e o padrão encontrado pode sofrer variações algum tempo após a apresentação do 
estímulo. Essas variações, bem como tempo decorrido para que o seu pico seja atingido, podem ser positivas ou negativas (Teplan, 2002). As ondas encontradas como resultados são interpretadas de acordo com o conhecimento disponível na literatura científica.

A onda P300, por exemplo, consiste em uma onda cujo pico de alteração no padrão de ativação é positiva e observada 300 milissegundos após a apresentação do estímulo. Essa onda geralmente está associada ao processamento de informações, especialmente em situações em que aparecem estímulos novos, para os quais há envolvimento da memória operacional e da inibição de respostas (Hruby \& Marsalek, 2003).

As vantagens para o uso das técnicas de eletroencefalografia se referem ao baixo custo de sua utilização, assim como o fato de não serem invasivas e, especialmente, de excelente resolução temporal (em milissegundos) quando comparadas a outros métodos, como a tomografia de emissão de pósitrons (PETScan); a ressonância eletromagnética, funcional ou não, (MRI e fMRI) e o imageamento óptico (p.e., tomografia óptica difusa, DOT) (Smith \& Kosslyn, 2006c). Além disso, o EEG pode ser utilizado tanto para estudos da atividade normal do cérebro, quando da sua atividade em presença de alguma patologia (Teplan, 2002).

Entretanto, também existem desvantagens associadas ao EEG, tais como limitação na resolução espacial, em comparação com as técnicas descritas acima (Smith \& Kosslyn, 2006c), com exceção do imageamento óptico. Outra desvantagem diz respeito à influência de artefatos no registro, como por exemplo, a atividade elétrica de músculos quando estes são movimentados 
(Smith \& Kosslyn, 2006c; Teplan, 2002). Contudo, o tratamento dos dados permite a remoção de tais artefatos.

\subsubsection{Eletrocardiografia}

A frequência cardíaca pode ser calculada a partir do registro da atividade elétrica do coração, medida por meio do eletrocardiograma (ECG), de maneira não-invasiva e com baixo custo (Bansal, Khan \& Salhan, 2009). Para tal, podem ser posicionados eletrodos no tórax do sujeito ou, como no caso do presente estudo, em pontos nos quais seja possível registrar a frequência de pulso, que em indivíduos saudáveis também produz a informação da frequência cardíaca com um sinal mais baixo.

A cada batimento cardíaco pode ser observada uma sequência de ondas P, QRS, T e U, sendo o complexo QRS o de maior amplitude. Quando detectado, esse complexo permite o cálculo dos intervalos entre dois picos consecutivos de ondas R, o intervalo RR. Em condições de repouso, indivíduos saudáveis exibem variações periódicas nos intervalos RR (Bansal et al., 2009).

Com base nas alterações existentes na duração dos vários intervalos RR, é possível calcular a variação da frequência cardíaca (VFC), parâmetro que pode ser analisado no domínio da frequência e do tempo. A VFC é sensível e responsiva ao estresse agudo. Em situações de tomada de decisões complexas, por exemplo, a VFC diminui (Bansal et al., 2009).

Um grupo de pesquisa defende a hipótese de que comportamentos orientados a um objetivo e a adaptabilidade de um organismo são regulados por um único mecanismo neurovisceral integrado (Thayer et al., 2009). Assim, a frequência cardíaca, as funções executivas, incluindo a memória operacional 
e o controle inibitório, o controle emocional e outros processos cognitivos seriam modulados pela mesma rede neural. Os resultados dos estudos realizados por esses autores, em que maiores índices de VFC se correlacionam com melhores desempenhos em tarefas sustentadas pelas funções executivas, corroboram esta hipótese. O papel do córtex pré-frontal, tanto no controle executivo, quanto na inibição da aceleração da frequência cardíaca, por intermédio do nervo vago, torna-se fundamental para tal integração. Portanto, a VFC pode ser considerada como um índice da capacidade funcional de estruturas cerebrais que subsidiam o sucesso executivo.

A Hipótese do Marcador Somático, elaborada por António Damásio em 1994, apresenta uma explicação potencial de como um indivíduo faz uso de informações provenientes das suas respostas fisiológicas para influenciar o seu comportamento e os seus pensamentos (Lent, 2010). Esta hipótese propõe a existência de um sistema de memória capaz de armazenar a associação entre o estado somático e eventos vivenciados por uma pessoa no passado, o que pode auxiliá-la na tomada de decisões e na elaboração de comportamentos complexos (Damasio, 1996). A suposição de que o CPFOF atribui significância afetiva a pessoas, objetos e situações possui papel importante para embasar esta hipótese (Squire et al., 2008). Assim, a avaliação de respostas fisiológicas, no caso do presente estudo, a avaliação da variação da frequência cardíaca, pode contribuir para uma compreensão mais abrangente dos padrões de desempenho dos sujeitos em testes cognitivos. 


\subsection{AVALIAÇÃO COGNITIVA}

Diversos testes neuropsicológicos clássicos avaliam os diferentes componentes das FE, como por exemplo, o teste de Classificação de Cartas de Wisconsin, teste de Trilhas, teste de Completar Sentenças de Hayling, Torre de Londres, Torre de Hanói, teste de Cancelamento de Dígitos, teste de Reconhecimento Espacial com Atraso, teste de Escolha de Acordo com (ou Diferente do) Modelo com Atraso, entre outros (Jurado \& Rosselli, 2007; Satler, 2012). Com a finalidade de avaliar o controle inibitório, a flexibilidade cognitiva, a memória operacional e a atenção, foram escolhidos dois dentre os instrumentos clássicos, o teste de Stroop e o teste de Tempo de Reação.

Ambos os testes escolhidos consistem em tarefas executivas, pois são baseados em processos controlados. Tarefas consideradas não-executivas são aquelas que envolvem apenas processos automáticos ou reflexivos, consideradas fáceis de serem realizadas por não demandarem atenção sustentada (Thayer et al., 2009). Apesar de o teste de Tempo de Reação ser também que mensura uma resposta reflexa, existem particularidades no nosso protocolo que requerem o uso de estratégias de controle cognitivo por parte do sujeito.

\subsubsection{Teste de Stroop}

O teste de Stroop (Stroop, 1935) é muito utilizado para o estudo de funções executivas, pois possibilita avaliar, principalmente, o controle inibitório verbal da manifestação de respostas automáticas, e ainda, a flexibilidade 
cognitiva e a tomada de decisões; além da atenção seletiva e sustentada e o tempo de resposta.

Em sua versão clássica, o teste é dividido em duas etapas. Em ambas as etapas, palavras que são nomes de cores são apresentadas ao sujeito. $\mathrm{Na}$ primeira etapa, a palavra e a cor em que ela está escrita coincidem (a palavra “azul" é escrita na cor azul, por exemplo). Na segunda etapa, um fator de interferência é inserido, pois esses atributos podem não coincidir ("azul" escrito em vermelho, por exemplo). Os participantes são instruídos a pronunciar em voz alta a cor em que as palavras estão escritas, inibindo a resposta automática de ler o que está escrito. Atualmente existem variações dessa versão, como é o caso do protocolo seguido no presente estudo, descrito na seção de materiais e métodos.

Um modelo de rede neural desenvolvido por Cohen e colaboradores tenta explicar a dinâmica de ativação cortical observada no teste de Stroop (Botvinick, Cohen \& Carter, 2004; Smith \& Kosslyn, 2006b). A representação mental da cor da palavra é atribuída ao córtex occipital, enquanto a representação da palavra em si, ao córtex temporal superior. A leitura da palavra, por ser um processo mais automático geralmente se sobrepõe à nomeação da cor, gerando uma resposta verbal mediada pelo córtex motor. Entretanto, o que leva os sujeitos a acertarem em condições incongruentes é a presença de um monitor de conflito, supostamente mediado pelo cingulado anterior e um sistema de controle da atenção, mediado pelo CPFDL. O primeiro monitora o conflito entre as duas respostas possíveis (cor e leitura), que é solucionado por meio do aumento da atenção mediada pelo sistema de controle atencional. Esse sistema leva em consideração o objetivo da tarefa (a 
nomeação da cor da palavra), aumentando a contribuição da representação mental da cor para a geração da resposta verbal. Contudo, o cingulado anterior pode estar relacionado tanto à resolução de conflitos, quanto ao controle inibitório de forma mais ampla.

\subsubsection{Teste de Tempo de Reação}

O teste de Tempo de Reação tradicional (Donders, 1969) permite avaliar a inibição de respostas impulsivas do tipo motor e a manipulação do tempo.

O teste consiste na apresentação de um estímulo ao sujeito, que deve responder emitindo um sinal. Havendo resposta, ou ausência de resposta, o estímulo é então suprimido após um intervalo. Obtém-se como resultados, o tempo decorrido entre a apresentação do estímulo e a resposta, além de possíveis ausências ou antecipações de respostas. Esse teste pode ser elaborado em diferentes versões e o protocolo utilizado no presente estudo está descrito com detalhes na seção de materiais e métodos. Na versão do TR com pista, esta deve ser exibida anteriormente à apresentação do estímulo, como uma dica para sua ocorrência, e permanecer presente até 0 aparecimento do mesmo. A resposta do sujeito ou a sua ausência dentro de um intervalo específico leva à supressão de ambos em cada tentativa do teste.

Além do controle inibitório e da manipulação do tempo, a versão do teste de Tempo de Reação utilizada no presente estudo também permite avaliar a atenção sustentada, pois os estímulos podem aparecer em diferentes locais da tela; a flexibilidade cognitiva, já que as várias posições do estímulo requerem resposta e ainda, porque o intervalo entre a exibição da dica e a apresentação 
do estímulo é variável e a memória operacional, para a manutenção da regra do teste nos sistemas de memória ao longo de todo o teste.

Para que se trate de um teste de Tempo de Reação é necessário que os sujeitos sejam instruídos a responder o mais rapidamente possível após a apresentação do estímulo. Quando os participantes são instruídos apenas a responder ao estímulo, sem que seja mencionado que a resposta deve ser imediata, então o intervalo decorrido entre a apresentação do estímulo e a resposta emitida é considerado como tempo de resposta. Portanto, o teste de Tempo de Reação exige a detecção do estímulo, o seu reconhecimento e a seleção da resposta ao estímulo numa perspectiva do tempo decorrido. 
2. JUSTIFICATIVA 
O controle inibitório pode ser considerado como um componente das funções executivas essencial para a convivência em sociedade e para uma vida bem-sucedida (Sauseng, Gerloff \& Hummel, 2013). Atualmente, não são raras as situações que exigem que os sujeitos inibam respostas prepotentes, como em casos em que se faz necessário adiar recompensas no presente ou realizar tarefas não gratificantes, a fim de garantir a obtenção de ganhos futuros. O comportamento social exige que os humanos e outros primatas inibam respostas dominantes, como a agressividade, a intolerância social e até mesmo a excitação sexual (Bjorklund \& Kipp, 1996).

Alguns autores sugerem que exista, inclusive, uma rede neural inibitória comum associada com uma grande variedade de processos, tais como a regulação emocional e as funções executivas, todos mediados, pela atividade não isolada do córtex pré-frontal (Thayer et al., 2009).

O presente estudo prevê o estudo de dois tipos diferentes de controle inibitório, verbal e motor, avaliados por meio dos testes executivos de Stroop e de Tempo de Reação, respectivamente, em indivíduos jovens. Jonides e colaboradores (1998) sugerem a realização de estudos sobre os vários tipos de controle inibitório, de forma a elucidar o papel das regiões do lobo frontal nesses mecanismos.

Um estudo amplo, que envolva tanto o desempenho em testes cognitivos, quanto a caracterização de respostas autonômicas e dos padrões de ativação cortical eliciados pelas tarefas, revela-se importante especialmente à luz da teoria apresentada por Thayer e colaboradores (2009), que prevê uma rede neural integrada para o controle de todos esses aspectos. 
3. OBJETIVOS 


\section{Geral}

Comparar o desempenho no controle inibitório verbal e motor, o padrão de ativação cortical e a variação da frequência cardíaca durante a realização de dois testes de funções executivas por jovens universitários.

\section{Específicos}

- Analisar o desempenho comportamental de jovens em testes que requerem controle inibitório verbal (teste de Stroop) e motor (teste de Tempo de Reação).

- Analisar, por meio da técnica de eletroencefalografia, os padrões de ativação cerebral na realização dos testes de Stroop e de Tempo de Reação;

- Descrever e interpretar a variação da frequência cardíaca, por meio da técnica de eletrocardiografia, em duas situações de controle inibitório, o teste de Stroop e o teste de Tempo de Reação.

- Investigar a existência de diferenças entre os gêneros nas duas tarefas, com relação aos dados comportamentais, aos padrões de ativação cortical e à variação da frequência cardíaca. 
4. MATERIAIS E MÉTODOS 


\subsection{CONSIDERAÇÕES ÉTICAS}

Os dados utilizados no presente estudo foram coletados como parte de um projeto de doutorado realizado no laboratório de Neurociência e Comportamento do Instituto de Biologia da Universidade de Brasília (Santos, 2011), porém não foram analisados nessa ocasião. O referido projeto, cujo registro é 160/08 (Anexo A), foi aprovado pelo Comitê de Ética em Pesquisa da Faculdade de Ciências da Saúde da Universidade de Brasília (CEP/FS-UnB).

A análise destes dados no contexto de um projeto de mestrado, com a inclusão de novos membros na equipe, tornou necessária a apresentação do novo projeto ao Comitê de Ética, com o pedido de dispensa de análise e isenção de nova assinatura de TCLE por parte dos sujeitos, o que foi aprovado pelo CEP/FS-UnB (Anexo B).

Todos os indivíduos foram voluntários e obedeciam aos critérios éticos de participação definidos para experimentação em humanos de acordo com as resoluções 196/96 e 466/2012 CNS/MS (Brasil, 1996;2012). Houve esclarecimento do procedimento aos participantes, sem que o seu real objetivo fosse declarado a fim de que não houvesse obliquidade no resultado dos testes.

Todos os participantes assinaram um termo de consentimento livre e esclarecido (TCLE) (Apêndice A). Após a conclusão do experimento, foi revelado o verdadeiro objetivo e solicitado mais uma vez o consentimento para a utilização dos dados coletados. O participante foi informado sobre o seu direito de desistir do experimento a qualquer momento sem sofrer nenhuma consequência e de que os dados adquiridos estão assegurados em termos de sigilo e confidencialidade. 


\subsection{PARTICIPANTES}

Participaram do estudo 53 jovens universitários (27 mulheres, 26 homens), hígidos, na faixa etária de 17 a 28 anos (média de idade \pm DP: 21,5 \pm 2,9), recrutados por meio de anúncio escrito no campus Darcy Ribeiro da Universidade de Brasília.

\subsubsection{Critérios de inclusão}

Para serem incluídos no estudo, os sujeitos deveriam ser estudantes universitários, jovens e hígidos. Além disso, os participantes foram avaliados pelo Inventário de Edinburgh (Oldfield, 1971), sendo incluídos no estudo apenas os indivíduos destros (Apêndice C).

\subsubsection{Critérios de exclusão}

Os dados dos indivíduos que declararam possuir história de transtorno neurológico, próprio ou familiar, ou que fizeram uso de drogas ou de bebidas alcoólicas nas 24 horas que antecederam a coleta, foram excluídos após a realização do experimento, não sendo utilizados nas análises estatísticas. Estes participantes não foram informados sobre sua exclusão do estudo. 


\subsection{EQUIPAMENTOS}

As medidas eletrofisiológicas foram realizadas utilizando-se o aparelho especializado de registros eletrofisiológicos Neuron-Spectrum-4/EPM do fabricante NeuroSoft@ (Ivanovo, Rússia) com conversão analógico-digital e taxa de amostragem de $2000 \mathrm{~Hz}$. Para o registro eletrocardiográfico foram utilizados um filtro passa-banda padrão $(0,5-75 \mathrm{~Hz})$ e uma taxa de rejeição de modo comum de $100 \mathrm{mV}$. O aparelho dispõe de sistema multifuncional para EEG, ERP e outros sinais biológicos em 29 canais, permitindo o seu registro simultâneo (Figura 3).

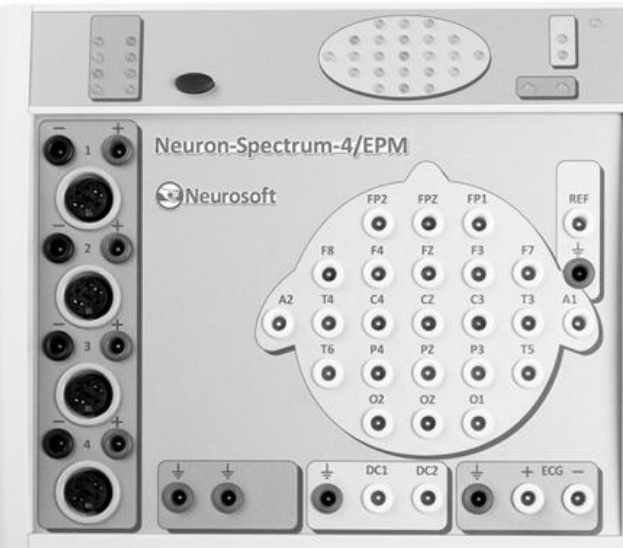

Figura 3. Aparelho Neuron-Spectrum-4/EPM (NeuroSoft®), Ivanovo, Rússia) utilizado para a coleta dos dados de EEG, ECG, RGP e EMG.

Foram utilizados 25 canais: 21 para EEG, 1 para o registro da FC (ECG), 1 para RGP e 2 para eletromiografia (EMG). Para o EEG, também foram incluídas duas referências auriculares. Os dados de RGP e EMG não foram analisados no presente estudo. 
O Neuron-Spectrum-4/EPM foi conectado a um computador e utilizou o

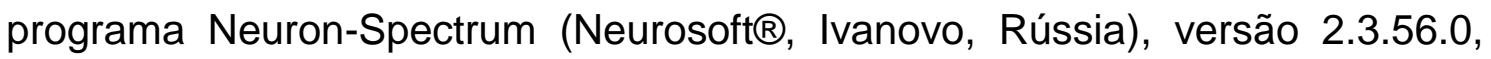
para a visualização do registro em tempo real. O computador utilizado foi de modelo portátil Satellite INTR® com processador AMD Athlon $(1,1 \mathrm{GHz}$ e 256MB de RAM) e um monitor colorido de 15".

Para aplicação dos testes cognitivos, foi utilizado o mesmo computador conectado ao aparelho de registro, com teclado, mouse e microfone adaptados e monitor de 17" para uso do participante. Para os testes, foram utilizados programas específicos desenvolvidos no Laboratório de Neurociência e Comportamento: em linguagem Borland Delphi, versão 7.0, o programa STROOP (teste de Stroop); e em linguagem C, o REFLEX (teste de Tempo de Reação).

\subsection{INSTRUMENTOS}

Antes de iniciar o experimento, os participantes responderam a uma ficha experimental (Apêndice B) sobre dados pessoais e hábitos recentes, que tinha como objetivo determinar suas condições para a participação no estudo, de acordo com os critérios de inclusão e exclusão. A ficha experimental possuía questões informativas, como identificação, sexo e idade. Outras questões eram restritivas, como uso de medicamentos, drogas ou álcool, história de transtornos neurológicos e dominância manual.

A fim de avaliar a dominância manual dos indivíduos, estes responderam ao Inventário de Edinburgh (Apêndice C) computadorizado, desenvolvido no próprio laboratório, que possuía uma lista de atividades para as quais os sujeitos deveriam informar qual mão utilizavam ao realizá-las. Caso eles 
sempre utilizassem a mesma mão para realizar a tarefa, deveriam marcar dois sinais de mais (++) na coluna correspondente à mão utilizada. Se utilizassem qualquer uma das mãos, então deveriam marcar apenas um sinal de mais (+) na coluna correspondente àquela utilizada com maior frequência. Um sistema de atribuição de pontos para cada atividade foi utilizado, gerando uma pontuação final, o quociente de lateralidade (LQ). Os resultados possíveis eram destro (maior que 40), sinistro (menor que -40) ou ambidestro (entre -40 e 40), sendo incluídos no estudo apenas os indivíduos destros.

Uma sequência de testes cognitivos foi realizada com os participantes, ao mesmo tempo em que eram registrados os parâmetros eletrofisiológicos previstos. Os testes aplicados fazem parte da bateria de testes executivos, segundo metodologia já validada no laboratório.

Os dados de execução de cada teste, tais como os horários de início e fim, horários de apresentação dos estímulos, tempos de resposta e resultados de desempenho (acertos, erros e falta de resposta) foram armazenados pelos programas para posterior análise.

\subsubsection{Teste de Stroop}

Utilizou-se uma versão computadorizada deste teste (programa STROOP), no qual uma palavra colorida por vez foi apresentada durante 800 ms, no centro de uma tela de cor cinza. Os participantes foram instruídos a pronunciar em voz alta a cor em que cada palavra estava escrita (Figura 4).

O teste foi dividido em três etapas. Antes da primeira etapa, os sujeitos tiveram um tempo de preparação, durante o qual fecharam os olhos e 
receberam as instruções. Entre as etapas também foi respeitado o intervalo de preparação, no qual as instruções foram repetidas.

Nas duas primeiras etapas, todas as palavras apresentadas eram nomes de cores. Na primeira, chamada de Congruente, a cor na qual a palavra estava escrita e o nome da cor apresentado coincidiam, por exemplo, a palavra "verde" escrita na cor verde. Na segunda etapa, nomeada Incongruente, a cor das palavras e o nome da cor eram diferentes, por exemplo, a palavra "verde" escrita em azul. Nas duas primeiras etapas, as palavras poderiam ser "verde", "azul", "amarelo" e "vermelho" nas cores verde, azul, amarela ou vermelha. Na terceira e última etapa, as palavras apresentadas eram foneticamente semelhantes às palavras das duas primeiras etapas, sendo elas "verdade" (verde), "cabul" (azul), "marmelo" (amarelo) e "velho" (vermelho), podendo ser escritas em qualquer uma das cores citadas anteriormente.

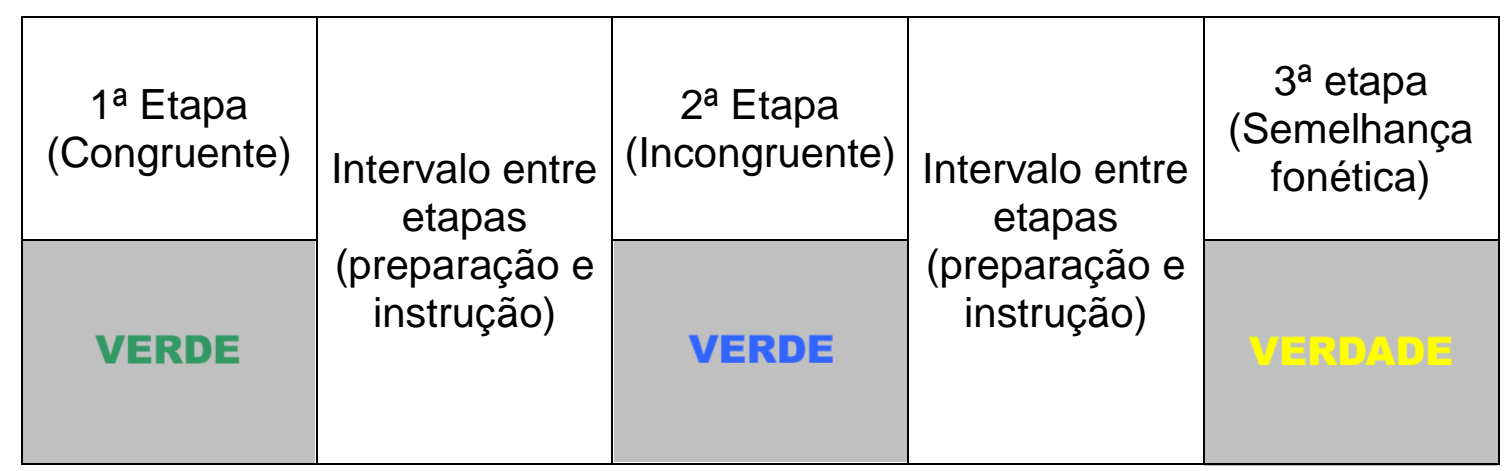

Figura 4. Esquema da sequência do teste de Stroop com imagens que exemplificam cada etapa do teste. O intervalo entre as etapas não foi controlado e consistia no tempo levado para abrir a próxima etapa no programa STROOP e repetir as instruções para os sujeitos. Estes ficavam de olhos fechados durante todo o intervalo.

As três etapas do teste compõe uma sessão e cada palavra apresentada representa uma tentativa. Em cada etapa, houve 32 ou 64 tentativas. As palavras foram ordenadas de forma aleatória. 
A versão utilizada no presente estudo se assemelha à versão Victoria do teste de Stroop, pelo fato de sua administração ser breve, o que dificulta que o participante adquira prática no teste e por incluir uma etapa que requer que 0 sujeito nomeie a cor de palavras neutras (Strauss, Sherman \& Spreen, 2006).

O programa do teste armazenou os horários de início e término da sessão, de cada etapa e de cada tentativa em arquivos separados para cada participante. O áudio foi captado pelo gravador de som padrão do MSWindows ${ }^{\circledR}$ por meio de um dispositivo de microfone acoplado ao computador.

Os arquivos gerados pelo programa STROOP incluíam as planilhas com as palavras e as cores em que estas foram apresentadas aos sujeitos. Os áudios foram degravados, e assim, foi possível inserir nas planilhas as respostas dos participantes e compará-las com as palavras apresentadas. Os resultados esperados foram: a) acertos, quando a resposta do sujeito coincidia com a cor da palavra; b) erros, quando a resposta diferia da cor apresentada e c) erros de omissão, quando os participantes não responderam à tentativa.

\subsubsection{Teste de Tempo de Reação}

Utilizou-se uma versão computadorizada do teste de Tempo de Reação (programa REFLEX) com dica e estímulo único (Tavares, 2002). Cada participante foi instruído a fixar o olhar em um ponto central da tela, a aguardar a exibição de uma dica e a pressionar uma tecla a cada vez que um alvo visual (estímulo) fosse apresentado (Figura 5).

A dica consistiu em uma cruz amarela $(2 \mathrm{~cm} \times 2 \mathrm{~cm})$ exibida no centro da tela e o estímulo em um quadrado de bordas brancas e sem preenchimento (3 
$\mathrm{cm} \times 3 \mathrm{~cm}$ ) apresentado em seis locais aleatórios, periféricos ao ponto de fixação (horizontalmente: à esquerda ou à direita; verticalmente: acima, abaixo ou ao centro).

O teste se iniciou com a apresentação de uma tela de cor preta, na qual era exibida a dica e em seguida, após um intervalo variável, era apresentado o estímulo. Os intervalos poderiam variar, aleatoriamente, de 100 a 2000 ms, na tentativa de evitar que os sujeitos fossem condicionados a responder ao estímulo de forma automática em intervalos fixos de tempo. O sujeito foi instruído a responder o mais rapidamente possível pressionando a barra de espaços e após a resposta, a dica e o estímulo eram suprimidos e haveria um novo intervalo de $1000 \mathrm{~ms}$ para que fosse iniciada uma nova tentativa (Figura $5)$.

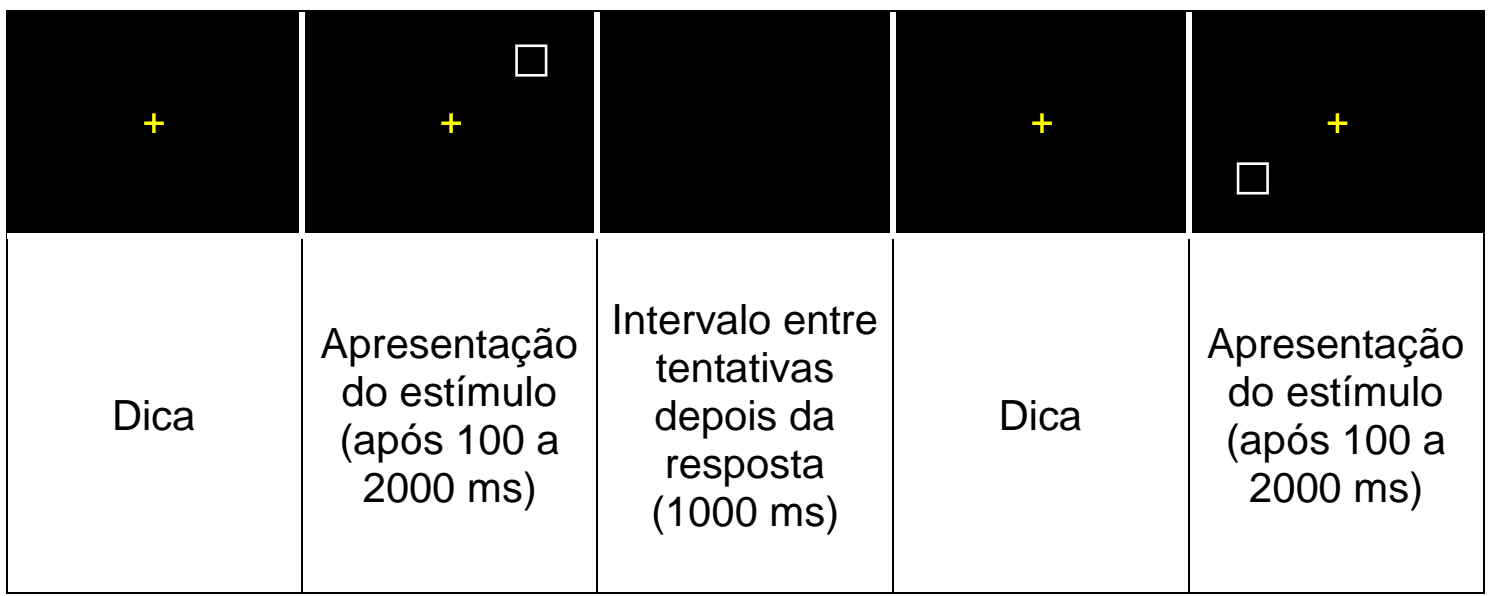

Figura 5. Esquema da sequência do teste de Tempo de Reação com imagens exemplificativas.

As respostas foram consideradas corretas caso a tecla fosse pressionada após a apresentação do estímulo e foram consideradas incorretas nos casos de falsos positivos e de antecipação das respostas. Foram considerados falsos positivos quando a tecla era pressionada antes da apresentação da dica. As respostas antecipadas foram aquelas em que o participante pressionava a tecla 
após a apresentação da dica, mas anteriormente à apresentação do estímulo. As respostas corretas eram seguidas de um tom agudo, e as incorretas, de um tom grave, ambos padronizados do MSWindows $\AA_{\text {. }}$

Havia ainda, a possibilidade do sujeito não apresentar resposta para a tentativa e nesses casos, o estímulo permanecia exposto na tela durante 5 segundos. Nesses casos, se o indivíduo não pressionasse a tecla durante os 5s, uma nova tentativa era apresentada para o sujeito. Para cada participante, foram apresentadas 36 ou 72 tentativas de teste.

O programa do teste armazenou os horários de início e término do teste e de cada tentativa e os intervalos entre a apresentação da dica e do estímulo (em $\mathrm{ms}$ ), os tempos de reação (em $\mathrm{ms}$ ) para cada resposta e o tipo de resposta (acerto ou erro) em arquivos separados para cada participante. Os arquivos puderam ser acessados posteriormente para fins de análise dos dados.

\subsection{PROCEDIMENTO}

Os experimentos foram realizados no Laboratório de Neurociência e Comportamento, do Instituto de Biologia da Universidade de Brasília, na sala de registros eletrofisiológicos, devidamente equipada com uma gaiola de Faraday (LxAxP: 259 × 223 × 396 cm), para minimizar as interferências eletromagnéticas no registro.

Para iniciar o experimento, o participante era convidado a sentar-se em frente ao computador e acomodar-se de maneira que pudesse utilizar o mouse e o teclado confortavelmente. Neste momento, ele era informado de que ficaria naquela posição enquanto estivesse disponível para a coleta dos dados. 
A sessão se iniciava com a preparação do participante para os registros das medidas eletrofisiológicas. Esta preparação consistia na marcação dos pontos e na fixação dos eletrodos de superfície, conforme as medidas e as especificidades de cada tipo de registro. Para o EEG, foi realizada a limpeza de cada ponto marcado com um gel abrasivo (Nuprep $\AA$, Weaver and Company, Aurora, USA), enquanto que para o ECG, apenas com álcool. Os sinais biológicos foram registrados continuamente durante toda a sessão com uma taxa de amostragem de $2000 \mathrm{~Hz}$ (Figura 6).

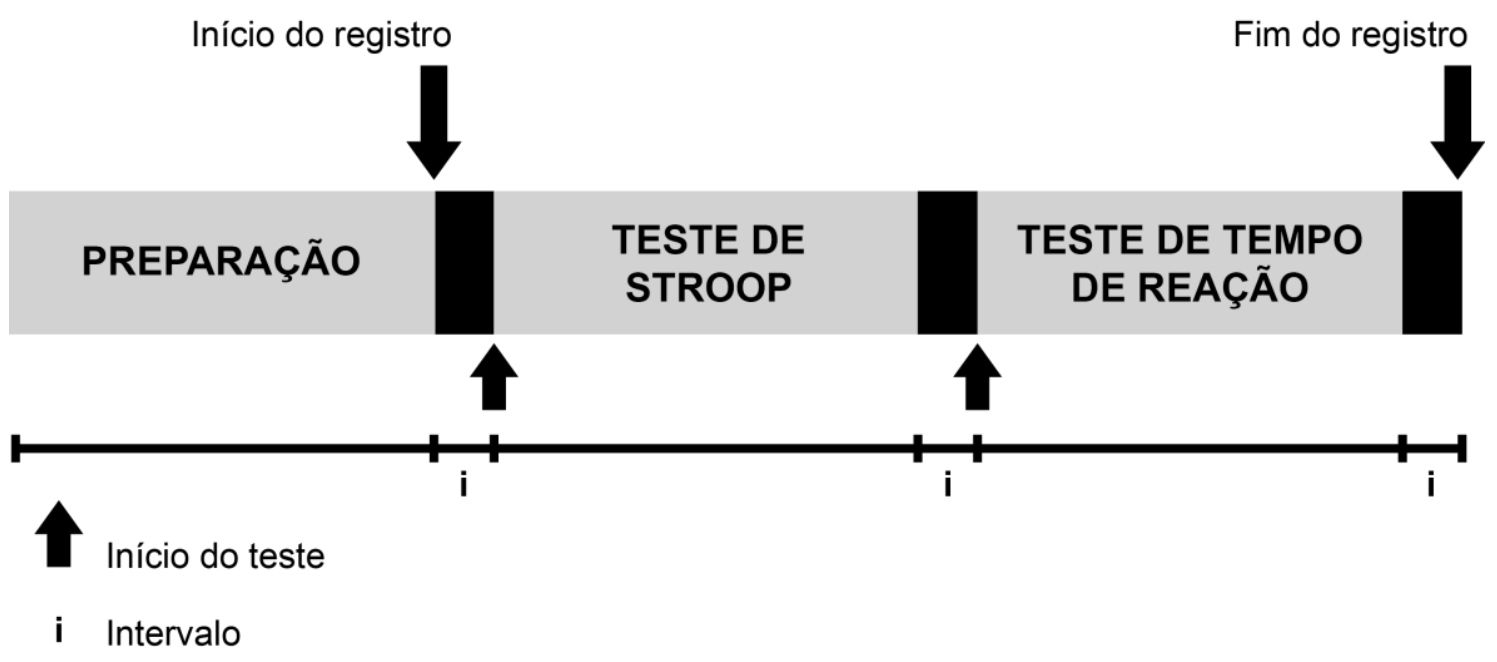

Figura 6. Fluxo do procedimento do estudo mostrando a ordem dos testes, o registro contínuo de medidas eletrofisiológicas e a preparação que antecede o registro. Durante 0 primeiro intervalo, o programa STROOP foi aberto e as instruções do teste de Stroop foram informadas ao sujeito. No segundo intervalo, o programa REFLEX foi aberto e foram fornecidas as instruções do teste de Tempo de Reação. Nesses dois intervalos, os participantes permaneceram de olhos fechados. No último intervalo, os eletrodos foram retirados dos sujeitos e foi feita a limpeza das regiões em que estes haviam sido colocados.

O tempo de execução dos testes dependeu da troca entre as etapas para o teste de Stroop e do tempo levado pelo participante para responder cada tentativa para o teste de TR, que variou entre os sujeitos. O tempo de intervalo entre os testes não foi controlado, consistindo apenas no tempo suficiente para a troca dos programas (STROOP para REFLEX) e para a informação das 
instruções do novo teste. Antes do início de cada teste, o indivíduo era solicitado a fechar os olhos, inclusive no momento de troca dos testes.

Para o registro eletroencefalográfico, os eletrodos de superfície foram posicionados de acordo com o sistema Internacional 10/20 (Klem et al., 1999) (Figura 7) e os referenciais foram alocados em correspondência com os processos mastoides. Os eletrodos foram fixados por uma pasta condutora (Ten20, Weaver and Company, Aurora, USA) e mantiveram as impedâncias abaixo de $5 \mathrm{k} \Omega$ durante toda a sessão.

A

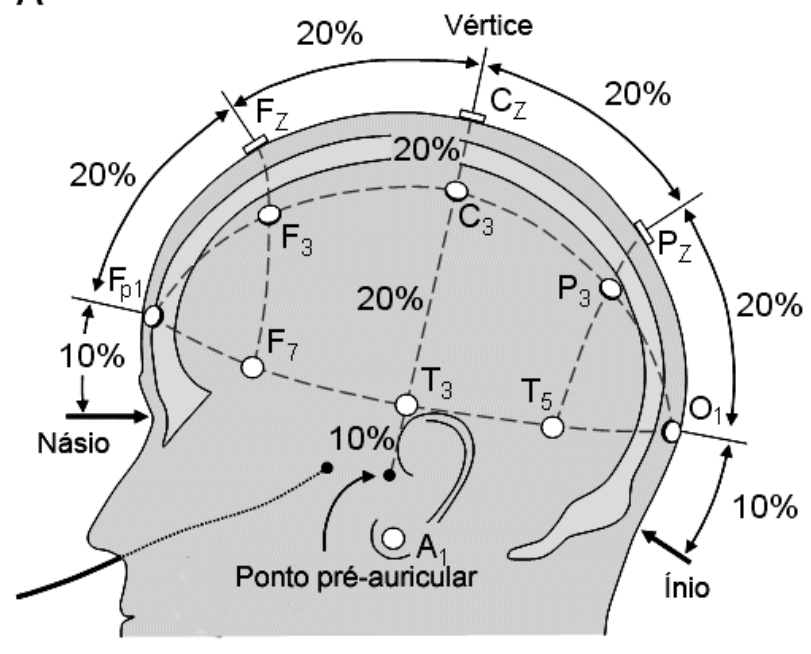

B

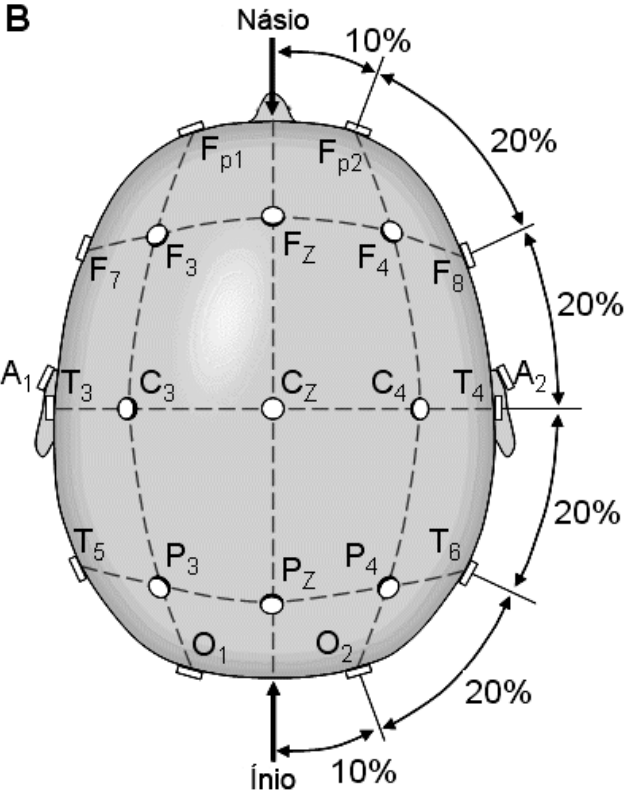

Figura 7. Sistema internacional $10 / 20$ para posicionamento de eletrodos de registro de eletroencefalograma, a partir de vista lateral (A) e vista superior (B). Os eletrodos com números pares estão localizados no hemisfério direito e os ímpares, no esquerdo. Os eletrodos posicionados na linha média recebem a letra z (zero). A: Ponto pré-auricular; C: central; P: parietal; F: frontal; Fp: frontopolar; O: occipital (retirado de http://www.bem.fi/book/13/13.htm, acesso em 10 de dezembro de 2013, tradução própria).

O registro da frequência cardíaca foi feito pela técnica de eletrocardiografia, utilizando-se 2 eletrodos adesivos de botão: um colocado no pescoço, sobre a veia jugular externa direita, e outro colocado na fossa cubital esquerda em correspondência com a artéria radial (Garcia et al., 2011). 
Após o posicionamento de todos os eletrodos, foram avaliados os seus valores de impedância para que estivessem menores do que $5 \Omega$. Após a preparação, os registros foram tomados simultaneamente à execução dos testes cognitivos.

Quando o teste de Tempo de Reação foi finalizado, os eletrodos foram retirados dos sujeitos e o experimentador realizava a limpeza, com algodão e álcool ou água, das regiões do escalpo do sujeito em que estes estavam posicionados.

\subsection{PROCESSAMENTO DOS DADOS ELETROFISIOLÓGICOS}

Os dados de EEG foram analisados utilizando o software livre e de código aberto, EEGLab toolbox, versão 9.0.4.5 (http://sccn.ucsd.edu/eeglab/) (Delorme \& Makeig, 2004). Os registros contínuos foram "cortados" de acordo com os horários de início e fim do teste de Tempo de Reação e de cada etapa do teste de Stroop. Além disso, foram re-referenciados para os eletrodos A1 e A2.

A taxa de amostragem de $2000 \mathrm{~Hz}$ utilizada na coleta foi reamostrada para $500 \mathrm{~Hz}$, com o objetivo de diminuir o tempo gasto pelo computador para o processamento dos dados. Como as faixas de frequências mais altas a serem analisadas foram as ondas Gama $(30-70 \mathrm{~Hz})$, a reamostragem não afetou os resultados.

Os fragmentos foram submetidos ao algoritmo Infomax para serem decompostos em fontes de atividades independentes (Bell \& Sejnowski, 1995). Esta decomposição dá origem aos componentes independentes (ICA), em quantidade igual ao número de canais utilizados. Os componentes relacionados a artefatos do registro, como o piscar ou movimento dos olhos e a 
atividade muscular de regiões do pescoço e da cabeça, possuem padrões característicos, o que possibilitou sua remoção do registro original. Posteriormente, o registro de EEG foi recalculado com os componentes restantes.

Após a remoção dos artefatos, os registros foram avaliados em um estudo gerado pelo EEGLab, para o qual foram incluídos os arquivos de registro de cada sujeito, além da sua condição (por exemplo, o gênero ou o teste realizado). O estudo foi pré-computado para o cálculo da potência espectral (em $\mu \mathrm{V}$ ) e os dados foram disponibilizados para análise. Os dados foram analisados de acordo com as bandas de frequência tradicionais: Teta $(4-8 \mathrm{~Hz})$, Alfa $(8-13 \mathrm{~Hz})$, Beta $(13-30 \mathrm{~Hz})$ e Gama $(30-70 \mathrm{~Hz})$. Uma das ferramentas do EEGLab foi utilizada para a geração de mapas topográficos da atividade cortical para cada faixa de frequência, utilizando a potência encontrada em cada eletrodo e a técnica de suavização (smoothing) ao redor dos canais de forma a preencher os espaços entre eles.

Os dados de ECG foram processados com programas em MatLab versão 7.8.0 (R2009a) desenvolvidos no Laboratório de Neurociência e Comportamento da UnB para separar digitalmente os fragmentos correspondentes ao período de aplicação dos testes.

Posteriormente, foram tratados com o módulo de análise de ECG (ECG Module) do programa Protolize! (Ocazionez, 2009) para detecção dos complexos QRS e marcação dos picos de ondas R. A marcação das ondas $R$ foi feita automaticamente pelo programa, porém conferida e ajustada manualmente, quando necessário. Com a informação sobre o número de 
intervalos RR disponível, foram calculados os índices de variação da frequência cardíaca (VFC).

A análise da VFC pode ser feita no domínio do tempo ou no domínio da frequência. Para o domínio do tempo, os intervalos RR podem ser considerados individualmente para o índice de desvio padrão da média dos intervalos RR (SDNN); ou podem ser considerados os intervalos adjacentes, para os índices de raiz quadrada da soma do quadrado das diferenças entre intervalos RR adjacentes (RMSSD) e para o percentual de intervalos RR adjacentes com diferença de duração superior a 50 milissegundos (pNN50). No domínio da frequência, foi calculada a razão entre baixas $(0,04-0,15 \mathrm{~Hz})$ e altas $(0,15-0,4 \mathrm{~Hz})$ frequências (razão LF/HF).

Os índices no domínio do tempo ajudam a avaliar a atividade autonômica parassimpática, assim, quanto menor a excitabilidade, maiores os seus índices. A razão LF/HF reflete o balanço autonômico cardíaco (Bansal et al., 2009), para a qual valores maiores refletem dominância autonômica simpática e valores menores refletem dominância parassimpática.

\subsection{ANÁLISE DE DADOS}

O número de sujeitos utilizado nas diferentes análises estatísticas (Tabela 1) variou em função da existência de problemas operacionais na gravação das respostas emitidas por alguns sujeitos durante o teste de Stroop e da eliminação de valores extremos (outliers). Apesar de ter havido perdas, os dados apresentaram distribuição normal. 
Tabela 1. Discriminação do número de sujeitos (total, mulheres e homens), da faixa etária e da idade (média e desvio padrão) para cada análise.

\begin{tabular}{|c|c|c|c|c|c|c|}
\hline & \multicolumn{6}{|c|}{ Sujeitos } \\
\hline & \multicolumn{3}{|c|}{$\mathbf{n}$} & \multicolumn{3}{|c|}{ Idade (n total) } \\
\hline & Total & Fem & Masc & Faixa etária & Média & DP \\
\hline \multicolumn{7}{|c|}{ Comportamento } \\
\hline Stroop & 22 & 10 & 12 & $18-27$ & 21,6 & 2,9 \\
\hline TR & 48 & 24 & 24 & $17-28$ & 21,6 & 2,9 \\
\hline \multicolumn{7}{|l|}{ EEG } \\
\hline Stroop & 49 & 24 & 25 & $17-28$ & 21,6 & 2,8 \\
\hline TR & 48 & 24 & 24 & $17-28$ & 21,6 & 2,9 \\
\hline SI vs. TR & 48 & 24 & 24 & $17-28$ & 21,6 & 2,9 \\
\hline \multicolumn{7}{|l|}{ ECG } \\
\hline Stroop & 49 & 24 & 25 & $17-28$ & 21,6 & 2,8 \\
\hline TR & 49 & 24 & 25 & $17-28$ & 21,6 & 2,8 \\
\hline SI vs. TR & 49 & 24 & 25 & $17-28$ & 21,6 & 2,8 \\
\hline
\end{tabular}

n: número de sujeitos; Fem: Feminino; Masc: Masculino; DP: desvio-padrão; Stroop: teste de Stroop; TR: teste de Tempo de Reação; SI: Etapa Incongruente do teste de Stroop; EEG: Eletroencefalograma; ECG: Eletrocardiograma.

O desempenho no teste de Stroop foi medido pela taxa de acertos e pela taxa de erros de omissão. Ambos os parâmetros foram comparados para 0 fator etapa (3 níveis) por meio da análise de variâncias (ANOVA) de medidas repetidas; para o fator gênero (2) por meio do teste $t$ para medidas independentes e para a interação entre os fatores gênero (2) e etapa (3) por meio da ANOVA bifatorial.

Para o teste de Tempo de Reação, o desempenho foi medido pela taxa de acertos e pelo tempo compreendido entre a apresentação do estímulo e a manifestação da resposta pelo sujeito, o tempo de reação (em milissegundos). As médias desses dois parâmetros foram comparadas, separadamente, para o fator gênero (2) por meio do teste t para medidas independentes e para o fator lado (2) por meio da ANOVA de medidas repetidas. 
Para os dados de frequência cardíaca no teste de Stroop, os índices foram comparados de acordo com o fator etapa (3), por meio da ANOVA de medidas repetidas e com o fator gênero (2) por meio do teste t para medidas independentes. Estes dados no teste de Tempo de Reação foram comparados apenas para o fator gênero (2) utilizando o mesmo teste (t independente).

Os dados de ECG também foram analisados levando-se em consideração o teste realizado, teste de Stroop (etapa SI) ou teste de TR, sendo as médias dos índices comparadas por meio da ANOVA de medidas repetidas.

As análises estatísticas supracitadas foram realizadas com o programa PSAW Statistics (Predictive Analysis Software, antigo SPSS), versão 18.0 para Windows. O nível de significância estatística foi ajustado pelo método de Bonferroni e foi estabelecido em $5 \%(p<0,05)$ para todos os testes. Os resultados são apresentados como média \pm DP.

A análise estatística dos dados eletroencefalográficos, por sua vez, foi realizada utilizando as ferramentas do programa EEGLab. O nível de significância estatística foi mantido em $5 \%(p<0,05)$, porém foi corrigido pelo método de controle das taxas de falsos positivos (FDR). Os resultados são apresentados em mapas topográficos para cada banda de frequência (Teta, Alfa, Beta e Gama). Nos mapas, a atividade cortical registrada em cada eletrodo foi comparada entre duas ou mais condições.

Os mapas topográficos de cada etapa do teste de Stroop foram comparados para os fatores etapa (3), utilizando o teste t pareado e gênero (2), por meio do teste t para medidas independentes. $O$ fator gênero também foi analisado para a ativação cortical no teste de tempo de Reação, utilizando o teste t para medidas independentes. 
O efeito do teste na ativação cortical foi avaliado por meio do teste $t$ pareado levando-se em consideração os mapas topográficos do teste de Stroop (etapa SI) e do teste de Tempo de Reação. 
5. RESULTADOS 
Nesta seção serão descritos os resultados comportamentais, eletroencefalográficos e eletrocardiográficos apresentados pelos jovens universitários submetidos ao protocolo utilizado, separadamente para cada um dos testes e por último para a comparação entre eles.

\subsection{TESTE DE STROOP}

\subsubsection{Comportamento}

Neste teste, foi obtida uma diferença significativa entre a taxa de acertos para todas as etapas (Figura 8), bem como para a taxa de erros de omissão (Figura 9), com exceção, da última, para a comparação entre a etapa Congruente e a de Semelhança fonética, em que foi observado apenas um efeito marginal $(p=0,051)$.

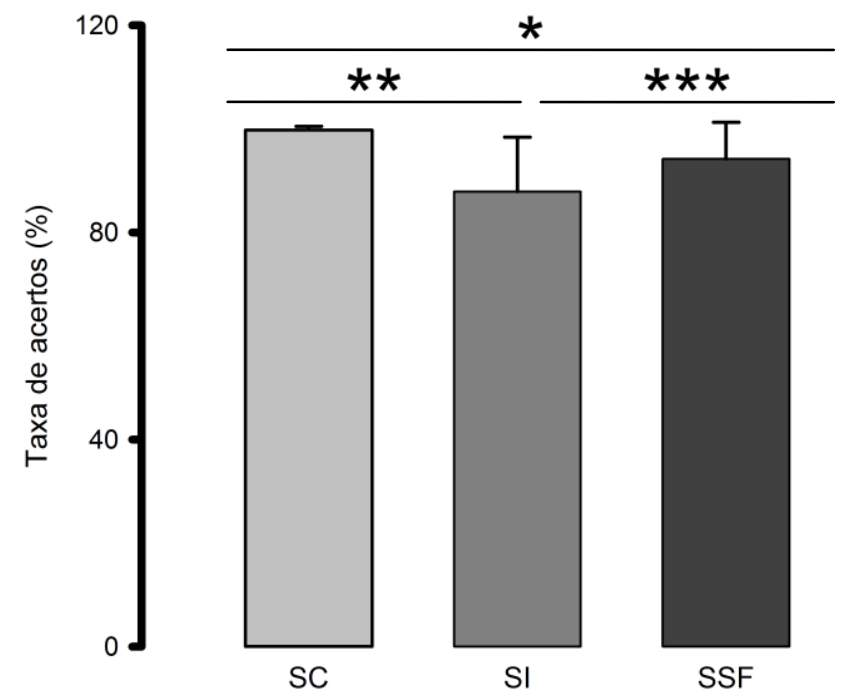

Figura 8. Média da taxa de acertos ( $\pm \mathrm{DP}$; em porcentagem) de jovens universitários $(n=22)$ para cada etapa do teste de Stroop. * SC $>S S F, p<0,01 ; * * S C>S I$ $\mathrm{p}<0,001 ; * * *$ SI $<S S F, \mathrm{p}<0,05 ;$ ANOVA de medidas repetidas. SC: Etapa Congruente; SI: Etapa Incongruente; SSF: Etapa de Semelhança fonética. 


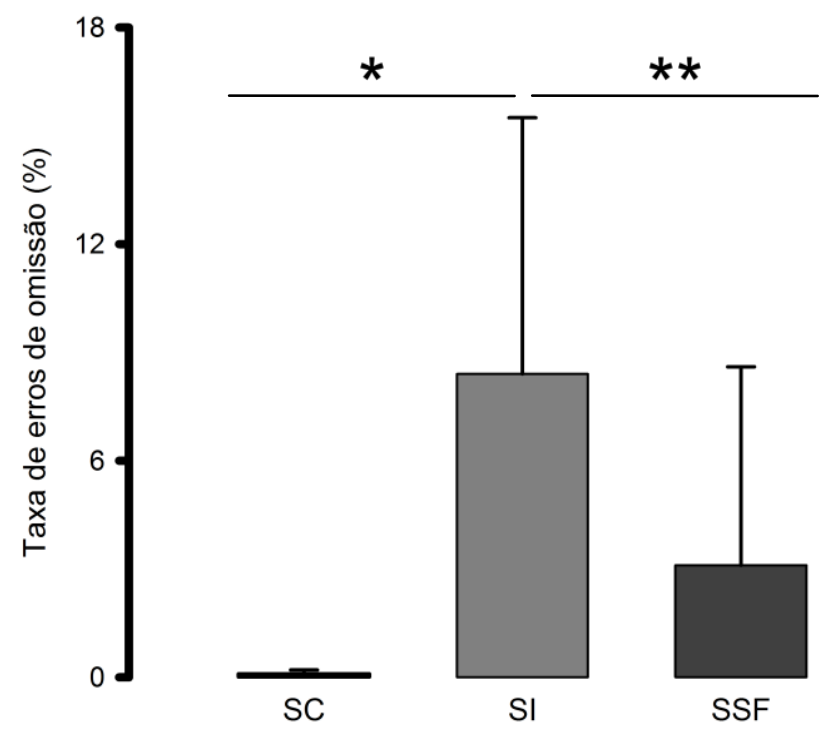

Figura 9. Média da taxa de erros de omissão ( \pm DP; em porcentagem) de jovens universitários $(n=22)$ para cada etapa do teste de Stroop. $* S C<S I, p<0,001$; ** SI $>S S F, p<0,01$; ANOVA de medidas repetidas. SC: Etapa Congruente; SI: Etapa Incongruente; SSF: Etapa de Semelhança fonética.

Não houve diferença na taxa de acertos com relação ao gênero, isto é, homens e mulheres apresentaram taxas de acertos semelhantes no teste de Stroop (Figura 10A). O mesmo padrão se repetiu para a taxa de erros de omissão (Figura 10B).
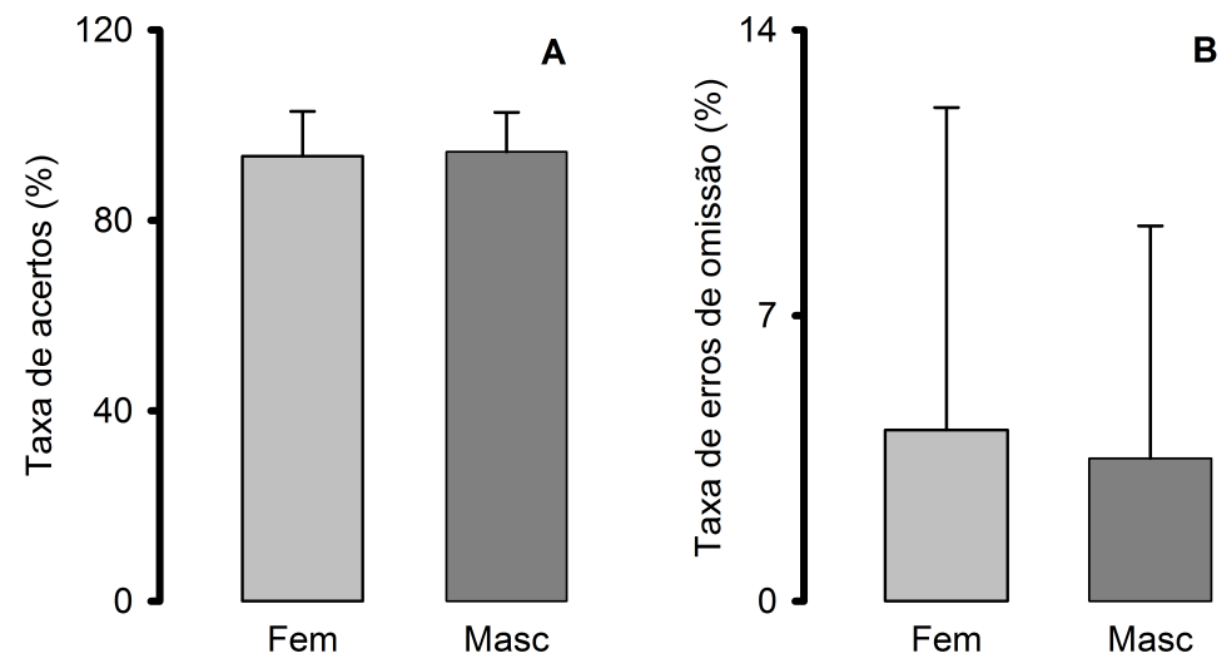

Figura 10. Média da taxa de acertos $(A)$ e da taxa de erros de omissão (B) ( \pm DP; em porcentagem), para cada gênero no teste de Stroop, realizado por jovens universitários ( $n=22 ; \circ: n=10 ; \delta: n=12)$. Teste t para medidas independentes. Fem: Gênero Feminino; Masc: Gênero Masculino. 
Para a taxa de acertos, não houve interação significativa entre gênero e etapa, no entanto, houve diminuição significativa no desempenho das mulheres da primeira para a segunda etapa, o que se repetiu para os homens (Figura 11).

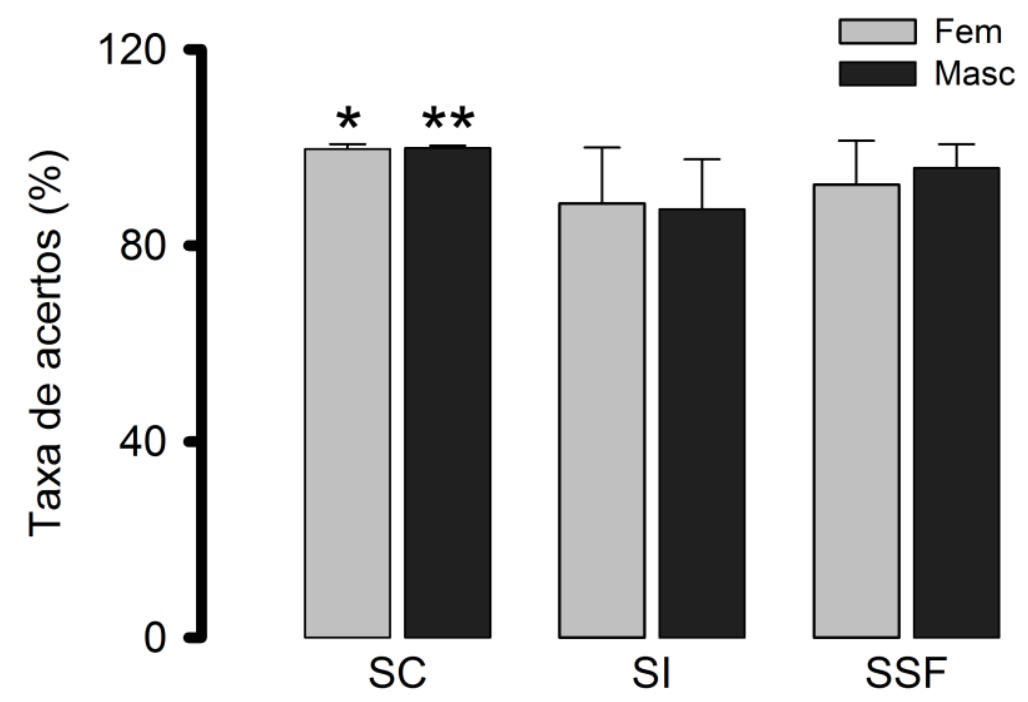

Figura 11. Média da taxa de acertos ( \pm DP; em porcentagem) para cada gênero nas etapas do teste de Stroop, realizadas por jovens universitários $(n=22 ; \circ: n=10$ $\hat{0}: \mathrm{n}=12)$. * Entre as mulheres, $\mathrm{SC}>\mathrm{SI}, \mathrm{p}<0,001 ; * *$ Entre os homens, $\mathrm{SC}>\mathrm{SI}$, $\mathrm{p}<0,001$; ANOVA bifatorial (como as variâncias não são iguais, valor de p=0,001). SC: Etapa Congruente; SI: Etapa Incongruente; SSF: Etapa de Semelhança fonética; Fem: Gênero Feminino; Masc: Gênero Masculino.

Com relação à taxa de erros de omissão, também não houve interação significativa entre gênero e etapa. Entretanto, houve aumento nessa taxa da primeira para a segunda etapa entre os homens, o que não se repetiu para as mulheres (Figura 12). 


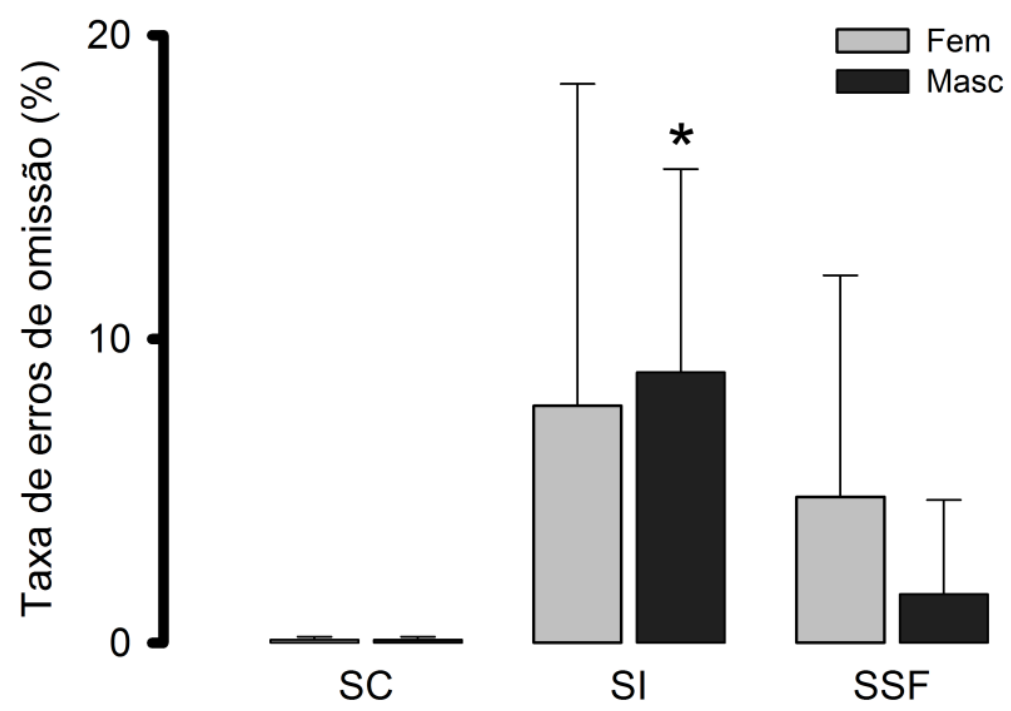

Figura 12. Média da taxa de erros de omissão ( $\pm D P$; em porcentagem) para cada gênero nas etapas do teste de Stroop, realizadas por jovens universitários $(n=22$; : $\mathrm{n}=10 ; \mathrm{O}^{*} \mathrm{n=12}$ ). * Entre os homens, $\mathrm{SC}<\mathrm{SI}, \mathrm{p}<0,001$; ANOVA bifatorial (como as variâncias não são iguais, valor de $p=0,001)$. SC: Etapa Congruente; SI: Etapa Incongruente; SSF: Etapa de Semelhança fonética; Fem: Gênero Feminino; Masc: Gênero Masculino.

\subsubsection{Eletroencefalograma}

Os mapas topográficos gerados a partir dos dados de EEG foram comparados entre as etapas do teste de Stroop, nas faixas de frequência Teta $(4-8 \mathrm{~Hz})$, Alfa $(8-13 \mathrm{~Hz})$, Beta $(13-30 \mathrm{~Hz})$ e Gama $(30-70 \mathrm{~Hz})$. Os resultados da ativação cortical também foram esquematizados em mapas topográficos para comparação entre os gêneros, em cada etapa do teste de Stroop. A barra colorida indica os valores da potência $(e m \mu \mathrm{V})$ medida em cada eletrodo, em um gradiente de maior (apresentado na cor vinho) a menor (apresentado em azul escuro) potência. A potência é uma medida que estima a magnitude da amplitude da oscilação em determinada janela de tempo (Klimesch, 2012).

Para a banda Teta, em todas as etapas, a atividade foi mais evidente

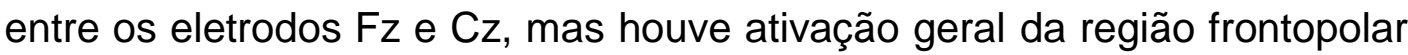


até a parietal na linha média, atenuando-se ao redor. Para SI e SSF, também houve expressão elevada no eletrodo F3. Em todas, foi possível notar uma tendência de lateralização esquerda, que se estendeu até o eletrodo 01 , correspondente à região occipital esquerda. A única comparação que não apresentou nenhuma diferença significativa foi aquela entre SI e SSF (Figura 13).

Teta

(4-8 Hz)

SC vs. SI
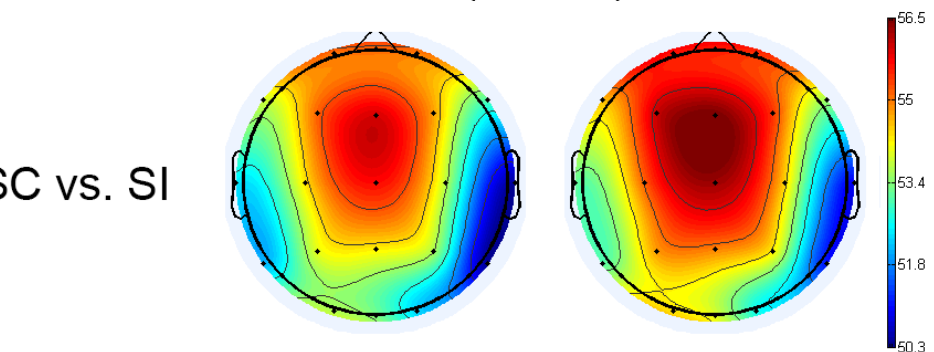

$p<0,05$

SC vs. SSF
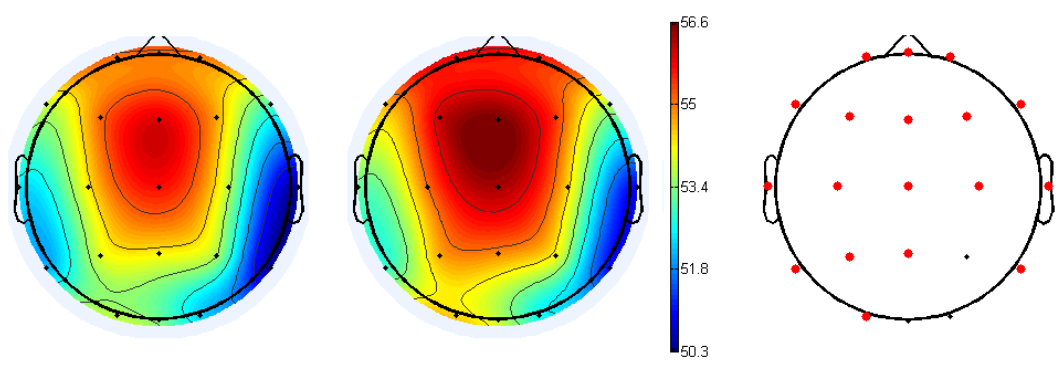

SI vs. SSF
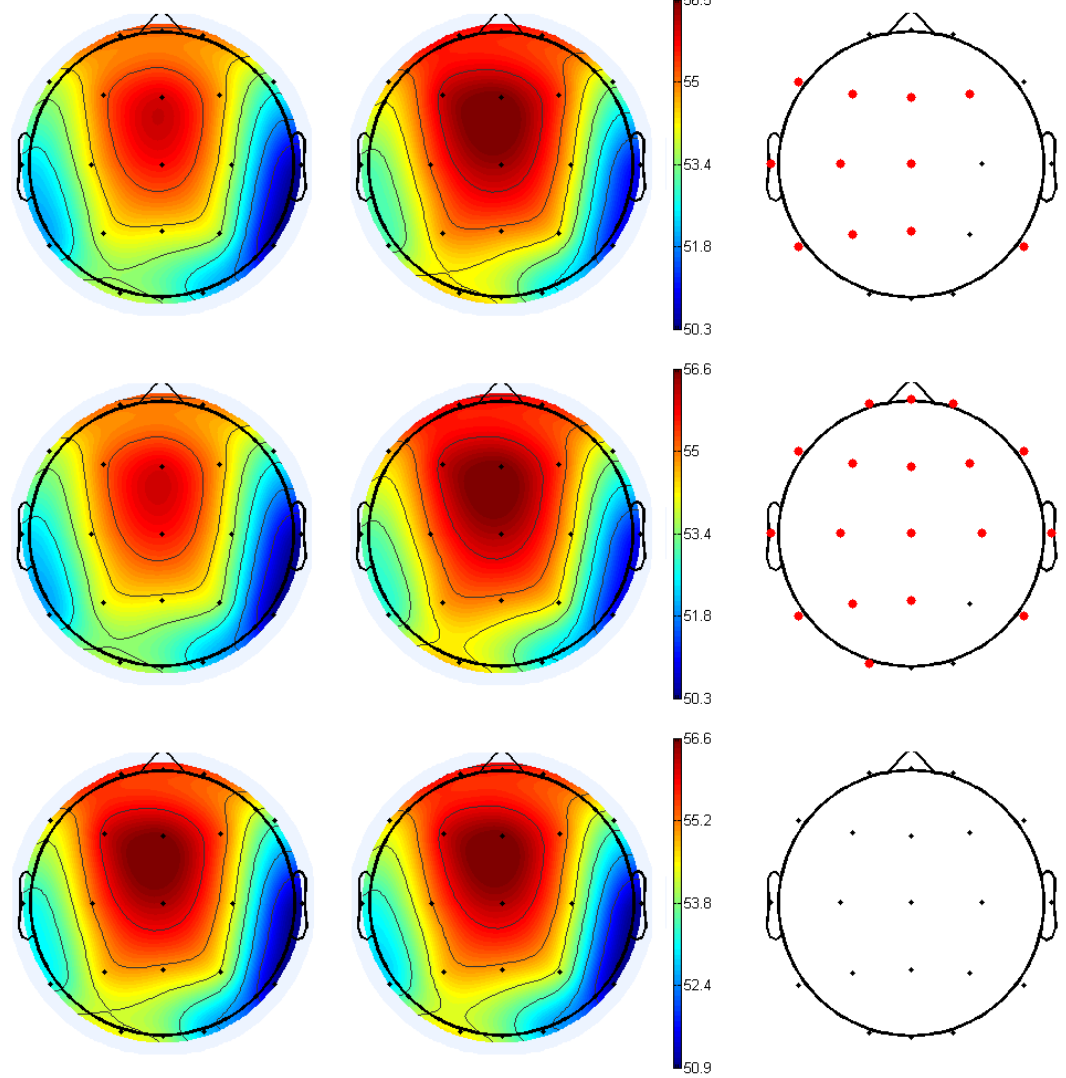

Figura 13. Mapas topográficos de comparação da atividade Teta entre SC, SI e SSF no teste de Stroop, realizado por jovens universitários $(n=49)$. Os pontos vermelhos na representação à direita indicam os eletrodos para os quais foram encontradas diferenças significativas de acordo com o teste t pareado com correção pelo método FDR. SC: Etapa Congruente; SI: Etapa Incongruente; SSF: Etapa de Semelhança Fonética.

Os mapas topográficos de SI e SSF na banda Alfa apresentaram atividade elevada do polo frontal esquerdo até a região occipital ipsilateral, 
passando pela linha média. Houve expressão máxima em F3, Fz, Cz. Apesar de SC possuir semelhança topográfica, não houve ativação acentuada na região frontopolar e no eletrodo F3, como observado nas outras etapas. Para todos os eletrodos foram encontradas diferenças significativas, com exceção de C3, P3, P4, Oz e O2 na comparação entre SC e SSF (Figura 14).

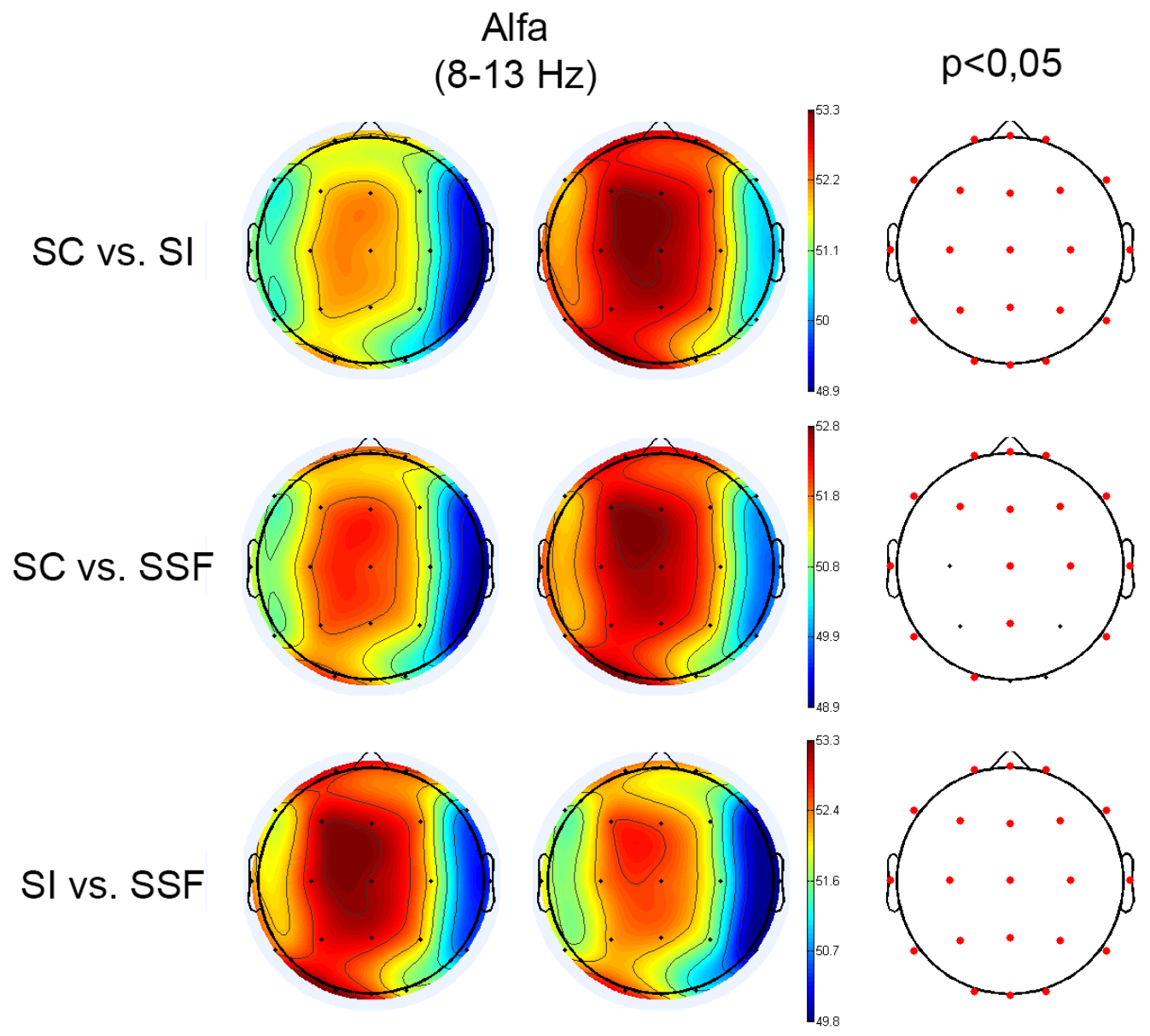

Figura 14. Mapas topográficos de comparação da atividade Alfa entre SC, SI e SSF no teste de Stroop, realizado por jovens universitários $(n=49)$. Os pontos vermelhos na representação à direita indicam os eletrodos para os quais foram encontradas diferenças significativas de acordo com o teste t pareado com correção pelo método FDR. SC: Etapa Congruente; SI: Etapa Incongruente; SSF: Etapa de Semelhança Fonética.

Em relação às ondas do tipo Beta, considerando-se todas as etapas, houve atividade elevada na região temporal anterior em ambos os 
hemisférios com atenuação sutil nos eletrodos Fp1, Fp2, F3, F4 e C3 e expressiva nas demais regiões. No hemisfério esquerdo, a distribuição estendeu-se até os eletrodos $\mathrm{Fp} 1, \mathrm{~T} 5$ e 01 . No hemisfério direito, houve baixa atividade em F8 e na região posterior próxima aos eletrodos T5, O2 e Oz. Para praticamente todos os eletrodos foram encontradas diferenças significativas, com exceção de $\mathrm{O} 1$ e T4 na comparação entre SI e SSF (Figura 15).

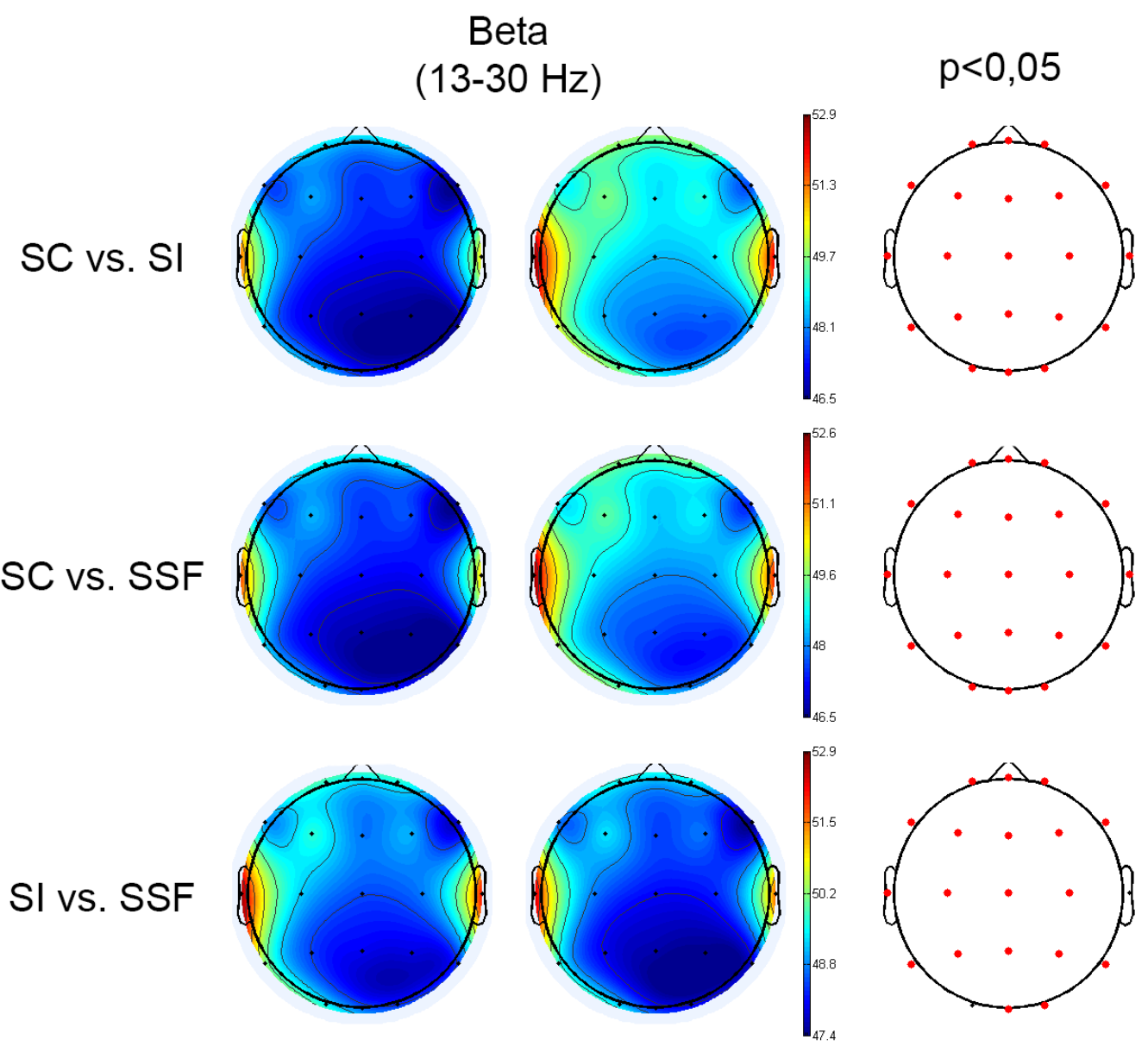

Figura 15. Mapas topográficos de comparação da atividade Beta entre SC, SI e SSF no teste de Stroop, realizado por jovens universitários $(n=49)$. Os pontos vermelhos na representação à direita indicam os eletrodos para os quais foram encontradas diferenças significativas de acordo com o teste $t$ pareado com correção pelo método FDR. SC: Etapa Congruente; SI: Etapa Incongruente; SSF: Etapa de Semelhança Fonética. 
Em todas as etapas, houve maior expressão da banda Gama nas regiões temporais anteriores em ambos os hemisférios e na região frontopolar com tendência de lateralização esquerda, que se estendeu aos eletrodos F3 e O1. A atividade atenuou-se em diagonal de maneira drástica para SC e gradualmente para SI e SSF, com expressão mínima na região temporal posterior direita. Todos os eletrodos apresentaram diferenças significativas, com exceção da comparação entre SI e SSF. Para esta, houve diferenças apenas para os eletrodos F3, F4, C3, C4, T3, T5, T6, P3, P4, Oz e O2 (Figura 16).

Gama

$(30-70 \mathrm{~Hz})$

SC vS. SI
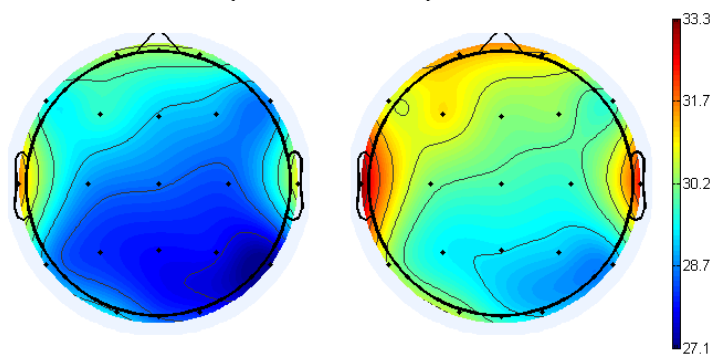

$p<0,05$

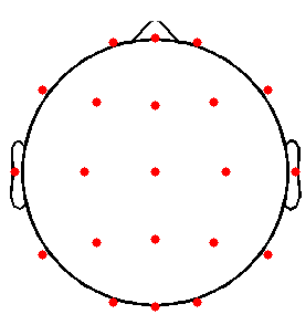

SC vs. SSF
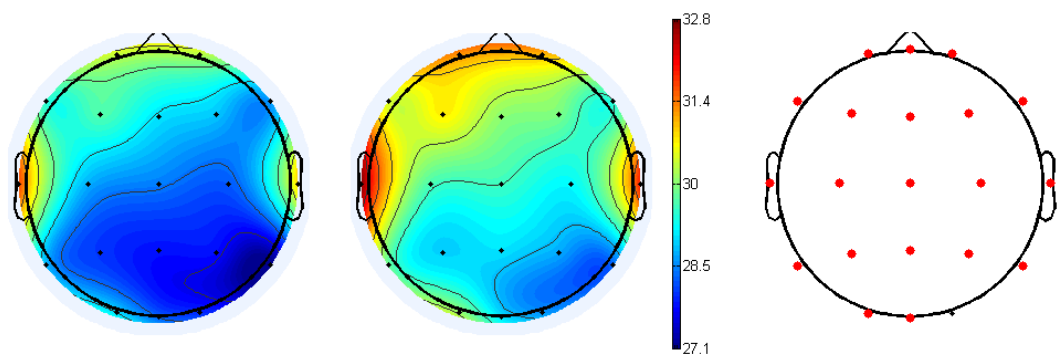

SI vS. SSF
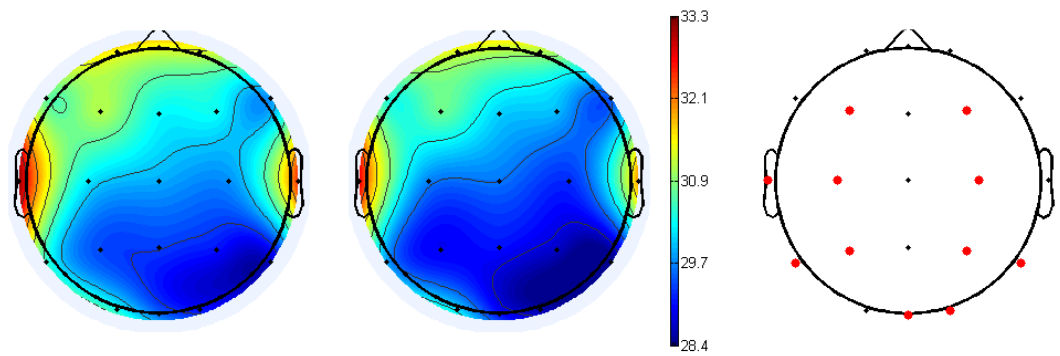

Figura 16. Mapas topográficos de comparação da atividade Gama entre SC, SI e SSF no teste de Stroop, realizado por jovens universitários $(n=49)$. Os pontos vermelhos na representação à direita indicam os eletrodos para os quais foram encontradas diferenças significativas de acordo com o teste t pareado com 
correção pelo método FDR. SC: Etapa Congruente; SI: Etapa Incongruente; SSF: Etapa de Semelhança Fonética.

Em todas as frequências, foi possível observar uma tendência de aumento da potência nas etapas SI e SSF, que, contudo, aparentemente não diferiu entre as duas etapas.

A atividade Teta apresentou distribuição ampla para todas as etapas em ambos os gêneros, sendo mais acentuada da região frontal até a parietal. Houve expressão máxima, dentro da faixa avaliada, nos eletrodos $\mathrm{Fz}$ e $\mathrm{Cz}$ e em F3 para as mulheres nas etapas SI e SSF. Ambas as regiões temporais apresentaram-se atenuadas, bem como a região occipital direita (O2). Considerando todas as comparações, apenas para o eletrodo O1, na comparação entre os gêneros na etapa SC não foi encontrada diferença significativa, sendo esta uma região de elevada atividade nas demais condições, especialmente entre as mulheres (Figura 17).

Entre as mulheres, houve expressão acentuada em Alfa da região frontal à parietal e da occipital direita, máxima próximo ao eletrodo F3 e em O1 para as etapas SI e SSF e adicionalmente próximo aos eletrodos Fz, C3, Cz, P3 e Pz em SC. A atividade atenuou-se na região direita próxima aos eletrodos F8, T4 e T6 e nas proximidades do eletrodo F7.

Para os homens, a atividade foi mais expressiva na região frontopolar esquerda (eletrodo Fp1) e na região da linha média e dos eletrodos adjacentes esquerdos até a região parietal. A importância da região occipital esquerda foi menor para eles comparado às mulheres. A atividade atenuou-se na região direita próxima aos eletrodos F8, T4, T6 e O2 e nas proximidades dos eletrodos T3 e T5 (Figura 18). 


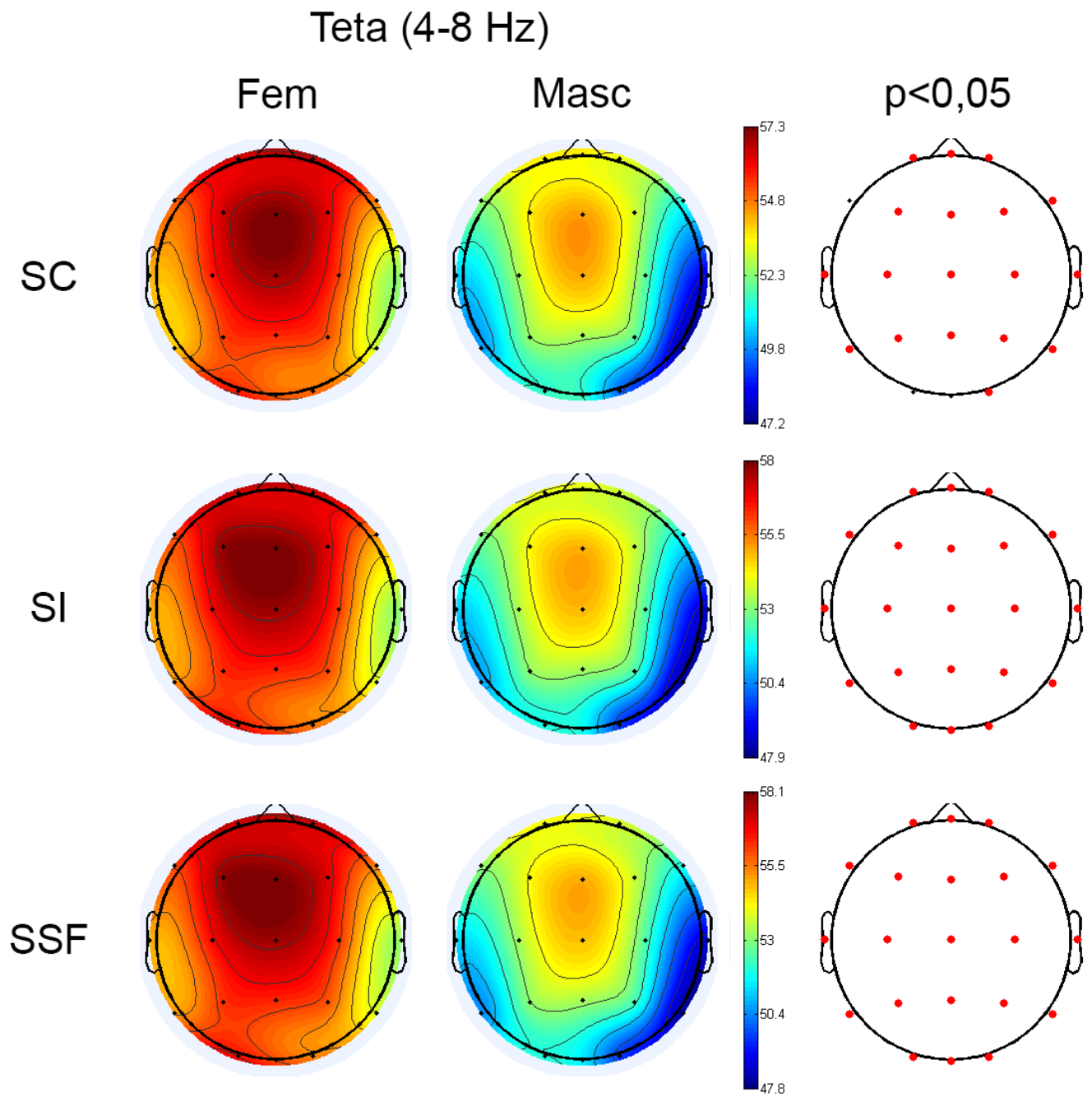

Figura 17. Mapas topográficos de comparação da atividade Teta entre os gêneros para cada etapa do teste de Stroop, realizado por jovens universitários $(n=49$; q: $\mathrm{n}=24 ; \hat{O}: \mathrm{n}=25$ ). Os pontos vermelhos na representação à direita indicam os eletrodos para os quais foram encontradas diferenças significativas de acordo com o teste t para medidas independentes com correção pelo método FDR. Fem: Gênero Feminino; Masc: Gênero Masculino; SC: Etapa Congruente; SI: Etapa Incongruente; SSF: Etapa de Semelhança Fonética.

Portanto, além de uma diferença nítida na potência da ativação cortical entre os gêneros, também foi possível observar uma tendência de ativação mais acentuada para as mulheres na região occipital esquerda e para os homens, na região frontopolar. Ambos apresentaram ativação da região frontal à parietal na linha média e nos eletrodos adjacentes do lado esquerdo (Figura 18). 


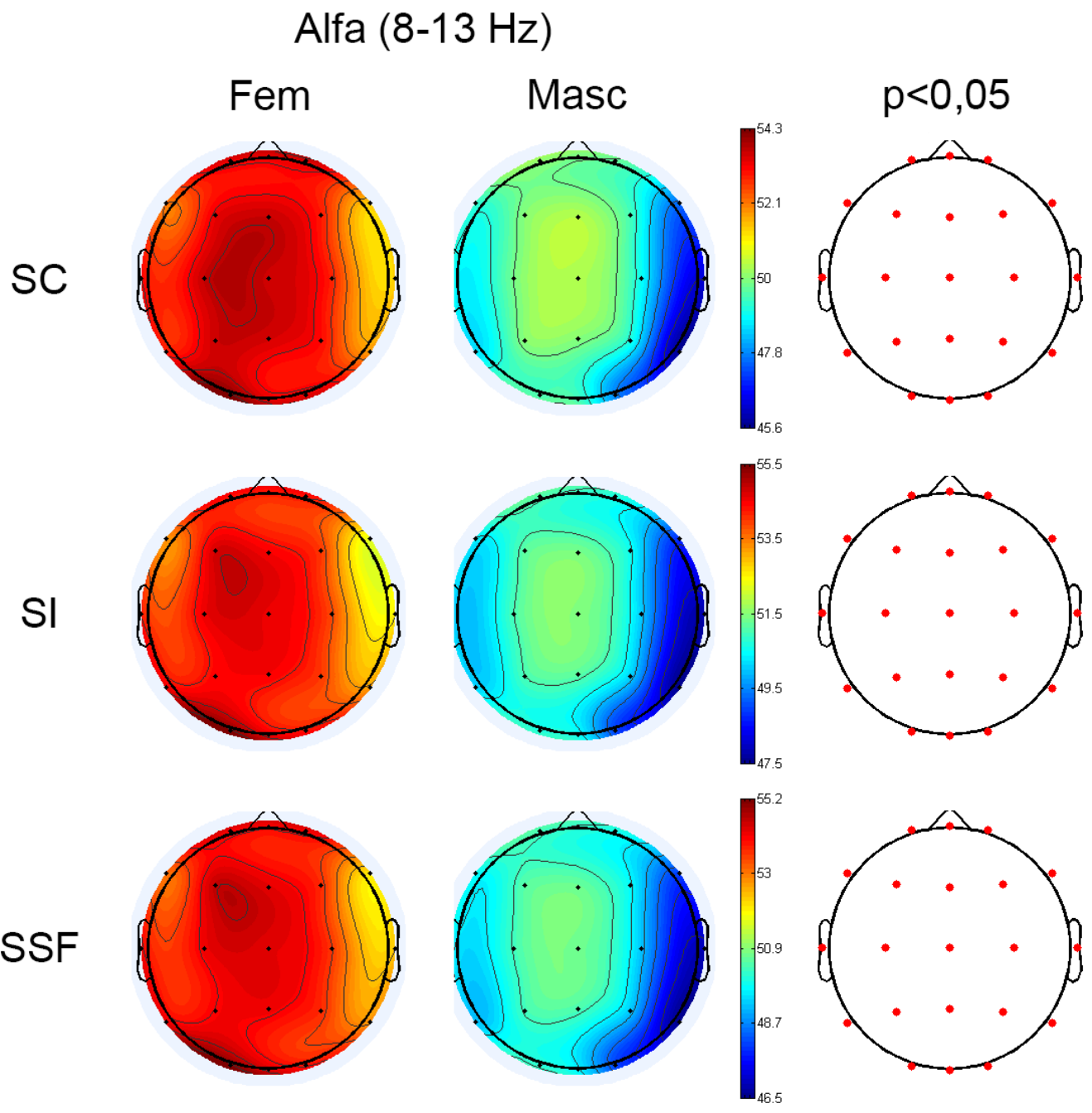

Figura 18. Mapas topográficos de comparação da atividade Alfa entre os gêneros para cada etapa do teste de Stroop, realizado por jovens universitários $(n=49$; $ᄋ$ : $n=24 ;$ in $n=25$ ). Os pontos vermelhos na representação à direita indicam os eletrodos para os quais foram encontradas diferenças significativas de acordo com o teste t para medidas independentes com correção pelo método FDR. Fem: Gênero Feminino; Masc: Gênero Masculino; SC: Etapa Congruente; SI: Etapa Incongruente; SSF: Etapa de Semelhança Fonética.

Considerando a banda Beta, houve maior ativação entre as mulheres nas regiões temporais, sendo mais acentuada no hemisfério esquerdo. Os mapas apresentaram, ainda, ativação em menor intensidade nas regiões frontopolares, frontais e centrais, atenuando-se na linha média, nas proximidades do eletrodo F8 e em direção aos eletrodos occipitais. Os homens apresentaram topografia semelhante, porém com intensidade 
reduzida em geral e na região occipital esquerda. Para todos os eletrodos foram obtidas diferenças significativas, em todas as condições (Figura 19).

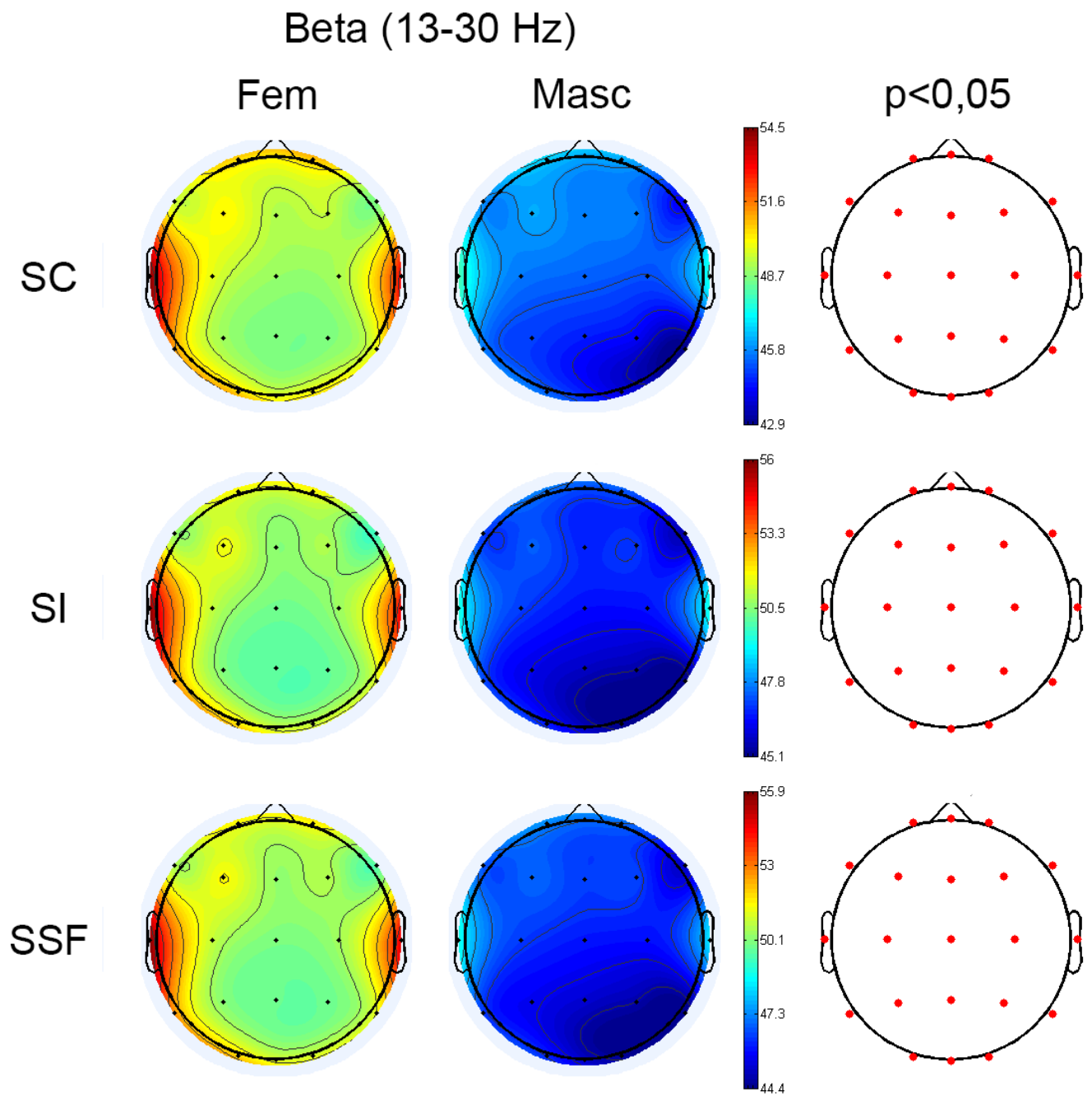

Figura 19. Mapas topográficos de comparação da atividade Beta entre os gêneros para cada etapa do teste de Stroop, realizado por jovens universitários $(n=49$; 9 : $n=24 ; \quad \hat{:}: n=25)$. Os pontos vermelhos na representação à direita indicam os eletrodos para os quais foram encontradas diferenças significativas de acordo com o teste t para medidas independentes com correção pelo método FDR. Fem: Gênero Feminino; Masc: Gênero Masculino; SC: Etapa Congruente; SI: Etapa Incongruente; SSF: Etapa de Semelhança Fonética.

Houve maior atividade na banda Gama para as mulheres nas regiões temporais em ambos os hemisférios, que se estendeu com menor intensidade para a região frontopolar e para a região occipital esquerda, passando pelo eletrodo F3. As demais regiões apresentaram-se 
atenuadas, incluindo as proximidades do eletrodo F7. Os homens apresentaram topografia semelhante, entretanto, com menor intensidade em geral e na região occipital esquerda. Foram encontradas diferenças significativas para todos os eletrodos (Figura 20).

\section{Gama $(30-70 \mathrm{~Hz})$}
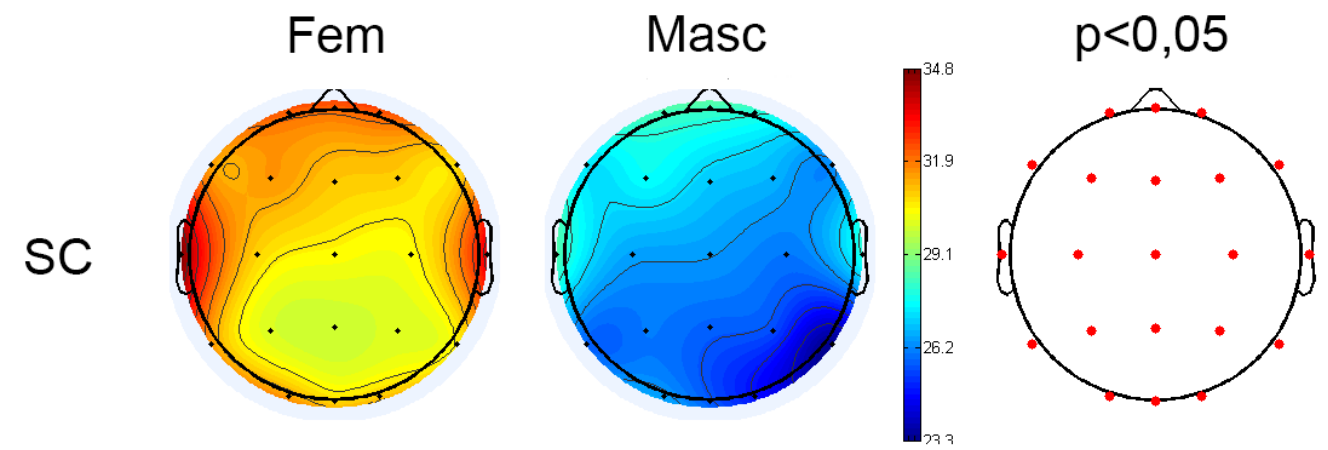

SI
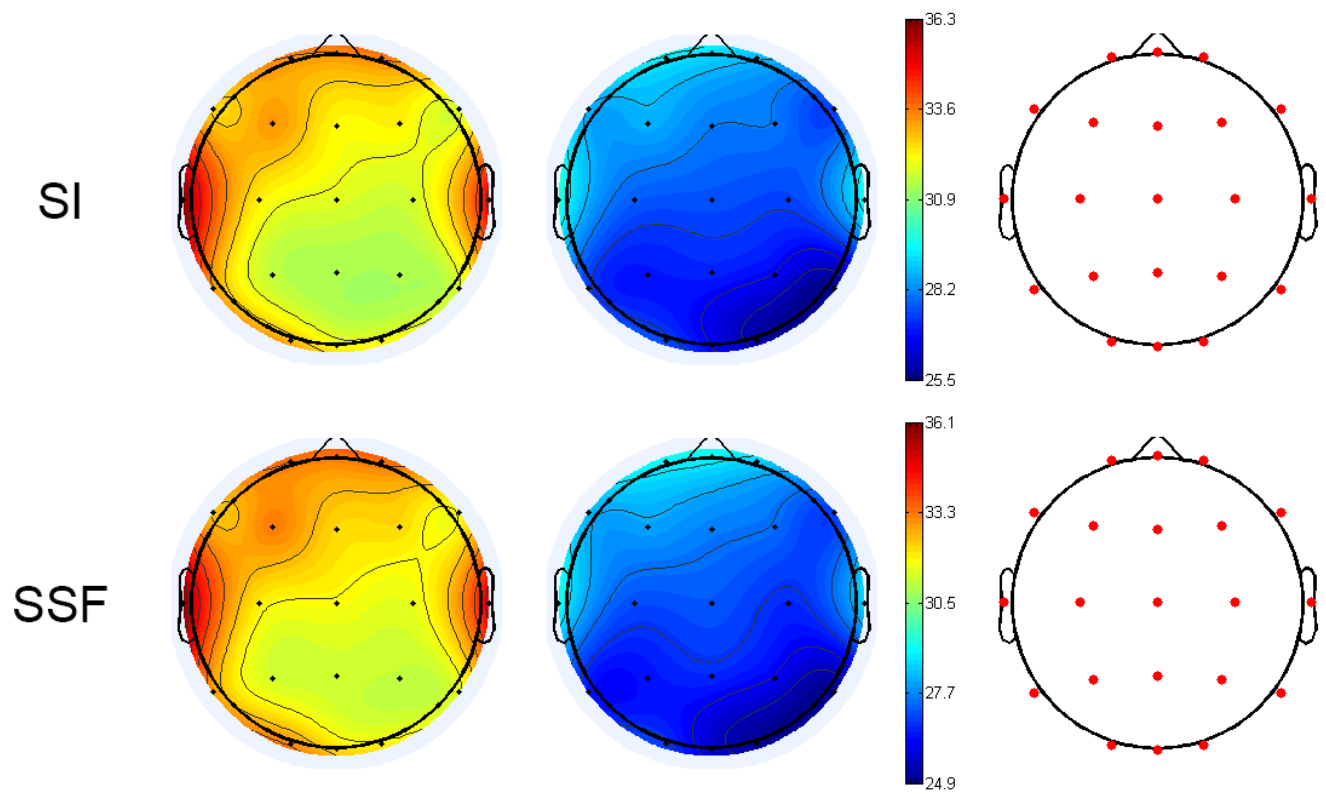

Figura 20. Mapas topográficos de comparação da atividade Gama entre os gêneros para cada etapa do teste de Stroop, realizado por jovens universitários $(n=49$; ;: $\mathrm{n}=24 ; \hat{O}: \mathrm{n}=25$ ). Os pontos vermelhos na representação à direita indicam os eletrodos para os quais foram encontradas diferenças significativas de acordo com o teste t para medidas independentes com correção pelo método FDR. Fem: Gênero Feminino; Masc: Gênero Masculino; SC: Etapa Congruente; SI: Etapa Incongruente; SSF: Etapa de Semelhança Fonética. 
De forma similar à comparação entre as etapas, a potência para os homens foi menor do que a das mulheres para todas as frequências de onda.

\subsubsection{Eletrocardiograma}

A variação da frequência cardíaca (VFC) foi analisada no domínio do tempo para os índices de desvio padrão da média dos intervalos RR (SDNN), raiz quadrada da soma do quadrado das diferenças entre intervalos RR adjacentes (RMSSD) e percentual de intervalos $R R$ adjacentes com diferença de duração superior a 50 milissegundos (pNN50) e no domínio da frequência para a razão entre baixas e altas frequências (razão LF/HF).

Foi observado um efeito principal na comparação das etapas Congruente e Incongruente com a etapa de Semelhança Fonética em termos do índice pNN50 (Figura 21A). O mesmo padrão se repetiu para o índice RMSSD (Figura 21C). O índice SDNN também foi influenciado pela etapa, na comparação da etapa Congruente com as etapas Incongruente e de Semelhança Fonética (Figura 21B). Contudo, não foi observado efeito da etapa do teste na razão LF/HF. 

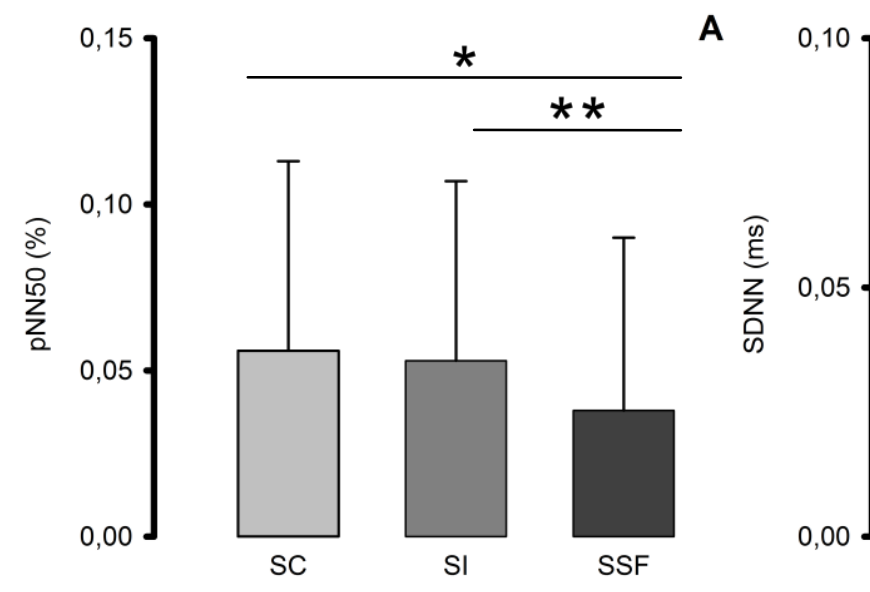

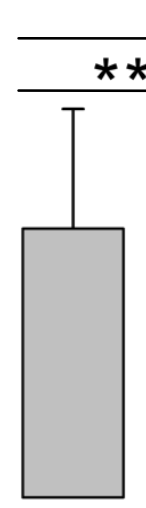

$\mathrm{SC}$
$*$

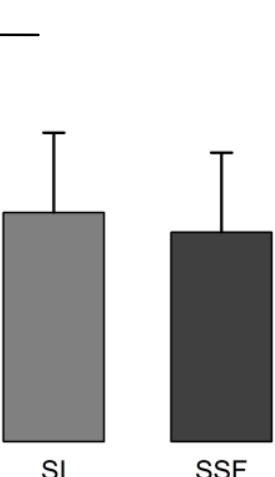

SI
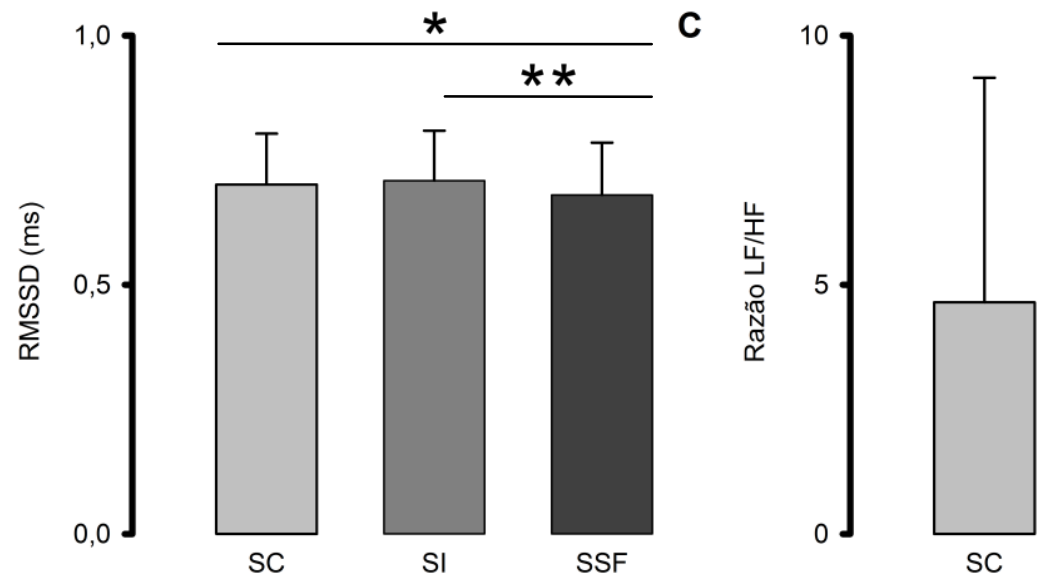

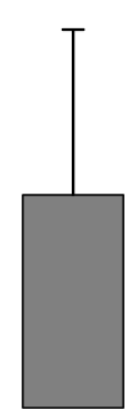

SI

D

Figura 21. Médias ( $\pm \mathrm{DP}$ ) dos índices de variação da frequência cardíaca de jovens universitários $(n=49)$ em função das etapas do teste de Stroop, no domínio do tempo - pNN50 (A; em porcentagem), SDNN (B; ms), RMSSD (C; ms) - e da frequência - razão LF/HF (D). A: * SC >SSF, $p<0,01 ; * *$ SI $>S S F, p<0,05$. B: * SC $>S S F, p<0,01 ; * *$ SC $>S I, p<0,05$. C: * SC>SSF, $p<0,01 ; * *$ SI $>S S F$, $p<0,001$. ANOVA de medidas repetidas. SC: Etapa Congruente; SI: Etapa Incongruente; SSF: Etapa de Semelhança fonética.

Houve efeito principal de gênero para os índices de VFC no domínio do tempo, isto é, as respostas autonômicas foram maiores entre os homens do que entre as mulheres (Figura 22A, B e C). Não houve, entretanto, diferenças entre os gêneros para a razão LF/HF (Figura 22D). 

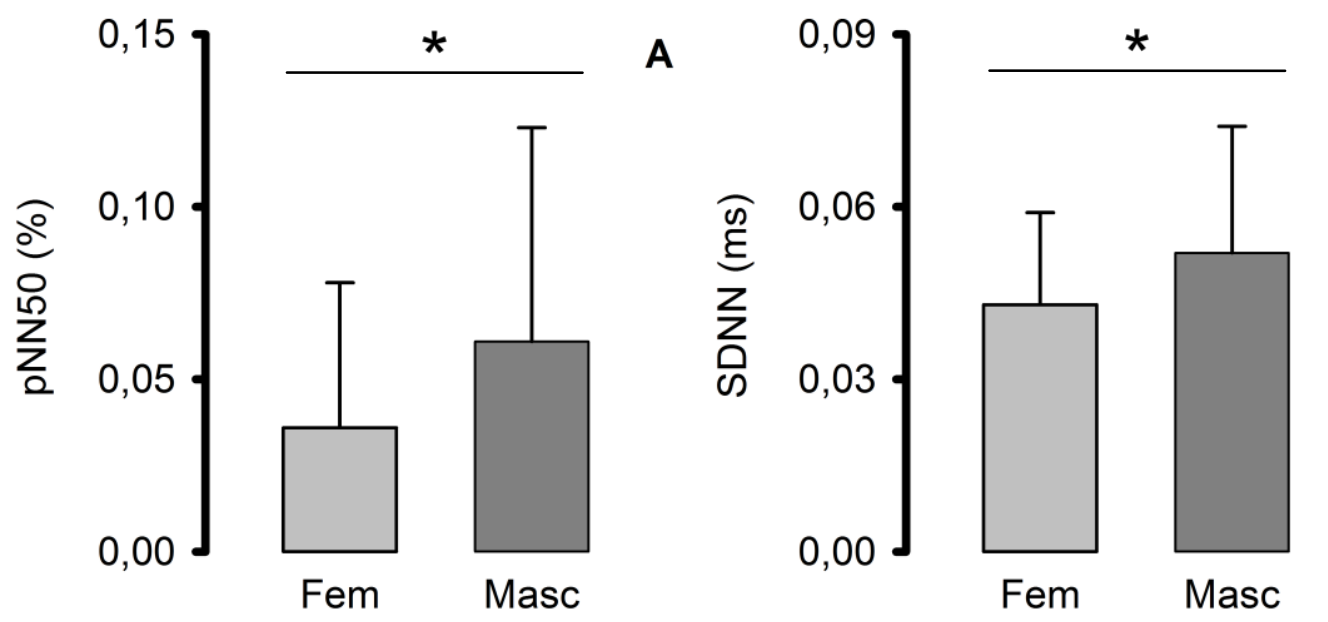

B
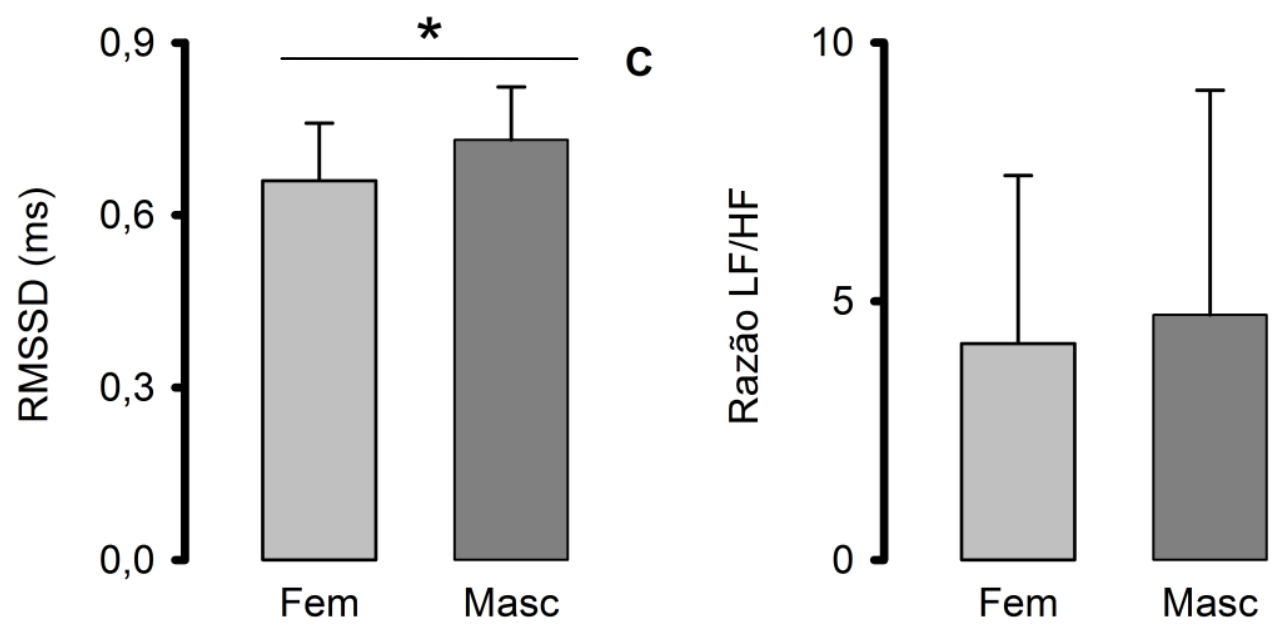

Figura 22. Médias ( \pm DP) dos índices de variação da frequência cardíaca de jovens universitários $(n=49 ;$; $: n=24 ; \hat{\delta}: n=25)$ em função do gênero no teste de Stroop, no domínio do tempo - pNN50 (A; em porcentagem), SDNN (B; ms), RMSSD (C; ms) - e da frequência - Razão LF/HF (D). A: * Fem<Masc, $p<0,01$. B: * Fem $<$ Masc, $p<0,01$. C: * Fem $<$ Masc, $p<0,001$. Teste t para medidas independentes. Fem: Gênero Feminino; Masc: Gênero Masculino.

\subsection{TESTE DE TEMPO DE REAÇÃO}

\subsubsection{Comportamento}

Para o teste de Tempo de Reação, a taxa de acertos foi calculada pela razão entre o número de respostas corretas e o número total de tentativas do teste, multiplicada por 100. Não houve diferença entre as 
médias para o gênero ou para o lado da tela em que o estímulo foi apresentado (Tabela 2).

Tabela 2. Médias das taxas de acertos ( \pm DP; em porcentagem) de jovens

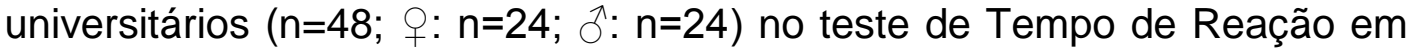
função do gênero e do lado em que o estímulo foi apresentado.

\begin{tabular}{cccc}
\hline \multicolumn{4}{c}{ Taxa de acertos (\%) } \\
Dir & $\begin{array}{c}\text { Esq } \\
\text { (Média } \pm \text { DP) }\end{array}$ & $\begin{array}{c}\text { Total } \\
\text { (Média } \pm \text { DP) }\end{array}$ \\
\hline Feminino & $99,5 \pm 1,1$ & $99,4 \pm 1,4$ & $99,5 \pm 1,0$ \\
Masculino & $99,3 \pm 1,7$ & $99,3 \pm 1,8$ & $99,3 \pm 1,5$ \\
Total & $99,4 \pm 1,4$ & $99,4 \pm 1,6$ & $99,4 \pm 1,2$ \\
\hline
\end{tabular}

Dir: Taxa de acerto para estímulos apresentados do lado direito da tela; Esq: Taxa de acerto para estímulos apresentados do lado esquerdo da tela.

Com relação às respostas incorretas, não houve casos de falsos positivos ou de ausência de resposta. Portanto, as respostas incorretas se resumiram aos casos de antecipação de respostas, quando o(s) participante(s) pressionou(aram) a tecla após a apresentação da dica e anteriormente ao aparecimento do estímulo. Entretanto, as médias da taxa de acertos foram altas em todas as condições (Tabela 2). Assim, o número de respostas antecipadas foi insignificante.

O tempo de reação correspondeu ao tempo decorrido entre a apresentação do estímulo e a emissão da resposta pelo sujeito, que foi orientado a responder o mais rapidamente possível. Não foram encontradas diferenças significativas para esse parâmetro em função do gênero ou do lado em que os estímulos foram apresentados na tela (Tabela 3). 
Tabela 3. Médias do Tempo de Reação ( $\pm \mathrm{DP}$, em ms) de jovens universitários ( $n=48$; $+: n=24 ; 0$ : $n=24)$ no teste de Tempo de Reação em função do gênero e do lado em que o estímulo foi apresentado.

\begin{tabular}{|c|c|c|c|}
\hline \multicolumn{4}{|c|}{ Tempo de reação (ms) } \\
\hline & $\begin{array}{c}\text { TRD } \\
(\text { Média } \pm \text { DP) } \\
\end{array}$ & $\begin{array}{c}\text { TRE } \\
(\text { Média } \pm \text { DP) } \\
\end{array}$ & $\begin{array}{c}\text { Total } \\
\text { (Média } \pm \text { DP) }\end{array}$ \\
\hline Feminino & $431,0 \pm 76,2$ & $425,8 \pm 78,0$ & $428,2 \pm 74,8$ \\
\hline Masculino & $407,9 \pm 90,9$ & $391,9 \pm 65,5$ & $400,5 \pm 76,5$ \\
\hline Total & $419,5 \pm 83,8$ & $408,8 \pm 73,3$ & $414,4 \pm 76,1$ \\
\hline
\end{tabular}

TRD: Tempo de reação para estímulos apresentados do lado direito da tela; TRE: Tempo de reação para estímulos apresentados do lado esquerdo da tela.

Não houve influência do gênero sobre a taxa de acertos dos sujeitos (Figura 23A). Este também não influenciou no tempo de reação apresentado pelos sujeitos e medido em milissegundos (Figura 23B).
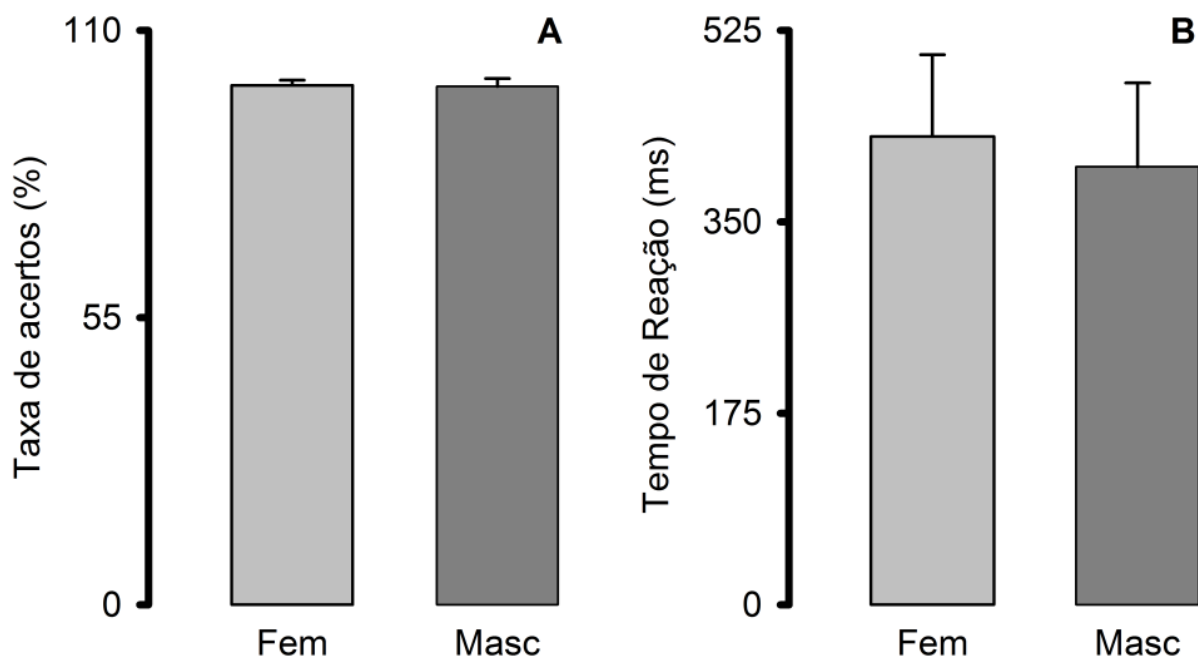

Figura 23. Média da taxa de acertos ( $A$; em porcentagem) e do tempo de reação (B; $m s)$ $( \pm D P)$ para cada gênero no teste de Tempo de Reação, realizado por jovens universitários $(n=48 ;$; $: n=24 ; 0$ : $n=24)$. Teste t para medidas independentes. Fem: Gênero Feminino; Masc: Gênero Masculino.

Não foi observado efeito do lado em que o estímulo aparecia na tela na taxa de acertos (Figura 24A) ou na velocidade de processamento (Figura 24B) dos participantes. 


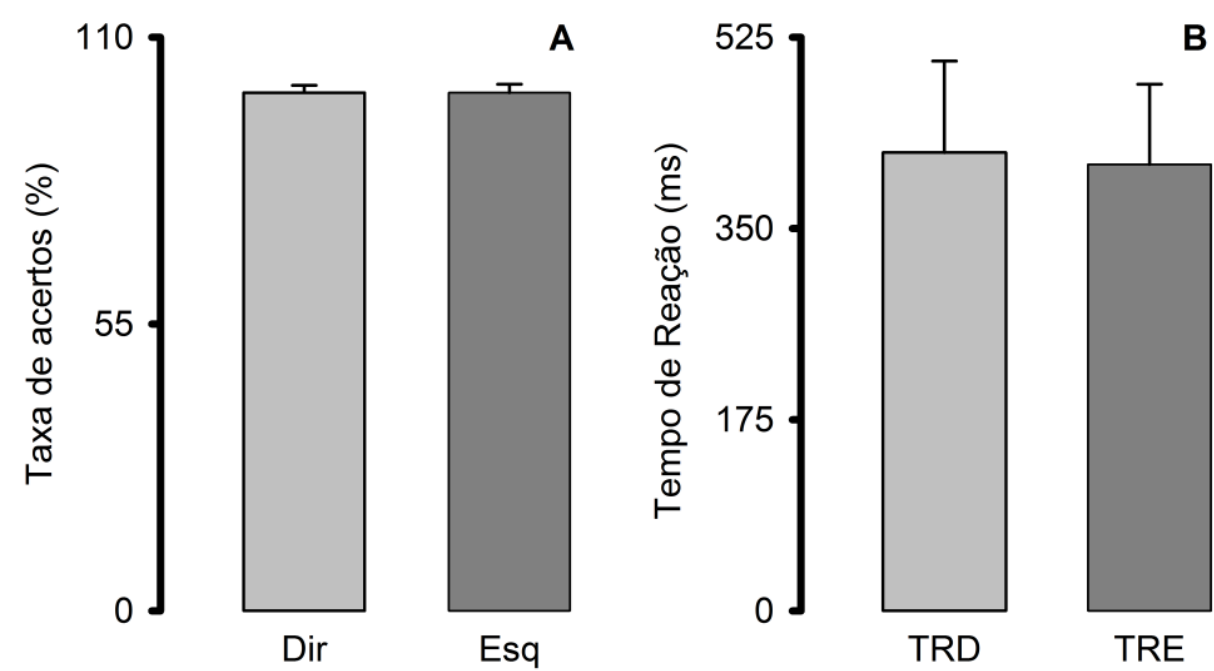

Figura 24. Média da taxa de acertos ( $A$; em porcentagem) e do tempo de reação (B; ms) $( \pm D P)$ de jovens universitários $(n=48)$ em função do lado em que o estímulo foi apresentado no teste de Tempo de Reação. ANOVA de medidas repetidas. Fem: Gênero Feminino; Masc: Gênero Masculino; TRD: Tempo de reação aos estímulos apresentados do lado direito e TRE: do lado esquerdo da tela.

\subsubsection{Eletroencefalograma}

Os dados de EEG para o teste de Tempo de Reação foram esquematizados em mapas topográficos para verificar a existência de possíveis diferenças na ativação cortical entre os gêneros.

Nas mulheres, o mapa topográfico da frequência Teta apresentou atividade acentuada na linha média da região frontopolar até a parietal e se estendeu até os eletrodos adjacentes em ambos os hemisférios, incluindo F7 e a região occipito-temporal esquerda. Houve tendência de lateralização esquerda, com atenuação entre T3, T5, Oz, O1, F8, T4 e T6. Entre os homens, o padrão foi similar. Não foi demonstrada nenhuma diferença significativa (Figura 25).

Em relação às ondas alfa, houve maior atividade na linha média, da região frontopolar até a região parietal para ambos os gêneros. As mulheres apresentaram ativação na região occipital em $\mathrm{O} 1$ e $\mathrm{O} 2$, com 
atenuação em Oz. Houve menor expressividade, ainda, no lado direito do eletrodo F8 ao T6 e sutilmente no lado esquerdo em T3. A topografia entre os homens foi semelhante, porém a atenuação do lado esquerdo foi mais acentuada e a atividade em $\mathrm{O} 2$ foi reduzida. Apenas os eletrodos F7, T3, T5, O1, Oz e T4 não apresentaram diferenças significativas (Figura 25).

A atividade beta foi maior entre as mulheres nas regiões frontopolar e frontal, além de temporal anterior e central no hemisfério esquerdo. A atividade se estendeu com menor intensidade para as regiões centrais e parietais, com sutil lateralidade esquerda. A região de menor expressividade foi nas proximidades do eletrodo T6. O mesmo foi descrito para os homens, entretanto a lateralidade esquerda foi mais acentuada. Apenas os eletrodos F7, T3, T5, O1 e T4 não apresentaram diferenças significativas, parecido com o padrão da banda Alfa (Figura 25).

A topografia para ondas Gama assemelhou-se com a de Beta para ambos os gêneros. Foram encontradas diferenças significativas para todos os eletrodos, com exceção de T3 (Figura 25). 


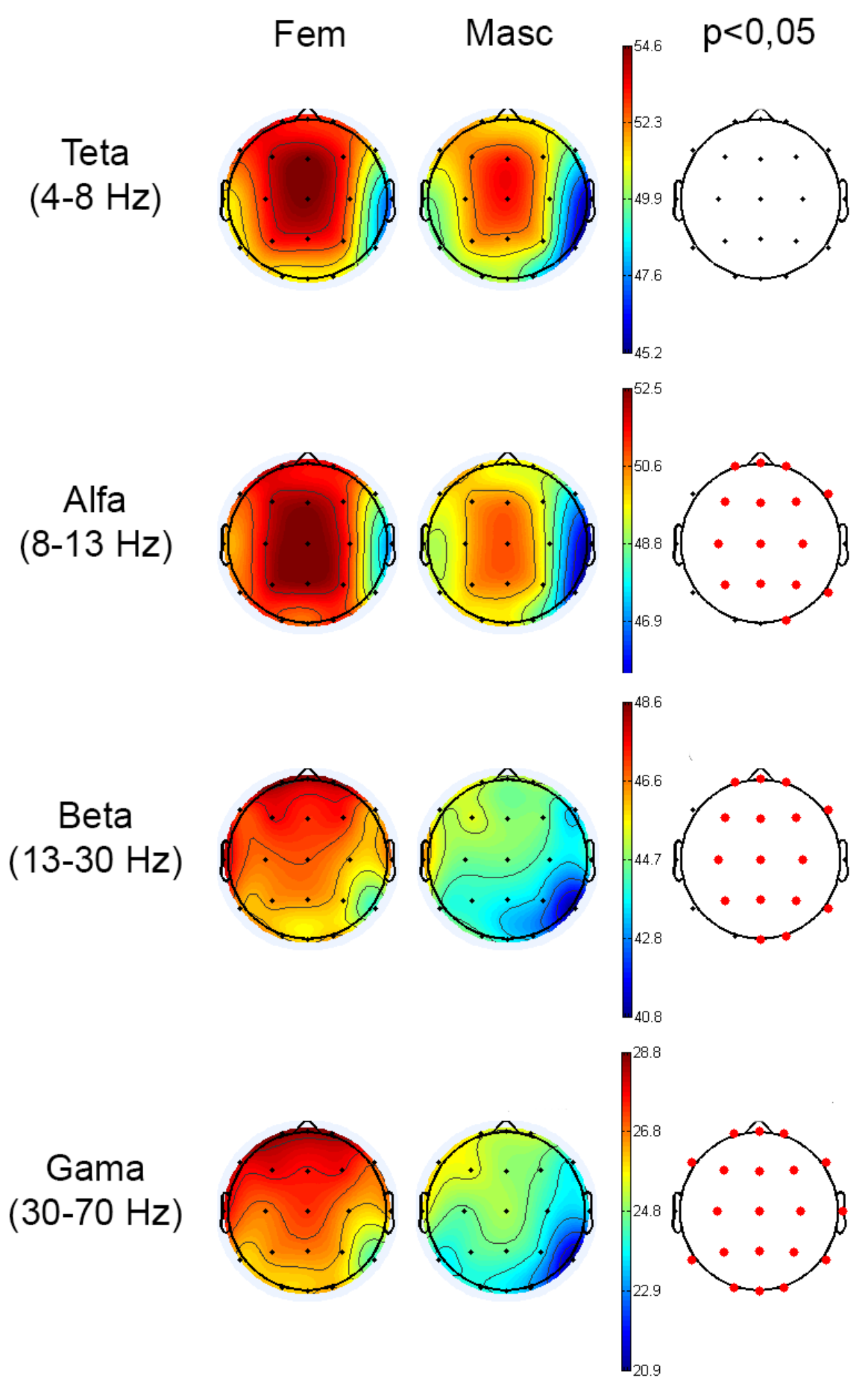

Figura 25. Mapas topográficos da atividade cortical de jovens universitários $(n=48 ; \uparrow$ : $n=24 ;$ : $n=24$ ) nas bandas Teta, Alfa, Beta e Gama para a comparação entre gêneros no teste de Tempo de Reação. Os pontos vermelhos na representação à direita indicam os eletrodos para os quais foram encontradas diferenças significativas de acordo com o teste $t$ para medidas independentes com correção pelo método FDR. Fem: Gênero Feminino; Masc: Gênero Masculino. 


\subsubsection{Eletrocardiograma}

A variação de frequência cardíaca foi analisada no domínio do tempo (índices pNN50, SDNN e RMSS) e no domínio da frequência (razão LF/HF). Apenas o índice RMSSD foi influenciado pelo gênero dos participantes, apresentando-se mais elevado entre os homens (Figura 26).
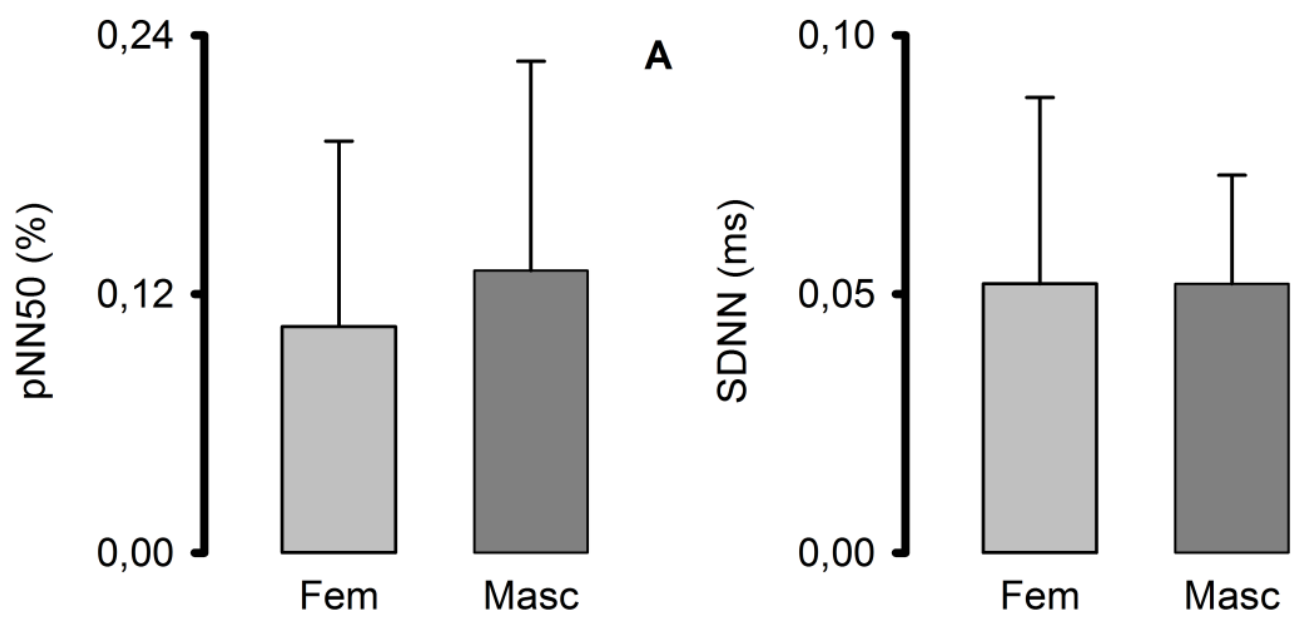

B
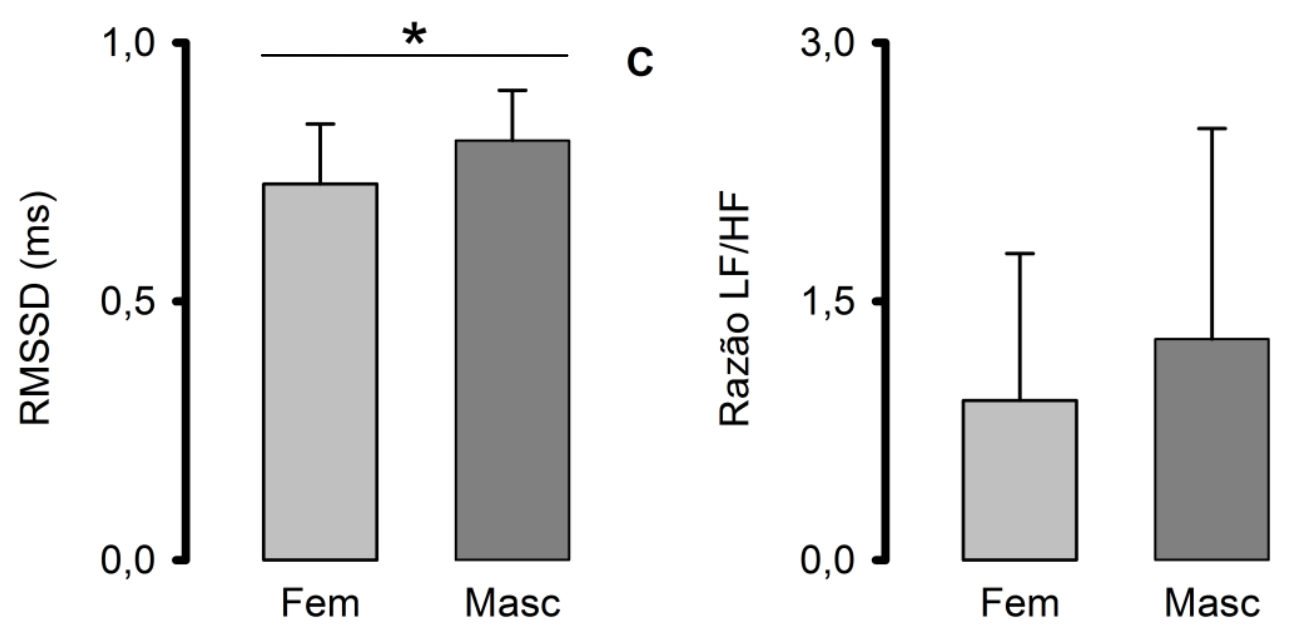

D

Figura 26. Médias ( $\pm \mathrm{DP}$ ) dos índices de variação da frequência cardíaca de jovens universitários $(n=49 ; \uparrow: n=24 ; \hat{\delta}: n=25)$, em função do gênero no teste de Tempo de Reação, no domínio do tempo - pNN50 (A; em porcentagem), SDNN (B; ms), RMSSD (C; ms) - e da frequência - Razão LF/HF (D). C: * Fem $<$ Masc, $p<0,01$. Teste $t$ para medidas independentes. Fem: Gênero Feminino; Masc: Gênero Masculino. 


\subsection{TESTE DE STROOP vs. TESTE DE TEMPO DE REAÇÃO}

\subsubsection{Eletroencefalograma}

Os mapas topográficos do teste de Stroop (Etapa Incongruente) e do teste de Tempo de Reação foram comparados para cada faixa de frequência tradicional.

Para SI, a atividade Teta distribuiu-se da região frontopolar até a parietal na linha média, com maior expressão entre os eletrodos F3, Fz e $\mathrm{Cz}$ e sutil lateralidade esquerda, que se estendeu até o eletrodo $\mathrm{O}$, atenuando-se ao redor. No teste de TR, a topografia assemelhou-se a SI, entretanto, houve menor participação dos eletrodos na região frontopolar, na região occipital esquerda e nos eletrodos do lado direito. Apenas para o eletrodo $\mathrm{Oz}$ não foi encontrada diferença significativa (Figura 27).

Houve atividade Alfa elevada, para SI, do polo frontal esquerdo até a região occipital ipsilateral, passando pela linha média, com expressão máxima em F3, Fz, C3 e $\mathrm{Cz}$ e lateralidade esquerda. Existiram semelhanças na topografia de TR, entretanto, houve atenuação na região temporal esquerda (T3 e T5) e menor ativação na extremidade do hemisfério direito, conforme demonstrado nas diferenças significativas para os eletrodos F7, F3, T3, C3 e T5 e seus correspondentes do lado direito (Figura 27).

Para o TR, comparado a SI, houve uma tendência de maior ativação central com atenuação nas regiões laterais esquerda e direita, com exceção da região frontal, nas bandas Teta e Alfa, porém mais evidente nesta última frequência (Figura 27). 
A condição SI na banda Beta apresentou atividade acentuada na região temporal anterior em ambos os hemisférios com atenuação sutil nos eletrodos Fp1, Fp2, F3, F4 e C3 e expressiva nas demais regiões. Em TR, houve ativação das regiões frontopolar e frontal, além de temporal anterior no hemisfério esquerdo. A atividade foi atenuada nas demais regiões com sutil lateralidade esquerda. A região de menor expressividade foi nas proximidades do eletrodo T6. Foram encontradas diferenças significativas para todos os eletrodos (Figura 27).

Houve maior expressão na banda Gama para SI nas regiões temporais anteriores em ambos os hemisférios e na região frontopolar com sutil lateralidade esquerda, que se estendeu aos eletrodos F3. A atividade atenuou-se nas demais regiões, com ativação mínima na região temporal posterior direita. A condição TR, por sua vez, apresentou maior ativação das regiões frontopolar e frontal, além de temporal anterior no hemisfério esquerdo e no eletrodo $\mathrm{Cz}$. A atividade se estendeu com menor intensidade para as regiões parietais, com sutil lateralidade esquerda. A região de menor expressividade foi nas proximidades do eletrodo T6. Para todos os eletrodos foram encontradas diferenças significativas (Figura 27). 


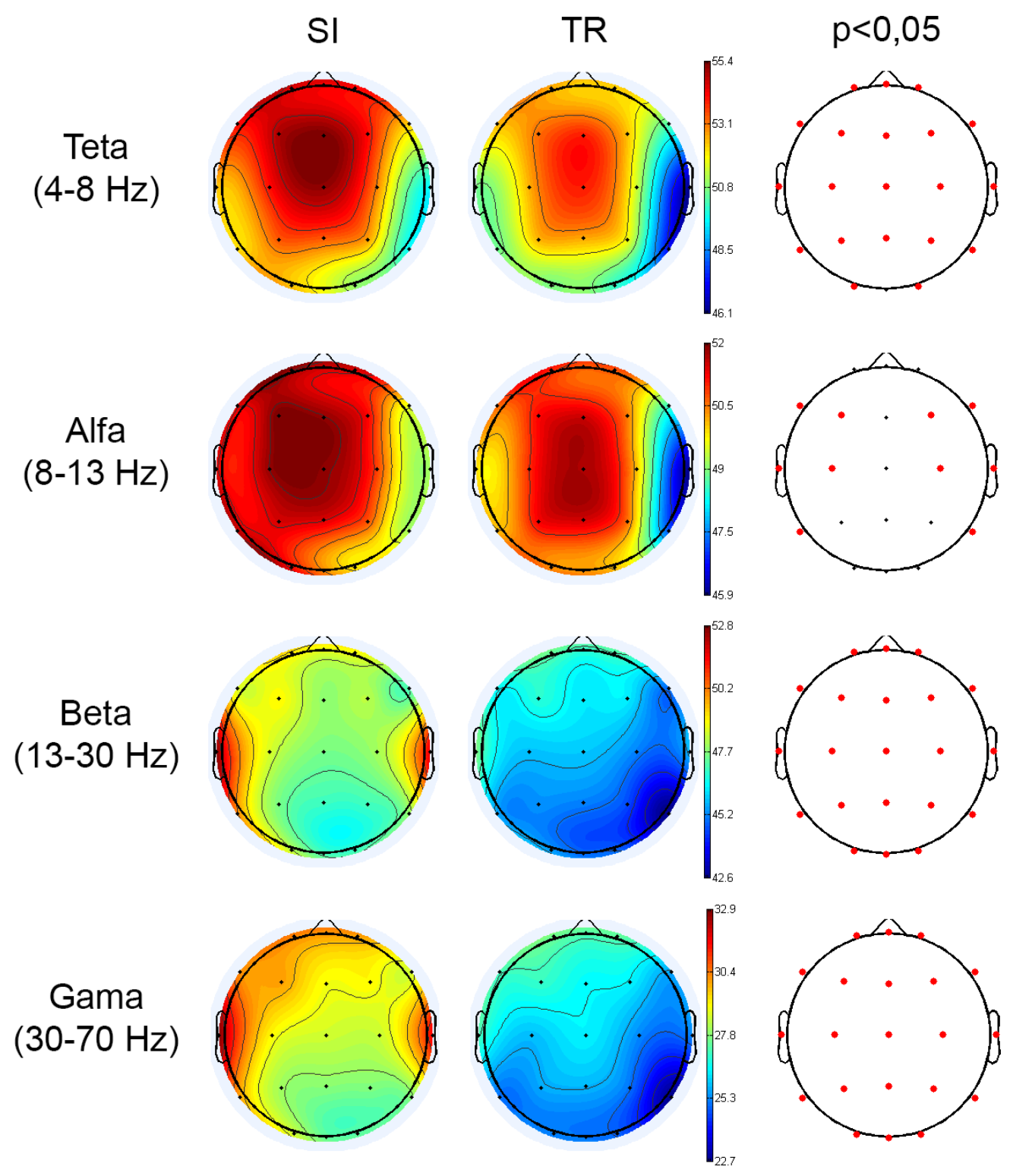

Figura 27. Mapas topográficos da atividade cortical de jovens universitários $(n=48)$ nas bandas Teta, Alfa, Beta e Gama para a comparação entre a etapa Incongruente do Teste de Stroop e o teste de Tempo de Reação. Os pontos vermelhos na representação à direita indicam os eletrodos para os quais foram encontradas diferenças significativas de acordo com o teste t pareado com correção pelo método FDR. SI: Etapa Incongruente; TR: teste de Tempo de Reação. 


\subsubsection{Eletrocardiograma}

Entre todos os índices da VFC, apenas o índice SDNN não apresentou diferenças significativas na comparação entre os testes de Stroop e de Tempo de Reação (Figura 28).
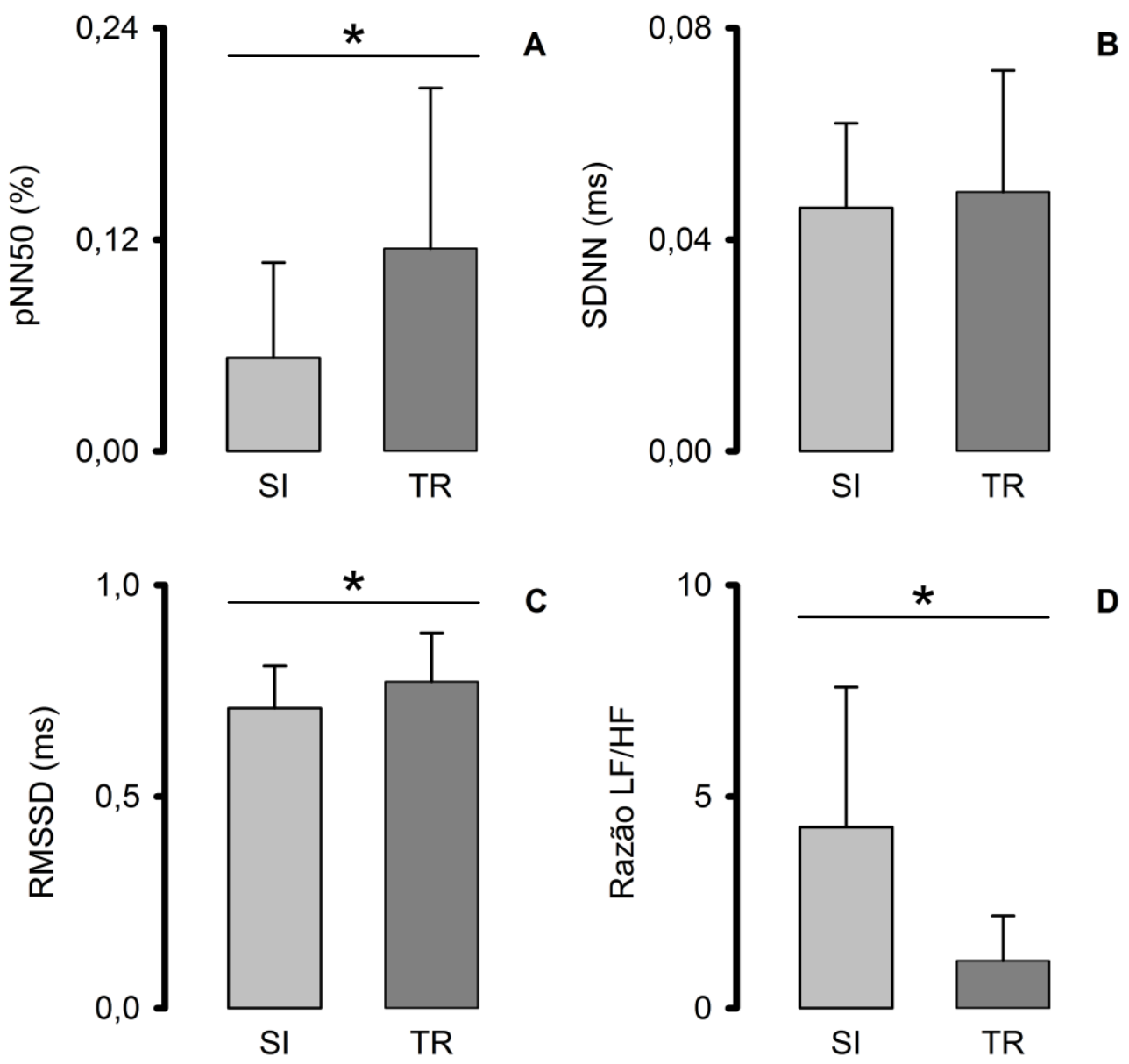

Figura 28. Médias ( \pm DP) dos índices de variação da frequência cardíaca de jovens universitários $(\mathrm{n}=49)$ nos testes de Stroop e de Tempo de Reação, no domínio do tempo - pNN50 (A; em porcentagem), SDNN (B; ms), RMSSD (C; ms) - e da frequência - Razão LF/HF (D). A: * Sl<TR, $p<0,001$. C: * $S \mid<T R, p<0,001$. $\mathrm{D}: * \mathrm{SI}>\mathrm{TR}, \mathrm{p}<0,001$. ANOVA de medidas repetidas. SI: Teste de Stroop (Etapa Incongruente); TR: Teste de Tempo de Reação. 
6. DISCUSSÃO 
Nesta seção, os resultados comportamentais e eletrofisiológicos, de ativação cortical e de variação da frequência cardíaca, serão discutidos levando-se em consideração resultados similares ou discrepantes encontrados na literatura. Em cada seção, são discutidos primeiramente os resultados do teste de Stroop, seguidos pelo teste de Tempo de Reação e finalmente, pela comparação entre os dois.

\subsection{Comportamento}

Os resultados de desempenho no teste de Stroop apresentaram diferenças significativas para a taxa de acertos entre todas as etapas, com dificuldade crescente da etapa Congruente (SC) para a etapa de Semelhança Fonética (SSF) e desta para a Incongruente (SI). O paradigma do teste de Stroop define como efeito de interferência o aumento no tempo necessário para a geração da resposta quando se compara a etapa congruente com a incongruente, supostamente devido à presença de conflito entre as duas dimensões do estímulo nessa última (Van Der Elst et al., 2006). No caso do presente estudo, apesar de não ter sido avaliado o tempo de resposta, pois esse parâmetro não foi gerado pelo programa do teste de Stroop utilizado, pode-se considerar que exista um efeito equivalente ao efeito de interferência para a precisão de resposta dos sujeitos.

A etapa de Semelhança Fonética mostrou-se como uma etapa de dificuldade intermediária entre SC e SI, o que foi evidenciado tanto pela taxa de acertos, como pelo fato desta etapa não se diferenciar significativamente de SC para a taxa de erros de omissão. Isso está de 
acordo com outros estudos, nos quais a precisão e os tempos de resposta em etapas que utilizam palavras que não representam nomes de cores, consideradas neutras, são intermediários em comparação com as etapas congruentes e incongruentes (Hanslmayr et al., 2008; Mead et al., 2002; Salo, Henik \& Robertson, 2001). Uma pesquisa que fez uso de etapas com palavras foneticamente semelhantes a nomes de cores, de forma similar ao presente estudo, também apresentou o mesmo padrão aqui obtido para o tempo de resposta (Spieler, Balota \& Faust, 1996).

Segundo o modelo de rede neural elaborado para o teste de Stroop (página 44), a etapa Congruente não envolve conflito entre as duas dimensões do estímulo - cor e significado, e assim, o sujeito é capaz de apresentar uma resposta correta com base em qualquer uma das características (Smith \& Kosslyn, 2006b). Por isso, apesar de se esperar que o sujeito apresente níveis basais de atenção concentrada, pois ele mantém o foco da atenção na regra do teste durante o seu decurso, ele não apresenta necessariamente atenção seletiva e inibição de respostas, o que torna a etapa SC menos complexa.

Como a palavra na etapa SSF não se refere a uma cor, mas se assemelha foneticamente ao nome de uma cor, espera-se que o conflito existente seja maior do que quando as duas dimensões são coincidentes (etapa SC), porém menor do que quando são incongruentes (etapa SI) (Hanslmayr et al., 2008). Essa hipótese foi corroborada pelos resultados da taxa de acertos e da taxa de erros de omissão apresentadas pelos participantes do presente estudo. 
No estudo realizado por Salo e colaboradores (2001), o tempo de resposta para estímulos neutros que consistiam em palavras não relacionadas a cores foi maior do que para estímulos neutros não léxicos (por exemplo, "XXXX") no teste de Stroop. Isso indica que existe conflito para palavras neutras, afinal, para elas também há maior tendência de leitura das palavras do que de nomeação da cor, porém o conflito é reduzido porque não existe incongruência entre as duas dimensões do estímulo, já que a palavra não consiste no nome de uma cor. Milham e colaboradores (2002) destacam que, quando o delineamento experimental do estudo inclui uma etapa em que há apenas palavras congruentes, esta realmente envolve menos conflito do que em uma etapa neutra e possivelmente demanda menos controle inibitório; porém as etapas congruente e incongruente necessitam de maior controle da atenção do que a etapa neutra, pois existem duas fontes de informação a respeito de cores, o significado da palavra em si e a cor em que ela está escrita, e no caso dessas informações não serem coincidentes, a demanda por atenção aumenta ainda mais.

Tanto para a taxa de acertos, quanto para a taxa de erros de omissão, foram observadas diferenças significativas entre a etapa Incongruente e as demais. Há indícios, portanto, de que SI tenha requerido maior demanda de controle inibitório, atenção e flexibilidade cognitiva dos sujeitos. O aumento na taxa de erros de omissão indica que para esta etapa, o conflito gerado foi suficiente para prejudicar o desempenho dos sujeitos, possivelmente por comprometimento do controle inibitório, isto é, da inibição da tendência em ler a palavra. 
O gênero não influenciou de forma consistente no desempenho em nenhuma das medidas analisadas (taxa de acertos e de erros de omissão). Apesar de os estudos que investigam diferenças de desempenho entre os gêneros no teste de Stroop serem contraditórios (Van Der Elst et al., 2006), na maioria das vezes estes chegam à conclusão de que realmente não há diferenças (Bjorklund \& Kipp, 1996). De acordo com a hipótese de Bjorklund e Kipp (página 28), o teste de Stroop pode ser considerado como um teste do domínio cognitivo, para o qual não são elevadas as pressões seletivas que evolutivamente favorecem as mulheres, quando comparado ao domínio social e comportamental.

Um estudo com a proposta de apresentar dados normativos para o teste de Stroop encontrou diferenças nos tempos de resposta apresentados entre os gêneros na versão impressa do teste de Stroop e a ausência de diferenças na versão computadorizada (Barbarotto et al., 1998). A interpretação dos autores para os resultados sugere que a velocidade de processamento é geralmente superior entre os homens (tempos de resposta menores) e isto pode compensar o desempenho superior das mulheres em nomear cores. Para eles, essa compensação ocorre apenas para a versão computadorizada porque esta define um tempo fixo de apresentação dos estímulos e consequentemente de geração das respostas, impossibilitando que os sujeitos escolham entre uma estratégia de maior velocidade ou de maior precisão na resposta.

Apesar de não haver interação significativa entre os fatores Etapa e Gênero, houve diferença significativa entre as etapas SC e SI tanto para as mulheres quanto para os homens, na taxa de acertos; e apenas para os 
homens na taxa de erros de omissão. Esses resultados indicam que é possível que a elevada taxa de erros de omissão dos homens na etapa SI (Figura 12) tenha influenciado mais do que o desempenho das mulheres para a diferença significativa observada nesse parâmetro na comparação geral entre as etapas independentemente do sexo (Figura 9). Porém esses resultados, no presente estudo, devem ser interpretados com cautela, principalmente porque a interação entre Etapa e Gênero não foi significativa.

O desempenho no teste de Tempo de Reação não variou em função do gênero ou do lado em que o estímulo foi apresentado. A taxa de acertos para este teste foi alta em todas as condições. De forma similar, o tempo de resposta também foi semelhante para todas as comparações.

Os tempos de reação, dados em milissegundos, foram relativamente altos ao se comparar com outros estudos que utilizam testes de Tempo de Reação simples (Barbarotto et al., 1998; Serrien, Fisher \& Brown, 2003; Thut et al., 1999). As características do protocolo utilizado no presente estudo, tais como a presença de dica, a apresentação do estímulo em locais diferentes da tela e a variabilidade dos intervalos entre a dica e o estímulo, podem ter resultado em um teste mais complexo do que um teste de Tempo de Reação Simples. Contudo, a ausência na literatura de protocolos experimentais idênticos ao do presente estudo dificulta a interpretação dos resultados.

No presente estudo, não foram encontradas diferenças significativas entre os gêneros. Na literatura, não está claro se existem diferenças 
consistentes no tempo de reação entre os gêneros (Der \& Deary, 2006). Em alguns casos, o desempenho dos sujeitos, levando-se em consideração tanto o tempo de reação, quanto a precisão, não foi influenciado pelo sexo (Garavan et al., 2006; Li et al., 2006; Li et al., 2009). Nos estudos que encontraram diferenças entre os gêneros, os homens foram mais rápidos (Barbarotto et al., 1998) do que as mulheres, e estas, por sua vez, ou cometeram mais erros do que os homens (Stoet, 2010) ou foram mais precisas (Der \& Deary, 2006).

Der e Deary (2006) sugerem que, quando encontradas, as diferenças existentes entre os gêneros para o tempo de reação residem na variabilidade do desempenho ao longo de uma tarefa e em diferenças na relação entre a velocidade e a precisão de um sujeito. Assim, as mulheres inicialmente são mais lentas, porém mais precisas do que os homens, mas após algumas tentativas, elas se tornam mais rápidas e mantêm a sua taxa de acertos (Der \& Deary, 2006).

O desempenho dos sujeitos não foi influenciado pelo lado em que o estímulo foi apresentado. Existe um consenso na literatura de que o tempo decorrido para que um sujeito responda a um estímulo é menor quando este é apresentado do mesmo lado da mão que será utilizada para responder (condição não-cruzada) do que quando o estímulo é apresentado do outro lado (condição cruzada) (Thut et al., 1999). Na condição não cruzada, o mesmo hemisfério que recebe a informação sensorial, controla a resposta motora. Já na condição cruzada, são necessárias conexões inter-hemisféricas para que a informação visual processada no hemisfério contralateral à apresentação do estímulo seja 
transferida para o outro hemisfério no qual a resposta motora é então preparada. Nos resultados encontrados por Thut e colaboradores (1999), apesar de haver uma tendência de maior velocidade de processamento na condição não-cruzada, também não houve diferença significativa para o fator lado (Thut et al., 1999).

Levando em consideração a ausência de diferenças significativas nos resultados comportamentais do teste de Tempo de Reação, levantou-se a questão de possível ofuscamento de diferenças devido a um efeito teto. Isso pode ter sido influenciado pela característica da amostra, composta apenas por jovens universitários que possivelmente tiveram relativa facilidade no teste. Assim, não foram demonstradas influências do gênero ou do lado em que o estímulo foi apresentado no desempenho, tanto para a taxa de acertos, quanto para o tempo de reação em si.

Em um estudo realizado no nosso laboratório (ainda não publicado), no qual o tempo de reação de jovens foi comparado com o de idosos hígidos e com Doença de Alzheimer, foi observado um efeito da idade sobre o desempenho. Isso indica que o teste é sensível para registrar variações na velocidade de processamento, entretanto, poderia ser adaptado para os jovens em oportunidades futuras, de forma a aumentar a sua dificuldade e evitar, assim, um possível efeito teto. Uma das possíveis adaptações seria aumentar o número de tentativas e tempo total de execução do teste. Por se tratar de um teste de deteç̧ão de sinal, seria esperado um declínio na atenção sustentada e consequentemente, no desempenho dos sujeitos. 


\subsection{Eletroencefalograma}

Nesta seção, primeiramente serão discutidos os padrões gerais de atividade cortical obtidos nos dois testes. Em seguida, os resultados de cada teste serão evidenciados separadamente, levando em consideração as faixas de frequência. Então, serão discutidos os resultados de comparação entre a etapa Incongruente do teste de Stroop (SI) e o teste de Tempo de Reação.

Funções cognitivas complexas provocam a sobreposição de vários tipos de oscilações de diferentes amplitudes, duração e faixas de frequência (Basar et al., 2001). Assim, é esperado que exista ativação cortical nas principais bandas do EEG em resposta a tarefas complexas que requerem um bom funcionamento executivo, como o teste de Stroop e o teste de Tempo de Reação. A regulação desses padrões oscilatórios simultâneos foi atribuída ao CPF, que é capaz de ativar as operações cognitivas relacionadas à banda Alfa e, ao mesmo tempo, inibir os impulsos emocionais e motivacionais associados com a atividade Teta, de forma que o resultado final seja a organização de comportamentos eficientes em direção a objetivos importantes (Knyazev, 2007).

Os resultados de EEG para os dois testes evidenciaram uma diferença no padrão de ativação cortical ao se comparar as frequências mais baixas (Teta e Alfa) com as mais altas (Beta e Gama). Essa diferença pode refletir as duas subdivisões das frequências do EEG humano, as modalidades globais e locais de processamento (página 39).

A distribuição das ondas Teta e Alfa ocorreu em um gradiente frontoparietal. Existem evidências de que as funções executivas não dependam 
apenas da ativação no CPF, mas de uma rede fronto-parietal sincronizada entre as bandas Teta e Alfa superior, especialmente quando há maior demanda do executivo central (Sauseng et al., 2005). No estudo realizado por (Knyazev, 2010), indivíduos com maiores índices de controle inibitório, introversão e ansiedade apresentaram maior gradiente antero-posterior, principalmente para a banda Teta.

De forma geral, foi possível perceber a ativação de ambos os hemisférios com tendência de lateralização esquerda, em todas as etapas do teste de Stroop e no teste de Tempo de Reação. Esse resultado está de acordo com a noção tradicional de especialização do hemisfério esquerdo para a linguagem e para o controle motor (Serrien, Ivry \& Swinnen, 2006).

O fato de a resposta requerida para o teste de Stroop ser do tipo verbal pode ter influenciado na tendência de lateralização esquerda, pela ativação de regiões envolvidas na linguagem. Para o TR, deve ser levado em consideração que todos os sujeitos eram destros, o que associado à execução da resposta motora com a mão direita, cujo movimento é controlado pelo hemisfério esquerdo, consiste em uma explicação potencial para o padrão observado.

O controle motor em uma tarefa de memória operacional verbal gerou maior ativação cortical no córtex pré-frontal lateral esquerdo (Jonides et al., 1998). De forma similar, estudos de estimulação elétrica anódica do CPFDL esquerdo (Boggio et al., 2007; Jeon \& Han, 2012; Plewnia et al., 2013) produziram melhores desempenhos em testes de controle inibitório.

Entretanto, o uso da mesma técnica em regiões do hemisfério direito, tais como o CPFDL (Jeon \& Han, 2012) e o giro frontal inferior direito (Ditye 
et al., 2012; Jacobson et al., 2012; Jacobson et al., 2011), além de estudos com lesões e técnicas de neuroimagem relacionados ao CPFVM sugerem que essas regiões também estejam associadas com o controle inibitório.

Serrien e colaboradores (2006) destacam a importância da ação combinada dos dois hemisférios para o sucesso no desempenho dos sujeitos. O tipo de tarefa e diferenças individuais também podem influenciar na especialização hemisférica. Esses dois fatores podem auxiliar a explicar a tendência de assimetria observada no presente estudo, para a qual, entretanto, a atividade cortical bilateral foi importante, de forma a conciliá-la com o observado na literatura tanto para o hemisfério esquerdo quanto para o direito.

Especificamente para o teste de Stroop, na banda Teta, houve atividade acentuada em Fz, Cz e F3. A participação mais expressiva dessas regiões, correspondentes ao córtex pré-frontal e ao córtex motor, nas condições SI e SSF pode indicar que essas etapas exigem mais recursos cognitivos, tais como atenção, esforço mental, controle inibitório e flexibilidade, do que a etapa Congruente.

Isso vai de encontro aos resultados comportamentais, para os quais a etapa SI foi considerada como a de maior dificuldade, seguida por SSF. Para a banda Teta, entretanto, não foram demonstradas diferenças significativas na ativação cortical dessas duas etapas.

Há destaque para o eletrodo F3, correspondente à região do córtex pré-frontal dorsolateral (CPFDL), cuja ativação está envolvida na manipulação de dados armazenados na memória operacional (Lent, 2010), 
o que reflete no sucesso comportamental da inibição de respostas (Boggio et al., 2007). Já a ativação na região occipital esquerda (eletrodo O1) pode estar relacionada com a representação mental e o processamento da cor da palavra, já que ambos ocorrem no córtex visual (Lent, 2010). O envolvimento da região occipital esquerda na banda Teta também foi observado no estudo de Ghimire e colaboradores (2015) e foi mais evidente na condição incongruente. Isso pode ser interpretado como um indício de maior influência da dimensão irrelevante do estímulo nesta etapa, o que pode ter contribuído para o comprometimento no desempenho em comparação com a etapa SC.

A distribuição topográfica na banda Alfa foi similar à Teta, entretanto, a atividade na região frontopolar possui ainda menos contribuição para SC, o que evidencia novamente menor dificuldade nessa etapa quando comparada às outras, por recrutar menos áreas associadas ao CPF. A ativação frontopolar, nas proximidades do córtex pré-frontal orbitofrontal (CPFOF), região correspondente aos eletrodos frontopolares, se correlacionou positivamente com o sucesso no desempenho comportamental em uma tarefa Go/No-Go (Smith \& Kosslyn, 2006b), indicando que essa região é importante para mecanismos inibitórios. Maior ativação frontopolar também foi observada para a condição incongruente no estudo de Hanslmayr e colaboradores (2008).

O modelo de rede neural para o teste de Stroop (página 44) (Botvinick et al., 2004) auxilia a explicar o envolvimento mais evidente do CPFDL nas etapas SI e SSF, pois essa região é supostamente responsável pela mediação do sistema de controle da atenção em resposta à detecção de 
um conflito pelo córtex cingulado anterior (mesmo que o conflito na etapa SSF seja menor), levando ao aumento da demanda da atenção. No presente estudo, a atividade do córtex cingulado, importante em tarefas que requerem atenção sustentada e refletida na linha frontal média da banda Teta (Ishii et al., 1999; Knyazev, 2010), também ficou evidente nessas duas etapas.

Ainda em relação ao teste de Stroop, a ativação no eletrodo T3, correspondente ao giro temporal superior e médio (Herwig, Satrapi \& Schonfeldt-Lecuona, 2003), observada nas bandas Beta e Gama, pode ter indicado a representação mental da palavra em si, de acordo com o modelo de rede neural para o teste de Stroop (Smith \& Kosslyn, 2006b). Também é possível que haja contribuições do processamento verbal para a ativação observada nas regiões temporais, conforme já foi demonstrado durante a execução do teste de Stroop (Milham et al., 2002).

A participação do lobo temporal esquerdo também já foi descrita quando substantivos são processados (Cappa \& Perani, 2002). Em uma tarefa em que os sujeitos tinham que gerar palavras de cores, houve ativação do CPFDL esquerdo, o que possivelmente reflete o processo mnemônico da evocação de palavras; e do lobo temporal, bilateralmente, porém mais evidente no hemisfério esquerdo (Martin et al., 1995), padrão semelhante ao encontrado neste estudo.

O processamento da cor da palavra foi evidenciado pela ativação no lobo occipital esquerdo (eletrodo O1), de forma similar ao observado em Teta e Alfa. Isso indica que ambas as características dos estímulos foram processadas e que em situações incongruentes realmente houve conflito. 
Também similarmente às ondas Teta e Alfa, houve ativação das regiões frontopolares e do CPFDL esquerdo.

Em Beta, houve aumento significativo na potência da ativação temporal entre SI e SSF para o lado esquerdo. Em Gama, não houve diferenças significativas entre SI e SSF para as regiões frontais (com exceção de F3 e F4), na região occipital esquerda, bem como na linha média central e parietal, o que evidencia um padrão de ativação cortical mais semelhante entre essas etapas em comparação a SC, similarmente ao descrito na banda Teta. Além disso, a amplitude de potência em SC foi menor do que nas outras condições para todas as frequências analisadas, o que reforça a hipótese de menor demanda de recursos executivos para essa etapa.

A comparação da atividade cortical entre os gêneros indicou que houve maior contribuição das mulheres para a expressividade máxima em F3 encontrada para SI e SSF nas bandas Teta e Alfa, o que sugere que houve maior recrutamento por parte das mulheres do CPFDL. Isso está de acordo com resultados que mostraram uma tendência de maior gradiente fronto-parietal para as mulheres em todas as bandas avaliadas, isto é, mais ativação em regiões frontais do que em regiões parietais do cérebro, e esse padrão se correlacionou com maiores índices de controle inibitório (Knyazev, 2010).

Em todas as bandas, foi possível observar uma maior tendência de ativação da região occipital esquerda e central $(\mathrm{O} 1 \mathrm{e} \mathrm{Oz})$ para as mulheres. Esse resultado sugere que as mulheres alocariam mais atenção para as características visuais dos estímulos do que os homens. Essa interpretação 
está em conformidade com evidências de um estudo de ERP, para o qual as mulheres, comparadas aos homens, apresentaram maior amplitude em um componente associado com processamento sensorial dos estímulos, o componente P3 na banda Gama (Jausovec \& Jausovec, 2009). O aumento na taxa de erros de omissão da etapa Congruente para a Incongruente, exclusivamente entre os homens, consiste em mais uma evidência de que o processamento da informação da cor tenha sido prejudicado para eles, resultando em um comprometimento na resolução do conflito entre a leitura e a nomeação da cor da palavra e um maior número de casos de erros de omissão.

Em todas as frequências, uma análise mais geral permite perceber um padrão de diminuição na amplitude de potência para os homens. Isso pode indicar que um nível menor de ativação para os homens foi suficiente para manter o mesmo desempenho das mulheres, já que não foram observadas diferenças entre os gêneros para os dados comportamentais. Um padrão contrastante foi descrito em dois estudos, nos quais foram encontradas evidências de que as mulheres necessitam de menos ativação neural que os homens para obter um desempenho semelhante ou que elas utilizam estratégias diferentes para o monitoramento de conflitos (Clayson, Clawson \& Larson, 2011; Li et al., 2006).

Li e colaboradores (2006), entretanto, destacam que o padrão observado em seu estudo, com menor ativação cortical entre as mulheres, não está em conformidade com o observado na literatura. Nos resultados apresentados por Garavan e colaboradores (2006), por exemplo, foi observada maior atividade para as mulheres em comparação com os 
homens, com exceção da atividade na linha média. A interpretação desses resultados indica que diferentes estratégias foram utilizadas pelos homens e pelas mulheres para a resolução do conflito envolvido no teste de Stroop e aponta para a explicação de que possivelmente as mulheres apresentariam maior esforço cognitivo para a realização das tarefas propostas e realizariam um recrutamento de mais recursos cognitivos para a realização da tarefa (Garavan et al., 2006). Porém, de forma intrigante, não foram encontradas diferenças entre o desempenho dos gêneros para nenhum dos dois estudos, o que sugere que ambas as estratégias utilizadas foram bem sucedidas. A realização de novas investigações poderia contribuir para elucidar os resultados encontrados.

Para o teste de Tempo de Reação, não foram descritas diferenças significativas na banda Teta, cuja atividade foi acentuada na linha média da região frontopolar até a parietal e incluiu atividade na região occipitotemporal entre as mulheres. Em tarefas de Go/No-Go, a ativação do CPFOF, correspondente à atividade frontopolar observada, se correlacionou positivamente com o desempenho dos sujeitos (Smith \& Kosslyn, 2006b), o que evidencia novamente a importância dessa região em tarefas que envolvem controle inibitório, como o TR.

Garavan e colaboradores (2006) destacam a importância de uma rede distribuída de ativação cortical para o sucesso na inibição de respostas, com diferentes contribuições de regiões fronto-parietais para os mecanismos de atenção e de seleção de respostas e da atividade na linha média para o monitoramento do estímulo. Nos resultados desses autores, 
apesar da participação do hemisfério direito na inibição de respostas ter se associado a desempenhos melhores, o fato de o hemisfério esquerdo também ter inibido com sucesso a maioria das tentativas, evidencia que o controle inibitório não é uma especialização do hemisfério direito (Garavan et al., 2006).

Para as ondas Alfa, as mulheres apresentaram mais ativação do que os homens na região occipital em ambos os hemisférios, com atenuação na região occipital central. Novamente, esses resultados podem indicar estratégias diferentes de processamento de estímulos visuais por parte das mulheres, como ocorrido no teste de Stroop. No caso do teste de Tempo de Reação, apesar de a resposta ser motora, o estímulo continua sendo visual. Em um estudo de ERP utilizando um teste de Tempo de Reação Simples, houve ativação do córtex occipital no momento do processamento do estímulo (mapas visuais) e ativação do córtex frontal durante a preparação ou emissão da resposta (mapas motores) (Thut et al., 1999). No presente estudo, os mapas topográficos da ativação cortical consideraram todo o tempo de execução do teste, impedindo a análise relacionada a eventos, porém o padrão de ativação foi semelhante, nos córtices frontal e occipital.

A manifestação do eletrodo F3, correspondente ao CPFDL em todas as bandas de frequência evidencia o seu papel fundamental na preparação do movimento, por meio da conexão entre os inputs sensoriais e os outputs motores a serem gerados, conforme relatado por Serrien e colaboradores (2003). Já a atividade do lobo temporal esquerdo no teste de Tempo de Reação, evidente em Beta e Gama, pode ter refletido mecanismos 
preparatórios para resposta motora, em consonância com um estudo em que o sulco temporal superior esquerdo, bem como o CPFVM e o córtex motor primário bilateralmente, subsidiaram o planejamento do movimento em um teste de Stop Signal (Hu \& Li, 2012).

Aparentemente, as diferenças significativas encontradas entre os gêneros para as bandas Alfa, Beta e Gama refletem em maior grau mudanças na potência, cujos valores foram menores entre os homens, afinal a topografia de ativação cortical foi semelhante entre homens e mulheres. Essa diferença na potência também pode ser observada para a banda Teta, apesar de não ter sido alcançada a significância estatística. Possivelmente, a diferença entre nos valores de potência não foi suficiente para gerar diferenças comportamentais, principalmente ao se levar em conta a ausência de diferenças na distribuição espacial de ativação cortical.

O padrão de menor ativação cortical para os homens consiste no mesmo que foi descrito para o teste de Stroop, o que novamente evidencia o uso de diferentes estratégias entre homens e mulheres em termos do recrutamento de áreas corticais.

Garavan e colaboradores (2006) também observaram maior atividade cortical entre as mulheres em comparação com os homens, com exceção da linha média, o que pode revelar um maior esforço cognitivo e recrutamento de mais recursos para a realização de uma tarefa mais difícil. No caso do estudo desses autores, também não houve diferenças no desempenho entre os gêneros. Eles afirmam que novas investigações devem ser realizadas. Nossos resultados são, portanto, importantes para a geração de novos dados. 
As regiões em que as mulheres demonstraram maior atividade do que os homens foram principalmente no hemisfério direito (Garavan et al., 2006), o que vai de encontro às diferenças significativas encontradas para as bandas Alfa, Beta e Teta. Os autores sugerem que isso é contrastante com a noção difundida na literatura de que as mulheres apresentariam menos especializações hemisféricas do que os homens.

Os resultados da comparação eletroencefalográfica entre a etapa Incongruente do teste de Stroop e o teste de Tempo de Reação permitiu elencar semelhanças e diferenças na ativação cortical requerida para o controle inibitório verbal e motor, respectivamente. Entre as semelhanças, primeiramente destaca-se o padrão de ativação em uma rede distribuída fronto-parietal para as bandas Teta e Alfa, o que indica que para a obtenção de sucesso em ambos os testes é necessário um funcionamento executivo adequado e controle inibitório (Knyazev, 2010; Sauseng et al., 2005). Isso também foi evidenciado pela ativação do CPFOF em ambos os testes, associado ao sucesso no desempenho dos sujeitos, e do CPFDL, que subsidia o sistema de controle da atenção executiva e a ligação entre os inputs sensoriais e os outputs motores (Serrien et al., 2003; Smith \& Kosslyn, 2006b).

Com relação às diferenças observadas entre os testes, a participação menos evidente da área occipital direita para o TR em Teta e Alfa pode indicar que apesar de o processamento visual ser importante para subsidiar o desempenho no TR, este é ainda mais evidente para o teste de Stroop, 
possivelmente devido ao fato de o estímulo visual ser uma das dimensões conflitantes na etapa Incongruente.

Apesar de haver ativação temporal em ambos os testes nas bandas Beta e Gama, no Stroop ela foi bilateral e no TR apenas no hemisfério esquerdo. No Stroop, a atividade temporal possivelmente esteve relacionada à representação mental da palavra representativa da cor (Smith \& Kosslyn, 2006b) e ao seu processamento (Cappa \& Perani, 2002; Martin et al., 1995), enquanto no TR, ao possível envolvimento do sulco temporal superior, associado a mecanismos preparatórios para o movimento (Hu \& Li, 2012).

\subsection{Eletrocardiograma}

A frequência cardíaca é modulada pela ação combinada das divisões simpática e parassimpática do Sistema Nervoso Autonômico (SNA) (Guyton \& Hall, 2006). Quando um indivíduo é exposto ao estresse agudo,

a divisão simpática do SNA torna-se mais ativa, e assim, a razão LF/HF aumenta, enquanto os índices SDNN e RMSSD diminuem (Prinsloo et al., 2013). Não só os índices SDNN e RMSSD, mas também o pNN50, refletem a atividade parassimpática em variações de curto prazo na FC a cada batimento cardíaco (Delaney \& Brodie, 2000) e assim, diminuem em situações de estresse mental.

No presente estudo, para o teste de Stroop, os índices de variação da frequência cardíaca (VFC) no domínio do tempo reforçam os resultados de desempenho, indicando um efeito de interferência ao se comparar as etapas. Apesar de a maioria dos estudos que avaliam a variação da $\mathrm{FC}$ no 
teste de Stroop apresentarem diferentes etapas (por exemplo, congruente, incongruente e neutra), comparações diretas entre elas raramente são feitas. As pesquisas desse tipo privilegiam a comparação do teste de Stroop com uma linha de base ou entre dois grupos (experimental e controle) e dão pouca ênfase às possíveis diferenças entre as etapas. Isso evidencia a importância do presente estudo na geração de novos dados.

Para todos os índices há uma tendência de aumento entre SSF, SI e SC, nessa ordem. Entretanto, houve aumento significativo em todos os índices apenas na comparação de SC com SSF, o que indica que houve aumento na atividade parassimpática para SC e sugere que esta etapa tenha requerido menos habilidades executivas dos sujeitos.

Os resultados dos índices pNN50 e RMSSD não foram na mesma direção daqueles observados para o índice SDDN, pois para os primeiros, houve diferença entre SI e SSF, enquanto que para o último, a diferença foi encontrada entre SC e SI. Há diferentes resultados nos estudos que avaliam a variação da frequência cardíaca durante o teste de Stroop, no que diz respeito aos índices no domínio do tempo. Os três podem diminuir durante a execução desse teste comparada à linha de base (Delaney \& Brodie, 2000; Salahuddin, 2007). Em outro estudo, SDNN e RMSSD exibiram a tendência de serem menores durante a etapa neutra e semelhantes entre as etapas congruente e incongruente (Dupuy et al., 2014). Em um desenho experimental com apenas uma etapa, semelhante à etapa SI do presente estudo, o índice RMSSD foi significativamente menor durante o teste do que em uma condição de repouso (Prinsloo et al., 2013). De forma similar, o índice RMSSD se correlacionou positivamente 
com o índice de alta frequência (HF: 0,15 a $0,40 \mathrm{~Hz}$, modulado pelo Sistema Nervoso Parassimpático), que por sua vez associou-se positivamente ao desempenho na etapa incongruente (Hovland et al., 2012).

No domínio da frequência, para a razão entre baixas e altas frequências (razão LF/HF), não houve diferenças significativas entre as etapas. Isso está de acordo com o encontrado na comparação da execução do teste de Stroop com uma linha de base realizada por (Salahuddin, 2007), em que não houve diferenças significativas na razão LF/HF; mas contrasta com o aumento encontrado para esse parâmetro em uma condição de elevada interferência de Stroop em comparação com a linha de base (Delaney \& Brodie, 2000; Petkar, 2011). Dupuy e colaboradores (2014) relataram uma diminuição na razão LF/HF entre as etapas incongruente, congruente e neutra, nessa ordem, apesar de não haver diferenças significativas, o que está em conformidade com o padrão encontrado no presente estudo.

Considerados em conjunto, os resultados dos índices no domínio do tempo indicam que há retirada vagal durante o teste de Stroop, isto é, diminuição na atividade autonômica parassimpática, especialmente para as etapas SSF e SI. Isso indica um aumento no estresse mental e maior demanda de habilidades executivas nessas duas etapas comparadas com SC. A ausência de diferenças entre as etapas para a razão LF/HF indica que, apesar de ter havido evidências de retirada vagal, não houve modificação no balanço simpato-vagal entre essas etapas. 
A análise da VFC no domínio do tempo na comparação entre os gêneros revelou maior atividade autonômica parassimpática para os homens. Dishman e colaboradores (2000) sugerem que a modulação vagal é sensível ao estresse independentemente do gênero, porém no caso do presente estudo essa modulação foi maior entre os homens. Os índices SDNN, RMSSD, pNN50, além de muitos outros, foram relatados como maiores entres os homens (Saleem et al., 2012), especialmente para indivíduos jovens (de 10 a 29 anos), porém há indícios de que essas diferenças diminuam ao longo do envelhecimento (Umetani et al., 1998). Essa diferença também foi relatada isoladamente para o índice SDNN (Pavithran, Madanmohan \& Nandeesha, 2008). Esses resultados sugerem a existência de maior atividade autonômica parassimpática entre os homens.

A ausência de diferença significativa entre os gêneros para a razão LF/HF está de acordo com os resultados encontrados para as comparações entre as etapas do teste de Stroop. Entretanto, isso não está em consonância com resultados da literatura para os quais ou essa razão é maior em mulheres do que em homens, o que sugere maior balanço simpato-vagal entre as elas (Liao et al., 1995; Pavithran et al., 2008); ou a razão LF/HF é menor entre as mulheres, o que poderia evidenciar a existência um sistema protetor contra doenças cardiovasculares para elas (Ramaekers et al., 1998). Os mecanismos subjacentes a essas diferenças não estão claros (Liao et al., 1995; Ramaekers et al., 1998), o que salienta a necessidade de novas investigações a esse respeito para elucidar os resultados encontrados no presente estudo. 
Os resultados para as diferenças entre os gêneros no teste de Stroop foram semelhantes aos encontrados no teste de Tempo de Reação, porém no último caso apenas o índice RMSSD foi significativo, gerando mais uma evidência de favorecimento da modulação parassimpática entre os homens (Pavithran et al., 2008; Saleem et al., 2012; Umetani et al., 1998).

A comparação entre a etapa Incongruente do teste de Stroop (SI) e o teste de Tempo de Reação é importante para investigar as diferenças entre o estresse mental gerado pelos testes. Todos os índices no domínio do tempo foram menores para SI em comparação com o TR, porém apenas as diferenças para os índices pNN50 e RMSSD atingiram a significância estatística. No domínio da frequência, a razão $L F / H F$ foi menor para o TR.

Os resultados evidenciam maior contribuição do SNA parassimpático para o TR em comparação com SI (índices pNN50 e RMSSD baixos, razão LF/HF alta). Isso indica que o teste de Stroop demanda mais recursos de atenção e maior esforço cognitivo do que o TR, possivelmente gerando maior estresse mental para os sujeitos. Há consenso na literatura de que o estresse mental gerado pelo teste de Stroop leva à diminuição dos índices no domínio do tempo, quando este é comparado a uma linha de base (Delaney \& Brodie, 2000; Prinsloo et al., 2013; Salahuddin, 2007).

É importante destacar que esses resultados não significam que o teste de tempo de Reação não exija habilidades executivas e esforço cognitivo, apenas que essa exigência é menor para ele quando comparado ao teste de Stroop. Nesse teste, já foi reportada diminuição no índice 
SDDN quando comparada a linha de base (Wood et al., 2002), o que sugere maior atividade simpática relacionada ao estresse gerado pelo teste.

Considerados em conjunto, os resultados revelaram que os índices de VFC foram correlatos periféricos sensíveis às diferenças entre a mediação dos dois testes pelo SNA. As evidências encontradas corroboram a hipótese de associações entre o funcionamento executivo relacionado à atividade do CPF e o controle cardíaco modulado pelo nervo vago, defendida por Thayer e colaboradores (2009), além da capacidade de influência das respostas fisiológicas no comportamento dos sujeitos de acordo com Hipótese do Marcador Somático (Damasio, 1996). 
7. CONCLUSÕES 
A interpretação conjunta dos resultados de comportamento, eletroencefalograma e eletrocardiograma permite inferir que houve ausência de conflito e menor dificuldade para a etapa SC do teste de Stroop, o que é evidenciado pelo aumento na taxa de acertos em relação às outras duas etapas, pela diminuição da taxa de erros de omissão em relação a SI, pela diminuição na potência de ativação cortical, pela atenuação na atividade do CPFOF na banda Alfa e pelo aumento dos índices no domínio do tempo.

Os resultados comportamentais sugerem que a etapa SSF apresentou dificuldade intermediária. Entretanto, para os resultados eletroencefalográficos não foram observadas diferenças na ativação cortical de SI e SSF na banda Teta e foram observadas diferenças para menor quantidade de eletrodos entre as duas etapas na banda Gama. Em Alfa e Beta, aparentemente houve maior contribuição da diminuição da potência do que da distribuição topográfica para as diferenças observadas entre SI e SSF. A diminuição dos índices pNN50 e RMSSD na etapa SSF comparada com SI e SC, e do índice SDNN comparado à SC indicam que o estresse mental para SSF foi mais elevado do que nas outras etapas.

Considerando que a VFC é um índice do sucesso nos mecanismos executivos, seria esperado um maior colapso no comportamento da etapa SSF em comparação com as outras etapas. Porém, a ausência de incongruência entre as duas dimensões da palavra em SSF e o fato de a ativação cortical nessa etapa ter sido semelhante a SI podem auxiliar a explicar porque houve menor comprometimento do desempenho nessa etapa do que em SI. Ainda assim, afirmar apenas que a etapa SSF 
apresentou dificuldade intermediária possivelmente é insuficiente para descrever os resultados encontrados. Há evidências de que ela se assemelhou muito à etapa Incongruente no nível eletroencefalográfico e gerou mais estresse mental.

O teste de Tempo de Reação utilizado no presente estudo apresentou características mais complexas que um teste de Tempo de Reação Simples. Isso foi evidenciado pelos valores tanto da taxa de acertos, quanto dos tempos de reação terem sido elevados. A ausência de diferenças significativas nos resultados comportamentais levantou a questão de um possível efeito teto para esse teste.

Os resultados da comparação entre os testes de Stroop e de Tempo de Reação que evidenciam que ambos demandaram controle inibitório consistem na existência de um gradiente fronto-parietal para a ativação cortical nas bandas Teta e Alfa e na ativação do CPFOF e do CPFDL em ambos os teste.

O controle inibitório requerido foi diferente entre os testes: verbal para o teste de Stroop e motor para o teste de Tempo de Reação. A ativação bilateral do córtex temporal e a lateralização esquerda no teste de Stroop se associaram à linguagem, à representação mental das palavras e à preparação da resposta verbal. Para o TR, a atividade no lobo temporal esquerdo esteve associada a mecanismos preparatórios do movimento, enquanto a lateralização esquerda, à execução da resposta motora com a mão direita, em consonância com a literatura. Na literatura fica evidente a especialização do hemisfério esquerdo para a linguagem e para o controle motor. Os resultados da comparação da VFC entre os testes, que 
evidenciaram maior retirada vagal para a etapa SI em comparação com o TR, também corroboram a hipótese de que diferentes mecanismos inibitórios subsidiaram esses testes, gerando níveis diferentes de estresse mental.

A existência de evidências que caracterizam o teste de Tempo de Reação como um teste de controle inibitório ressalta a importância de levar em consideração a possibilidade da existência de outra explicação para a ausência de diferenças significativas no desempenho do teste de TR, além do possível efeito teto. Há evidências de esforço cognitivo nos padrões de ativação cortical do TR e nos resultados da VFC. Porém, em jovens universitários o estresse mental gerado possivelmente não foi suficiente para causar comprometimento no desempenho durante o teste, devido ao excelente funcionamento de mecanismos inibitórios nessa fase do desenvolvimento. Assim, é possível que os resultados do TR descrevam com precisão o fenômeno observado sem haver necessariamente um efeito teto.

Os resultados da comparação entre os gêneros nos dois testes utilizados sugerem que o sexo dos participantes não influenciou de forma consistente 0 seu desempenho, mas influenciou as medidas eletrofisiológicas.

A análise da VFC revelou maior atividade autonômica simpática para as mulheres, o que indica que estas realizaram maior esforço cognitivo para o cumprimento dos objetivos da tarefa. Isso vai de encontro aos resultados eletroencefalográficos, que demonstraram maior recrutamento cortical por parte destas. Porém, os resultados de VFC também sugerem 
que a estratégia adotada por elas resultou em maior estresse mental. É possível que os homens tenham modulado diferentemente suas respostas autonômicas de forma a permitir que eles apresentassem menores índices de estresse mental.

Levando-se em consideração a rede neurovisceral integrada postulada por Thayer e colaboradores (página 41), responsável por associar as respostas fisiológicas, a atividade cerebral e o sucesso no funcionamento executivo, torna-se razoável inferir que o recrutamento elevado de áreas cerebrais por parte das mulheres tenha acarretado maiores índices de respostas autonômicas. Entretanto, há indícios de que as diferentes estratégias adotadas pelos gêneros foram bem sucedidas, visto a ausência de diferenças significativas no desempenho comportamental na comparação entre homens e mulheres.

A mesma interpretação pode ser empregada para o teste de Tempo de Reação. De forma similar ao teste de Stroop, para o TR não houve influência do gênero dos participantes no seu desempenho, mas foi observada maior potência na ativação cortical para as mulheres e houve indícios de maior retirada vagal para as mulheres resultantes da análise da VFC.

Os resultados da comparação entre os gêneros corroboram a hipótese de Bjorklund e Kipp (página 28), ao supor que não há favorecimento do desempenho das mulheres durante a realização de testes no domínio cognitivo, como o teste de Stroop, pois nesse domínio não há maiores pressões seletivas para elas. Consideramos que as características do teste de Tempo de Reação utilizado no presente estudo 
atendam aos critérios desses autores para a sua classificação como um teste no domínio cognitivo.

O presente estudo contribuiu para elucidar as semelhanças e diferenças existentes nos mecanismos subjacentes a dois tipos de controle inibitório do ponto de vista comportamental e eletrofisiológico. Em sua maioria, os resultados estiveram em consonância com a literatura, com algumas ressalvas, descritas a seguir.

O aumento nos valores das taxas de acertos e dos tempos de reação (em milissegundos) observados no presente estudo, em comparação com o descrito na literatura referente ao teste de Tempo de Reação Simples, pode ter refletido o aumento na complexidade do protocolo do TR utilizado na presente investigação.

Por fim, a revisão bibliográfica realizada destacou uma incoerência nos resultados de diferenças entre os gêneros do ponto de vista eletroencefalográfico, com alguns estudos indicando aumento e outros, diminuição na potência de ativação cortical para as mulheres. Em outros estudos, essas contradições tornaram-se inconclusivas, visto que houve ausência de diferenças entre os gêneros no desempenho comportamental. Os resultados do presente estudo, levando em consideração a análise adicional de variação de frequência cardíaca, acrescentam evidências na direção do uso de diferentes estratégias pelos sujeitos em função de seu gênero. 
8. CONSIDERAÇÕES FINAIS 


\subsection{LIMITAÇÕES DO ESTUDO}

No presente estudo, os dados analisados foram coletados no contexto de um projeto de doutorado, porém não foram analisados naquela ocasião. Dessa forma, este projeto de mestrado não envolveu a coleta de dados. Porém, é importante considerar a imensa quantidade de dados gerados na realização de um estudo eletrofisiológico e comportamental e consequentemente 0 tempo levado para o processamento desses dados, especialmente porque foram realizados dois testes. Além disso, a participação da autora na coleta de dados de outros projetos vinculados ao laboratório de Neurociência e Comportamento, alguns com protocolo semelhante ao utilizado no presente estudo, supriu a necessidade de experiência nessa importante etapa de um projeto de pesquisa.

Alguns fatores podem ter prejudicado os resultados do presente estudo, tais como: a) o baixo número de sujeitos na avaliação comportamental do teste de Stroop; b) o possível efeito teto na avaliação comportamental do teste de TR; c) o número variável de tentativas em ambos os testes; d) a ausência de dados de tempo de resposta no teste de Stroop e e) a dificuldade em separar as contribuições do padrão de distribuição cortical e da potência para as diferenças significativas observadas nos mapas topográficos de EEG.

Outros fatores poderiam ter incrementado os resultados, de forma a levar a uma compreensão mais abrangente dos fenômenos estudados, como a inclusão de questionários que avaliassem o ciclo menstrual das mulheres que participaram do experimento, para subsidiar as comparações entre os gêneros; além da inclusão de escalas de ansiedade nos 
instrumentos utilizados, a fim de complementar a discussão dos resultados do eletrocardiograma.

\subsection{PERSPECTIVAS FUTURAS}

Novas análises poderiam ser realizadas futuramente com os dados coletados, como uma possível análise de diferença entre a condição cruzada e a não cruzada para o teste de TR, para investigar o tempo e o local em que ocorre transferência inter-hemisférica, utilizando a técnica de potenciais relacionados a eventos (ERP). Essa mesma técnica poderia ser utilizada para investigar possíveis diferenças nos padrões de ativação cortical para estímulos apresentados do lado direito e do lado esquerdo da tela.

Nos próximos estudos realizados no laboratório, considera-se de extrema importância realizar ajustes no programa STROOP para que seja possível mensurar o tempo de resposta, isto é, o tempo decorrido entre a apresentação da palavra e a manifestação da resposta verbal por parte do sujeito. A maioria dos dados disponíveis na literatura para o teste de Stroop utiliza o tempo de resposta como variável comportamental.

Novas evidências sobre a existência de um possível efeito teto na execução do teste de Tempo de Reação serão obtidas em um estudo com estimulação transcraniana por corrente contínua (tDCS) que está sendo realizado atualmente no laboratório no contexto de projetos de iniciação científica. 


\section{REFERÊNCIAS BIBLIOGRÁFICAS}

Anderson, V. et al. Executive Functions and the Frontal Lobes: A Lifespan Perspective. New York: Taylor \& Francis, 2008. 541 p.

Anghinah, R. et al. Eletroencefalograma Quantitativo e Topográfico. Arq Neuropsiquiatr, v. 56, n. 1, p. 59-63, 1998.

Ardila, A. On the Evolutionary Origins of Executive Functions. Brain and Cognition, v. 68, p. 92-99, 2008.

Aron, A. R. et al. Inhibition and the Right Inferior Frontal Cortex. Trends in Cognitive Science, v. 8, n. 4, p. 170-177, 2004.

Baddeley, A. D. Working Memory. Science, v. 255, p. 556-559, 1992.

. The Episodic Buffer: a New Component of Working Memory? Trends in Cognitive Science, v. 4, n. 11, p. 417-423, 2000.

. Is Working Memory Still Working. American Psychologist, v. 56, n. 11, p. 864-878, 2001.

Baddeley, A. D.; Hitch, G. J. Working Memory. In: Bower, G. A. (Ed.). Recent Advances in Learning and Motivation. New York: Academic Press, v.8, 1974. p.47-90.

Bansal, D. et al. A Review of Measurement and Analysis of Heart Rate Variability. Proceedings of the 2009 International Conference on Computer and Automation Engineering: IEEE Computer Society: 243246 p. 2009.

Barbarotto, R. et al. A Normative Study on Visual Reaction Times and Two Stroop Colour-word Tests. Ital J Neurol Sci, v. 19, p. 161-170, 1998.

Basar, E. et al. Gamma, Alpha, Delta, and Theta Oscillations Govern Cognitive Processes. International Journal of Psychophysiology, v. 39, p. 241248, 2001.

Bell, A. J.; Sejnowski, T. J. An Information-Maximization Approach to Blind Separation and Blind Deconvolution. Neural Comput., v. 7, n. 6, p. 1129-1159, 1995.

Bjorklund, D. F.; Kipp, K. Parental Investment Theory and Gender Differences in the Evolution of Inhibition Mechanisms. Psychological Bulletin, v. 120, n. 2, p. 163-188, 1996. 
Boggio, P. S. et al. Go-No-Go Task Performance Improvement After Anodal Transcranial Dc Stimulation of the Left Dorsolateral Prefrontal Cortex in Major Depression. Journal of Affective Disorders, v. 101, p. 91-98, 2007.

Botvinick, M. M. et al. Conflict Monitoring and Anterior Cingulate Cortex: an Update. Trends in Cognitive Science, v. 8, n. 12, p. 539-546, 2004.

Brasil,Ministério da Saúde. Resolução 196/96 do Conselho Nacional de Saúde/MS Sobre Diretrizes e Normas Envolvendo Pesquisas com Seres Humanos. Diário Oficial da União, 10 de outubro de 1996.

,Ministério da Saúde. Resolução 466/2012 do Conselho Nacional de Saúde/MS Sobre Diretrizes e Normas Envolvendo Pesquisas com Seres Humanos. Diário Oficial da União, 12 de dezembro de 2012.

Bunge, S. A. et al. Brain Changes Underlying the Development of Cognitive Control and Reasoning. In: Gazzaniga, M. S. (Ed.). The cognitive neurosciences. $4^{\underline{a}}$ ed. Cambridge, Massachusetts: The MIT Press, 2009. Cap. 5, p.73-85.

Cappa, S. F.; Perani, D. Nouns and Verbs: Neurological Correlates of Linguistic Processing. Rivista di Linguistica, v. 14, n. 1, p. 73-83, 2002.

Chan, R. C. K. et al. Assessment of Executive Functions: Review of Instruments and Identification of Critical Issues. Archives of Clinical Neuropsychology, v. 23, p. 201-216, 2008.

Clayson, P. E. et al. Sex Differences in Electrophysiological Indices of Conflict Monitoring. Biological Psychology, v. 87, p. 282-289, 2011.

Damasio, A. R. The Somatic Marker Hypothesis and the Possible Functions of the Prefrontal Cortex. Phil. Trans. R. Soc. Lond., v. 351, p. 1413-1420, 1996.

Déak, G. O. The Development of Cognitive Flexibility and Language Abilities. In: Kail, R. (Ed.). Advances in child development and behavior. San Diego: Academic Press, v.31, 2003. p.271-327.

Delaney, J. P. A.; Brodie, D. A. Effects of Short-Term Psychological Stress on the Time and Frequency Domains of Heart Rate Variability. Perceptual and Motor Skills, v. 91, p. 515-524, 2000.

Delorme, A.; Makeig, S. EEGLAB: an Open Source Toolbox for Analyis of Single-Trial EEG Dynamics Including Independent Component Analysis. J. Neurosci. Methods, v. 134, n. 1, p. 9-21, 2004. 
Der, G.; Deary, I. J. Age and Sex Differences in Reaction Time in Adulthood: Results From United Kingdom Health and Lifestyle Survey. Psychology and Aging, v. 21, n. 1, p. 62-73, 2006.

Diamond, A. Executive Functions. Annu. Rev. Psychol., v. 64, p. 135-168, 2013.

Dishman, R. K. et al. Heart Rate Variability, Trait Anxiety, and Perceived Stress Among Phisically Fit Men and Women. International Journal of Psychophysiology, v. 37, p. 121-133, 2000.

Ditye, T. et al. Modulating Behavioral Inhibition by tDCS Combined With Cognitive Training. Exp Brain Res, v. 219, p. 363-368, 2012.

Donders, F. C. On the Speed of Mental Processes. Acta Psychologica, v. 30, n. Attention and Performance II, p. 412-431, 1969.

Dupuy, O. et al. Effect of Overreaching on Cognitive Performance and Related Cardiac Autonomic Control. Scand J Med Sci Sports, v. 24, p. 234-242, 2014.

Elliot, R. Executive Functions and Their Disorders. British Medical Bulletin, v. 65, p. 49-59, 2003.

Garavan, $\mathrm{H}$. et al. Individual Differences in the Functional Neuroanatomy of Inhibitory Control. Brain Research, v. 1105, p. 130-142, 2006.

Garcia, A. et al. EEG and Autonomic Responses During Performance of Matching and Non-Matching to Sample Working Memory Tasks With Emotional Content. Frontiers in Behavioral Neuroscience, v. 5, n. 82, p. 1-9, 2011.

Gazzaniga, M. S. et al. Executive Functions and the Frontal Lobes. In: (Ed.). Cognitive neuroscience: The biology of the mind. $1^{\text {a }}$ ed.: W. W. Norton \& Company, 1998. Cap. 11, p.423-464.

Ghimire, N. et al. Electroencephalographic Changes During Selective Attention. Asian Journal of Medical Sciences, v. 6, n. 2, p. 51-56, 2015.

Goldberg, E. The New Executive Brain: Frontal Lobes in a Complex World. New York: Oxford University Press, 2009. 335 p.

Guyton, A. C.; Hall, J. E. Textbook of Medical Physiology. 11th Ed. Philadelphia: Elsevier Saunders, 2006. 1152 p. 
HansImayr, S. et al. The Electrophysiological Dynamics of Interference During the Stroop Task. Journal of Cognitive Neuroscience, v. 20, n. 2, p. 215-225, 2008.

Herwig, U. et al. Using the International 10-20 EEG System for Positioning of Transcranial Magnetic Stimulation. Brain Topography, v. 16, n. 2, p. 9599, 2003.

Hovland, A. et al. The Relationships Among Heart Rate Variability, Executive Functions, and Clinical Variables in Patients With Panic Disorders. International Journal of Psychophysiology, v. 86, p. 269-275, 2012.

Hruby, T.; Marsalek, P. Event-Related Potencials - the P3 Wave. Acta Neurobiol. Exp., v. 63, p. 55-63, 2003.

Hsu, T.-Y. et al. Modulating Inhibitory Control With Direct Current Stimulation of the Superior Medial Frontal Cortex. Neurolmage, v. 2011, n. 56, p. 2249-2257, 2011.

Hu, S.; Li, C.-S. R. Neural Processes of Preparatory Control for Stop Signal Inhibition. Human Brain Mapping, v. 33, p. 2785-2796, 2012.

Ishii, R. et al. Medial Prefrontal Cortex Generates Frontal Midline Theta Rythm. NeuroReport, v. 10, p. 675-679, 1999.

Jacobson, L. et al. Modulating Oscillatory Brain Activity Correlates of Behavioral Inhibition Using Transcranial Direct Current Stimulation. Clinical Neurophysiology, v. 123, p. 979-984, 2012.

Jacobson, L. et al. Activation of Inhibition: Diminishing Impulsive Behavior by Direct Current Stimulation Over the Inferior Frontal Gyrus. Journal of Cognitive Neuroscience, v. 23, n. 11, p. 3380-3387, 2011.

Jausovec, N.; Jausovec, K. Do Women See Things Differently Than Men Do? Neurolmage, v. 45, p. 198-207, 2009.

Jeon, S. Y.; Han, S. J. Improvement of the Working Memory and Naming by Transcranial Direct Current Stimulation. Ann Rehabil Med, v. 36, n. 5, p. 585-595, 2012.

Jonides, J. et al. Inhibition in Verbal Working Memory Revealed by Brain Activation. Proc. Natl. Acad. Sci., v. 95, p. 8410-8413, 1998.

Jurado, M. B.; Rosselli, M. The Elusive Nature of Executive Functions: A Review of our Current Understanding. Neuropsychol Rev, v. 17, p. 213223, 2007. 
Kehagia, A. A. et al. Learning and Cognitive Flexibility: Frontostriatal Function and Monoaminergic Modulation. Current Opinion In Neurobiology, v. 20, p. 199-204, 2010.

Klem, G. H. et al. The Ten-Twenty Electrode System of the International Federation. The International Federation of Clinical Neurophysiology. Recommendations for the Practice of Clinical Neurophysiology: Guidelines of the International Federation of Clinical Neurophysiology, Suppl., v. 52, p. 3-6, 1999.

Klimesch, W. Alpha-Band Oscillations, Attention, and Controlled Access to Stored Information. Trends in Cognitive Science, v. 16, n. 12, p. 606617, 2012.

Knyazev, G. G. Motivation, Emotion, and Their Inhibitory Control Mirrored in Brain Oscillations. Neuroscience and Biobehavioral Reviews, v. 31, p. 377-395, 2007.

Antero-Posterior EEG Spectral Power Gradient as a Correlate of Extraversion and Behavioural Inhibition. The Open Neuroimaging Journal, v. 4, p. 114-120, 2010.

Kwon, Y. H.; Kwon, J. W. Is Transcranial Direct Current Stimulation a Potencial Method for Improving Response Inhibition? Neural Regeneration Research, v. 8, n. 11, p. 1048-1054, 2013.

Lent, R. Cem Bilhões de Neurônios. 2ª ed. São Paulo: Atheneu, 2010. 765 p.

Li, C.-S. R. et al. Gender Differences in the Neural Correlates of Response Inhibition During a Stop Signal Task. Neurolmage, v. 32, p. 1918-1929, 2006.

Li, C.-S. R. et al. Gender Differences in Cognitive Control: an Extended Investigation of the Stop Signal Task. Brain Imaging and Behavior, v. 3, p. 262-276, 2009.

Liao, D. et al. Age, Race, and Sex Differences in Autonomic Cardiac Function Measured by Spectral Analysis of Heart Rate Variability. Am J Cardiol, v. 76, p. 906-912, 1995.

Martin, A. et al. Discrete Cortical Regions Associated with Knowledge of Color and Knowledge of Action. Science, v. 270, n. 5233, p. 102-105, 1995.

Mead, L. A. et al. Neural Basis of the Stroop Interference Task: Response Competition or Selective Attention? Journal of the International Neuropsychological Society, v. 2002, n. 8, 2002. 
Milham, M. P. et al. Attentional Control in the Aging Brain: Insights from an fMRI Study of the Stroop Task. Brain and Cognition, v. 49, p. 277-296, 2002.

Ocazionez, S. a. C. Processamento no Domínio da Frequência de Sinais de Eletroencefalografia Coletados Durante Protocolo de Estresse Moderado. 2009. 119 p. Dissertação (Mestrado em Engenharia Elétrica). Faculdade de Tecnologia, Universidade de Brasília, Brasília, Distrito Federal.

Oldfield, R. C. The Assessment and Analysis of Handedness: the Edinburgh Inventory. Neuropsychologia, v. 9, p. 97-113, 1971.

Pavithran, P. et al. Sex Differences in Short-Term Hear Rate Variability in Patients With Newly Diagnosed Essential Hypertension. J Clin Hypertens (Greenwich), v. 10, p. 904-910, 2008.

Petkar, H. C. Effects of Working Memory Demand on Performance and Mental Stress During the Stroop Task. 2011. 89 p. Thesis (Ph.D.). Department of Concordia Institute for Information Systems Engineering, Concordia University, Canada.

Plewnia, C. et al. Effects of Transcranial Direct Current Stimulation (tDCS) on Executive Functions: Influence of Comt Val/Met Polymorphism. Cortex, v. 49 , p. 1801-1807, 2013.

Prinsloo, G. E. et al. The Effect of a Single Session of Short Duration Heart Rate Variability Biofeedback on EEG: A Pilot Study. Appl Psychophysiol Biofeedback, v. 38, p. 45-56, 2013.

Ramaekers, D. et al. Heart Rate Variability and Heart Rate in Healthy Volunteers. European Hear Journal, v. 19, p. 1334-1341, 1998.

Salahuddin, L. Hear Rate Variability Analysis for Mental Stress Measument in Mobile Settings. 2007. 126 p. Thesis (Masters of Science). School of Engineering, Information and Communications University, Korea.

Saleem, S. et al. Gender Differences of Heart Rate Variability in Healthy Volunteers. J Pak Med Assoc, v. 62, p. 422-425, 2012.

Salo, R. et al. Interpreting Stroop Interference: An Analysis of Differences Between Task Versions. Neuropsychology, v. 15, n. 4, p. 462-471, 2001.

Santos, A. C. O. G. Respostas Autonômicas e Eletroencefalográficas no Desempenho de Jovens em Testes de Memória Operacional Visual e Visuo-Espacial. 2011. 134 p. Tese (Doutorado em Ciências da 
Saúde). Faculdade de Ciências da Saúde, Universidade de Brasília, Brasília, DF.

Satler, C. E. Influência da Emoção Sobre o Desempenho de Funções Executivas em Testes Neuropsicológicos Tradicionais e Computadorizados na Doença de Alzheimer 2012. 115 p. Tese (Doutorado em Ciências da Saúde). Faculdade de Ciências da Saúde, Universidade de Brasília, Brasília, DF.

Sauseng, P. et al. Two Brakes Are Better Than One: The Neural Bases of Inhibitory Control of Motor Memory Traces. Neurolmage, v. 65, p. 52-58, 2013.

Sauseng, P. et al. Fronto-parietal EGG Coherence in Theta and Upper Alpha Reflect Central Executive Functions of Working Memory. International Journal of Psychophysiology, v. 57, p. 97-103, 2005.

Serrien, D. J. et al. Transients Increases of Synchronized Neural Activity During Movement Preparation: Influence of Cognitive Constraints. Exp Brain Res, v. 153, p. 27-34, 2003.

Serrien, D. J. et al. Dynamics of Hemispheric Specialization and Integration in the Context of Motor Control. Nature Reviews, v. 7, p. 160-167, 2006.

Smith, E. E.; Kosslyn, S. M. Attention. In: (Ed.). Cognitive Psychology: Mind and Brain: Pearson Higher, 2006a. Cap. 3, p.103-146.

. Executive Processes. In: (Ed.). Cognitive Psychology: Mind and Brain: Pearson Higher, 2006b. Cap. 7, p.103-146.

. How the Brain Gives Rise to the Mind. In: (Ed.). Cognitive Psychology: Mind and Brain: Pearson Higher, 2006c. Cap. 1, p.1-48.

Sohlberg, M. M.; Mateer, C. A. Management of Attention Disorders. In: Sohlberg, M. M. e Mateer, C. A. (Ed.). Cognitive Rehabilitation: an integrative neuropsychological approach. New York, NY: The Guilford Press, 2001. Cap. 5, p.125-160.

Spieler, D. H. et al. Stroop Performance in Healthy Younger and Older Adults and in Individuals With Dementia of the Alzheimer's Type. Journal of Experimental Psychology, v. 22, n. 2, p. 461-479, 1996.

Squire, L. R. et al. The Prefrontal Cortex and Executive Brain Functions. In: (Ed.). Fundamental Neuroscience. 3rd Edition. London: Academic Press, 2008. Cap. 52, p.1199-1222. 
Stoet, G. Sex Differences in the Processing of Flankers. The Quarterly Journal of Experimental Psychology, v. 63, n. 4, p. 633-638, 2010.

Strauss, E. et al. Executive Functions. In: (Ed.). A Compendium of Neuropsychological Tests: Administration, Norms, and Commentary, Third Edition. New York: Oxford University Press, 2006. Cap. 8, p.401-545.

Stroop, J. R. Studies of Interference in Serial Verbal Reaction. Journal of Experimental Psychology, v. XVIII, n. 6, p. 643-662, 1935.

Tavares, M. C. H. Ritmicidade Biológica e Desempenho Cognitivo em Primatas Humanos e Não-Humanos. 2002. 147 p. Tese (Doutorado em Neurociências e Comportamento). Instituto de Ciências Biomédicas, Universidade de São Paulo, São Paulo, SP.

Teplan, M. Fundamentals of EEG Measurement. Measurement Science Review, v. 2, n. 2, p. 1-11, 2002.

Thayer, J. F. et al. Heart Rate Variability, Prefrontal Neural Function and Cognitive Performance: the Neurovisceral Integration Perspective on Self-Regulation, Adaptation, and Health. Ann. Behav. Med., v. 37, p. 141-153, 2009.

Thut, G. et al. Evidence for Interhemispheric Motor-Level Transfer in a Simple Reaction Time Task: an EEG Study. Exp Brain Res, v. 128, p. 256-261, 1999.

Umetani, K. et al. Twenty-Four Hour Time Domain Heart Rate Variability and Heart Rate: Relations to Age and Gender Over Nine Decades. JACC, v. 31, n. 3, p. 593-601, 1998.

Van Der Elst, W. et al. The Stroop Color-Word Test: Influence of Age, Sex, and Education; and Normative Data for a Large Sample Across the Adult Age Range. Assessment, v. 13, n. 1, p. 62-79, 2006.

West, R.; Bell, M. A. Stroop Color-Word Interference and Electroencephalogram Activation: Evidence for Age-Related Decline of the Anterior Attention System. Neuropsychology, v. 11, n. 3, p. 421-427, 1997.

Wood, R. et al. Short-Term Heart Rate Variability During a Cognitive Challenge in Young and Older Adults. Age and Ageing, v. 31, p. 131-135, 2002. 


\section{APÊNDICE A - TERMO DE CONSENTIMENTO LIVRE E ESCLARECIDO}

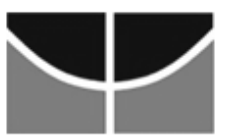

\author{
Universidade de Brasília \\ Instituto de Ciências Biológicas \\ Programa de Pós Graduação em Biologia Animal \\ Laboratório de Neurociências e Comportamento
}

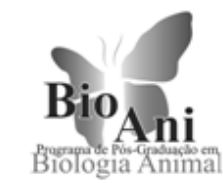

\section{Termo de Consentimento Livre e Esclarecido}

Estudo Eletrofisiológico de Funçôes Executivas de Jovens.

Você está sendo convidado a participar como sujeito experimental de um projeto de pesquisa que envolve o estudo de mecanismos neurais relacionados às habilidades de funções executivas. $O$ estudo consiste no registro simultâneo de sinais eletrofisiológicos distintos ao mesmo tempo em que você será submetido a tarefas responsáveis por eliciar diferentes habilidades executivas.

A sessão se iniciará com a preparação para os registros sinais biológicos que se dará através da fixação de eletrodos de superfície em locais definidos, a saber, na cabeça e no peitoral. Em seguida, terão início as tarefas para as quais, antes da execução de cada uma delas, the será dada uma explicação sobre sua execução. Não existe nenhum procedimento invasivo ou necessidade de administração de qualquer substância. Será necessária a sua participação em uma sessão com duração de aproximadamente 2 horas no Laboratório de Neurociências e Comportamento da UNB.

Sua participação é voluntária e a qualquer momento você pode desistir de participar da pesquisa sem nenhuma conseqüência. Seu nome e seu RG não serão divulgados. Os dados coletados no estudo não serão analisados individualmente, mas considerando os dados do grupo de participantes. Caso seja do seu interesse, os resultados obtidos com sua participação poderão ser disponibilizados mediante solicitação direta ao pesquisador ao final do estudo.

Estão à sua disposição os contatos deste laboratório, do pesquisador e, também, do Comitê de Ética em Pesquisa em Ciências da Saúde.

Laboratório de Neurociências e Comportamento, IB-UnB: 61 3201-2175

Pesquisadora Ana Garcia: 61 8401-6292

Comitê de Ética em Pesquisa em Ciências da Saúde: 613207 -

$\mathrm{Eu}$ portador do RG $n^{\circ}$ declaro estar de acordo com os procedimentos acima descritos e esclarecidos pessoalmente pelo pesquisador $\mathrm{e}$ ciente dos benefícios e riscos que posso ser submetido durante o experimento.

Atenciosamente,

Participante

Ana Garcia

Pesquisador responsável 


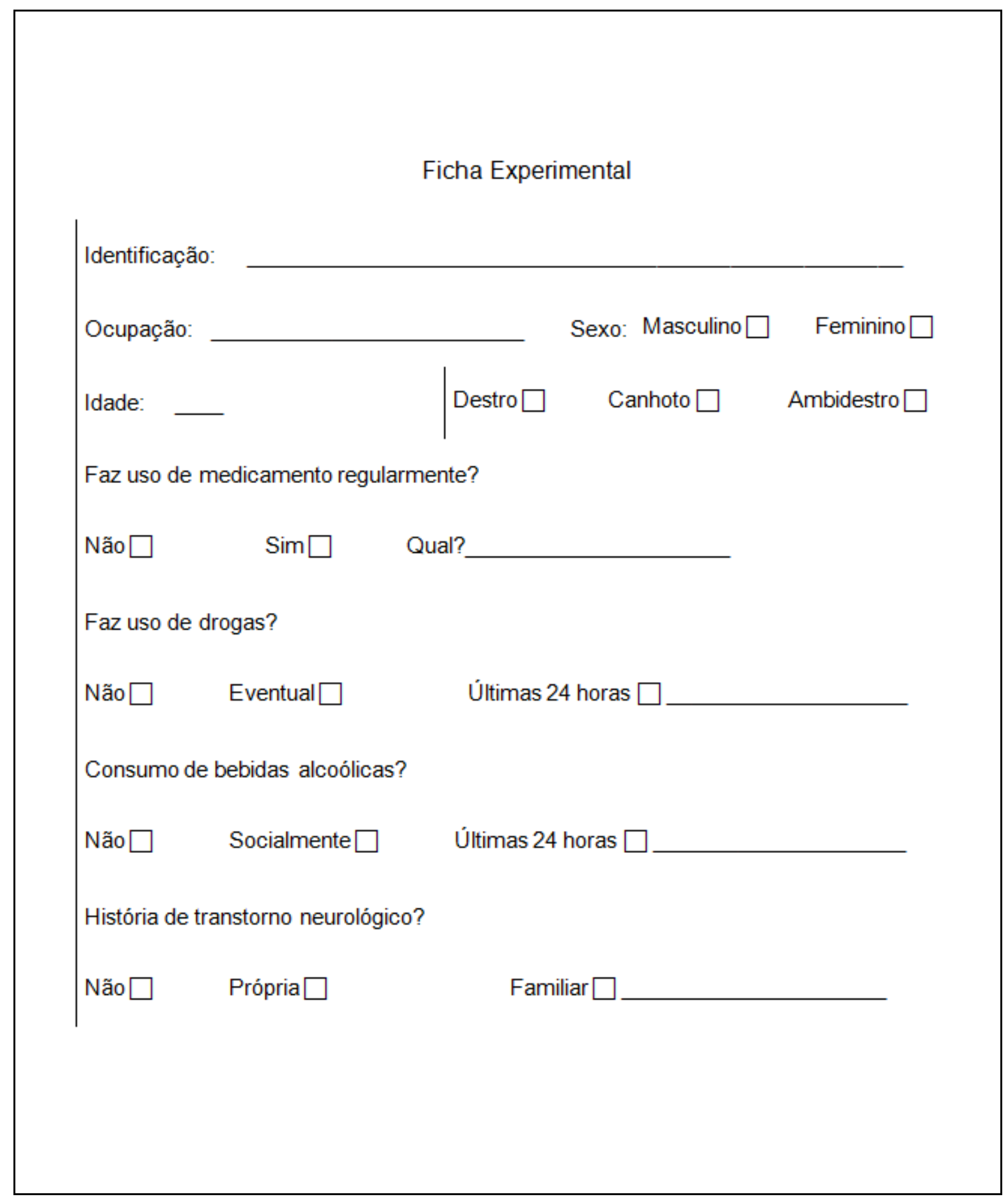




\section{APÊNDICE C - INVENTÁRIO DE EDINBURGH}

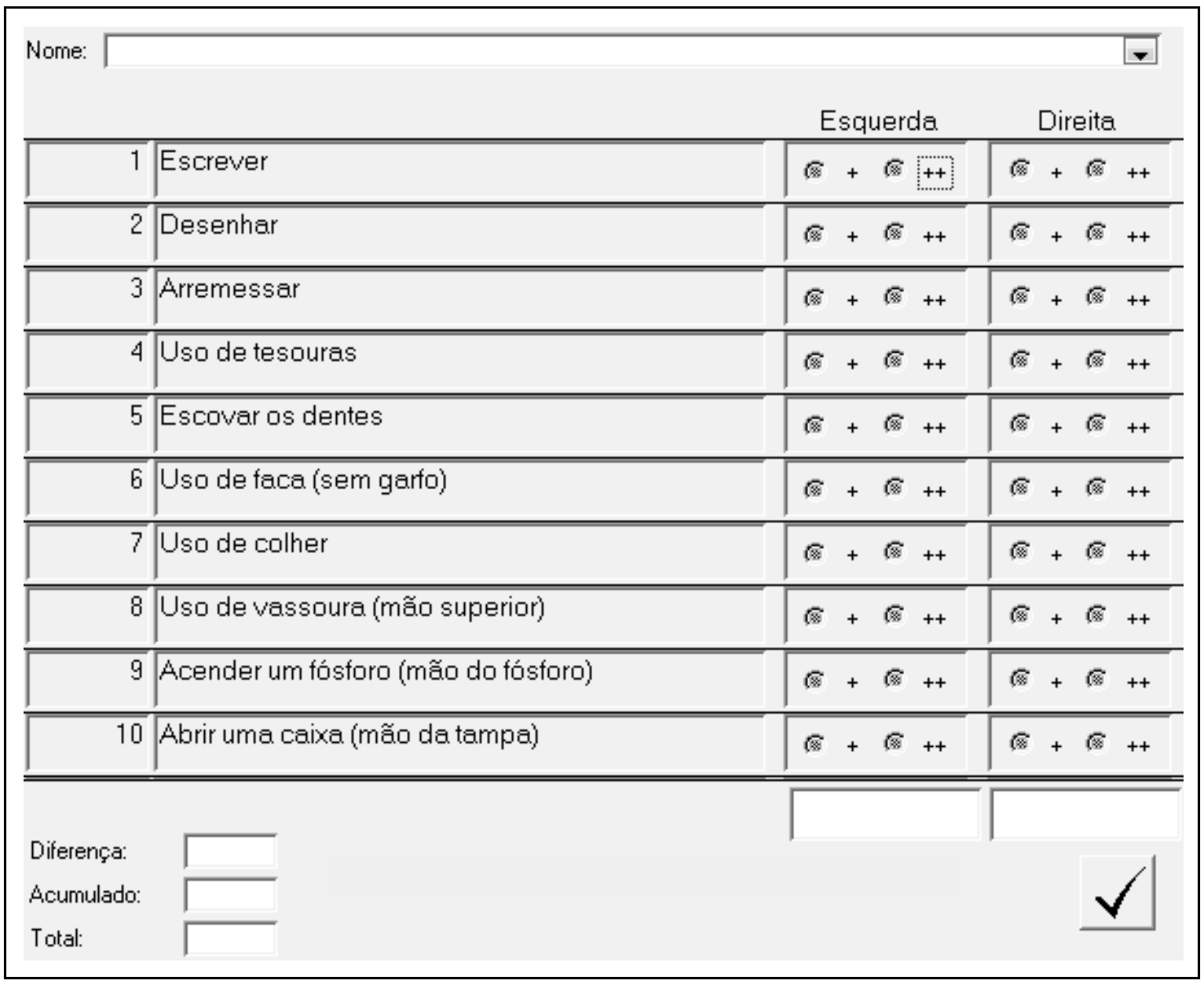




\title{
ANEXO A - APROVAÇÃO DO PROJETO 160/08 PELO COMITÊ DE ÉTICA \\ EM PESQUISA (CEP/FS-UNB)
}

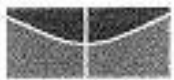 \\ Universidade de Brasilia \\ Faculdade de Ciências da Saúde \\ Comitê de Ética em Pesquisa - CEP/TS
}

\section{PROCESSO DE ANÁLISE DE PROJETO DE PESOUISA}

Registro do Projeto: $160 / 08$

Titulo do Projeto: Estudo Eletrofisiológico de Funções Executivas de Jovens.

Pesquisadora Responsável: Ana Cláudia Oliveira Garcia dos Santos

Data de entrada: $29 / 10 / 2008$

Com base nas Resoluçōes 196/96, do CNS/MS, que regulamenta a ética da pesquisa em seres humanos, o Comitê de f́tica em Pesquisa com Seres Humanos da Faculdade de Ciências da Saúde da Universidade de Brasilia, após análise dos aspectos éticos e do contexto técnico-científico, resolveu APROVAR o projeto 160/08 com o título: "Estudo Eletrofisiológico de Funções Executivas de Jovens", analisado na $10^{\mathrm{a}}$ Reunião Ordinária realizada no dia 11 de Novembro de 2008.

A pesquisadora responsável fica, desde já, notificada da obrigatoriedade da apresentaçăo de um relatório semestral e relatório final sucinto e objetivo sobre o desenvolvimento do Projeto, no prazo de 1 (um) ano a contar da presente data (item VII.13 da Resoluçato 196/96).

Brasilia, 18 de Novembro de 2008.

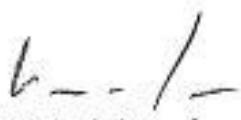

Prof. Volnei Garrafa

Coordenador do CEP-FS/UnB

Comitê de Ética em Pesquisa com Seres Humanos - Faculdade de Cièncias da Saúde - Universidade de Brasillia - Campus Universitario Darcy Ribeiro - Cep: 70.910-900 - Telefone: $61-33073799$ 


\section{ANEXO B - APROVAÇÃO DO PRESENTE PROJETO PELO COMITÊ DE ÉTICA EM PESQUISA (CEP/FS-UNB)}

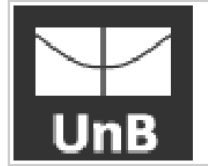

\section{FACULDADE DE CIÊNCIAS DA SAÚDE DA UNIVERSIDADE DE BRASÍLIA - CEP/FS-UNB}

\section{PARECER CONSUBSTANCIADO DO CEP}

\section{DADOS DO PROJETO DE PESQUISA}

Título da Pesquisa: Comparação entre controle inibitório motor e verbal no desempenho de jovens em tarefas de funções executivas.

Pesquisador: Soraya Lage de Sá

Área Temática:

Versão: 1

CAAE: 24418013.2 .0000 .0030

Instituição Proponente:FACULDADE DE SAÚDE - FS

Patrocinador Principal: Financiamento Próprio

\section{DADOS DO PARECER}

Número do Parecer: 493.051

Data da Relatoria: 12/11/2013

\section{Apresentação do Projeto:}

Trata-se de pesquisa que utilizará base de dados secundárias oriundas de tese de doutorado de Ana Claudia Oliveira Garcia dos Santos intitulada "Estudo Eletrofisiológico de função executiva de jovens", aprovada por este Comitê sob registro $n^{\circ} 160 / 08$.

Objetivo da Pesquisa:

Analisar o banco de dados da tese acima descrita referente aos testes "tempo de reação e teste de Stroop" que não foram analisados anteriormente.

Avaliação dos Riscos e Benefícios:

não se aplica

Comentários e Considerações sobre a Pesquisa:

conclusões

Considerações sobre os Termos de apresentação obrigatória:

Apresenta carta de apresentação ao CEP, carta da pesquisadora responsavel pelo projeto autorizando o acesso ao banco de dados e análise do mesmo

Recomendações:

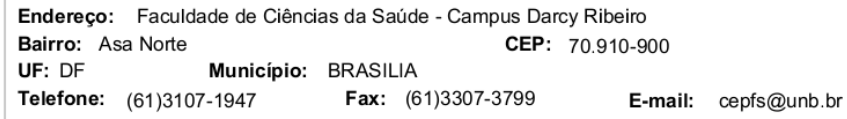




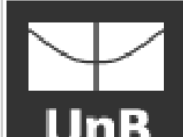

\section{FACULDADE DE CIÊNCIAS DA SAÚDE DA UNIVERSIDADE DE BRASÍLIA - CEP/FS-UNB}

Continuação do Parecer: 493.051

\section{Conclusões ou Pendências e Lista de Inadequações:}

Trata-se de solicitação de dispensa de análise, tendo em vista que o presente projeto prevê apenas análise de dados secundários oriundos da tese de doutorado da pesquisadora Ana Claudia Oliveira Garcia dos Santos, que autorizou tal análise conforme consta em carta anexo. Dessa forma, sou de parecer favorável à aprovação.

\section{Situação do Parecer:}

Aprovado

Necessita Apreciação da CONEP:

Não

Considerações Finais a critério do CEP:

BRASILIA, 13 de Dezembro de 2013

Assinador por:

Natan Monsores de Sá

(Coordenador)

Endereço: Faculdade de Ciências da Saúde - Campus Darcy Ribeiro

Bairro: Asa Norte

UF: DF

CEP: $70.910-900$

Telefone: (61)3107-1947 Fax: $(61) 3307-3799 \quad$ E-mail: cepfs@unb.br 